\title{
Global modeling of aerosol dynamics: Model description, evaluation, and interactions between sulfate and nonsulfate aerosols
}

\author{
Xiaohong Liu, Joyce E. Penner, and Michael Herzog \\ Department of Atmospheric, Oceanic, and Space Sciences, University of Michigan, Ann Arbor, Michigan, USA \\ Received 8 December 2004; revised 31 May 2005; accepted 28 June 2005; published 24 September 2005.
}

[1] The IMPACT global chemistry and transport model has been updated to include an aerosol dynamics module. Here it is used to simulate the dynamics of sulfate aerosol and its interaction with nonsulfate aerosol components: carbonaceous aerosol (organic matter (OM) and black carbon (BC)), dust, and sea salt. The sulfate aerosol dynamics is based on the method of modes and moments. In the current implementation, two modes are used for sulfate aerosol (nuclei and accumulation mode), and two moments are predicted within each mode (sulfate aerosol number and mass concentration). The aging of carbonaceous aerosol and dust particles from hydrophobic to hydrophilic depends on the surface coating of sulfate which occurs as a result of the condensation of sulfuric acid gas $\mathrm{H}_{2} \mathrm{SO}_{4}(\mathrm{~g})$ on their surface, and coagulation with pure sulfate aerosol. The model predicts high sulfate aerosol number concentrations in the nuclei mode $\left(\right.$ over $10^{4} \mathrm{~cm}^{-3}$ ) in the tropical upper troposphere, while accumulation mode sulfate number concentrations are generally within $50-500 \mathrm{~cm}^{-3}$ in most parts of the free troposphere. The model predicted mass concentrations of sulfate, $\mathrm{OM}, \mathrm{BC}$, dust, and sea salt, $\mathrm{H}_{2} \mathrm{SO}_{4}(\mathrm{~g})$ concentration, aerosol number, and size distributions are compared with measurement data. Our model predicts $\sim 80 \%$ of global sulfate existing as a pure sulfate aerosol $(9.7 \%$ in nuclei and $69.8 \%$ in accumulation mode), with $14.3 \%$ on carbonaceous aerosol, $3.3 \%$ on dust, and $2.7 \%$ on sea salt. In the boundary layer, over $40 \%$ of sulfate is associated with nonsulfate aerosols in many regions of the world whereas less than $10 \%$ of sulfate is associated with nonsulfate aerosols in the upper troposphere. The model predicted mass fraction of sulfate in the sulfate-carbonaceous aerosol mixture suggests that carbonaceous aerosol in most of the troposphere is internally mixed with sulfate and thus generally hygroscopic except near the source regions where the mass fraction is less than $5 \%$. On the global mean, $54 \%$ and $93 \%$ of carbonaceous aerosol are coated with sulfate in the boundary layer and in the upper troposphere, respectively. Our result suggests that carbonaceous aerosols have a shorter lifetime ( $3 \sim 4$ days) than predicted (4 8 days) using models that treat these aerosols as partly hydrophobic with an arbitrary $e$-folding time from hydrophobic to hydrophilic.

Citation: Liu, X., J. E. Penner, and M. Herzog (2005), Global modeling of aerosol dynamics: Model description, evaluation, and interactions between sulfate and nonsulfate aerosols, J. Geophys. Res., 110, D18206, doi:10.1029/2004JD005674.

\section{Introduction}

[2] Aerosols have generally been identified as one of the most important anthropogenic agents that tends to disturb the radiation balance of Earth and to perturb global climate. Increasing concentrations of anthropogenic aerosols may be partially counteracting the effects of greenhouse gas warming, perhaps explaining some of the inconsistency between model predictions and observations of global surface temperature change [IPCC, 2001]. Various aerosol components including sulfate, carbonaceous aerosol, mineral dust and sea salt contribute to this effect. These aerosols can scatter and absorb incoming solar radiation increasing the

Copyright 2005 by the American Geophysical Union. 0148-0227/05/2004JD005674 planetary albedo (the direct effect), and they can enhance the albedo and extent of clouds by increasing the number of cloud droplets (the first indirect effect or Twomey effect) and by changing the precipitation efficiency of clouds (the second indirect effect or Albrecht effect) [e.g., IPCC, 2001; Twomey, 1977, 1991; Charlson et al., 1992; Kiehl and Brieglieb, 1993; Lohmann et al., 1999a; Rotstayn and Penner, 2001].

[3] Current confidence in the estimates of aerosol radiative forcing is "low" for the sulfate direct effect and "very low" for the direct effects of carbonaceous aerosol and the indirect effect $[I P C C, 2001]$. The large uncertainties in current estimates of the radiative effects of aerosols reflect the use of empirical relationships used to derive the radiative effects. For example, most of the global 3-D sulfur cycle models have simulated only the mass concentration of 
sulfate aerosol and not number and size distributions [e.g., Langner and Rodhe, 1991; Pham et al., 1995; Feichter et al., 1996; Chin and Jacob, 1996; Chuang et al., 1997; Kasibhatla et al., 1997; Koch et al., 1999; Rasch et al., 2000]. The direct effect of sulfate aerosol has often been estimated from mass concentration fields by assuming a size distribution from which a mass-scattering coefficient can be calculated [e.g., Kiehl and Brieglieb, 1993] and the indirect effect estimated by deriving the cloud droplet number concentrations (CDNC) from the sulfate mass concentration [e.g., Boucher and Lohmann, 1995; Jones et al., 1994]. Global models capable of resolving the aerosol size distribution allowing the calculation of the radiative effects from physical principles would help to reduce these uncertainties. In such models, aerosol dynamical processes such as nucleation, condensation, coagulation, cloud processing, and deposition that determine aerosol size distribution and number concentration can be explicitly simulated. As shown in the aerosol dynamics model of Pirjola et al. [2004], nucleation is an important process in the atmosphere as it affects the number of cloud condensational nuclei $(\mathrm{CCN})$ and thus should be included in regional/global models.

[4] Incorporating size-resolving aerosol dynamics into a global model is a challenging task and only recently have effects been reported. A mixed aerosol dynamical module representing the aerosol size distribution by eight modes (nucleation mode sulfate, Aitken mode sulfate, accumulation mode sulfate, pure fossil fuel $\mathrm{BC}$, a mixed mode of fossil fuel $\mathrm{BC}, \mathrm{OC}$, and sulfate, pure biomass burning $\mathrm{BC}$, a mixed mode of biomass burning $\mathrm{BC}, \mathrm{OC}$, and sulfate, and a sea-salt mode) was implemented in a chemical transport model [Wilson et al., 2001]. The model reproduced both observed zonal average marine aerosol number concentrations and observed sulfate mass/accumulation mode number concentration ratios from the North Atlantic but did less well at reproducing number concentrations at individual sites and consistently overpredicted nucleation and Aitken mode concentrations in the free troposphere. A modal aerosol dynamics algorithm has been used to predict CCN concentrations and to estimate the magnitude of the indirect effect in the MIRAGE model [Ghan et al., 2001a, 2001b]. A single-moment sectional aerosol dynamics module has been incorporated into the NARCM model [von Salzen et al., 2000] to predict CCN concentrations over a portion of Northern Hemisphere. However, it is difficult to accurately and efficiently conserve aerosol number with this single moment sectional method. More recently, a two-moment sectional aerosol dynamics algorithm which explicitly conserves aerosol number was incorporated into the GISS GCM II-prime model [Adams and Seinfeld, 2002]. The model reproduced important features of the sulfate aerosol such as number concentrations that increase with altitude and land-sea contrasts in aerosol number concentrations and size distributions. However, this model considered only sulfate and neglected other important aerosol constituents. Thus interactions between the sulfur cycle and nonsulfate aerosol components were neglected. The moment approach [Yu et al., 2003], modal approach [Mebust et al., 2003] and sectional approach [Zhang et al., 2004] have been used in the regional models to simulate aerosol size distribution in the troposphere.
[5] In the calculations of the direct radiative forcing by aerosols models generally assume an external mixture of different aerosol components although observations [e.g., Bates et al., 1998; Russell et al., 1999; Raes et al., 2000] indicate that aerosols are often internally mixed. It is now recognized that $\mathrm{BC}$ is the major light-absorbing aerosol species [Chylek et al., 1995; Haywood and Shine, 1995]. However, studies found different $\mathrm{BC}$ forcing when different BC mixing states were assumed. Ackerman and Toon [1981] showed that the single scattering albedo in an internal mixture of soot and sulfate is lower than that in an external mixture. Haywood et al. [1997] simulated the global and hemispheric radiative forcing of soot and sulfate aerosols, and showed that the radiative forcing was modified in the positive direction in an internal mixture compared with an external mixture, which causes the direct effects of aerosols to become weakened. Jacobson's [2001] calculations gave a positive direct radiative forcing of $+0.31 \mathrm{~W} \mathrm{~m}^{-2}$ for $\mathrm{BC}$ in an external mixture and $+0.55 \mathrm{~W} \mathrm{~m}^{-2}$ for $\mathrm{BC}$ in an internal mixture (in a coated core case).

[6] The interaction between sulfate and nonsulfate aerosols (BC and mineral dust) is also very important for determining changes in the hygroscopic properties for $\mathrm{BC}$ and mineral dust in the atmosphere. Although fresh soot is mostly hydrophobic, aged BC-containing aerosols become more hygroscopic by atmospheric processing. Thus soot particles can be effective as CCN [Chylek and Hallett, 1992; Kaufman and Fraser, 1997] when they are internally mixed with sulfate. For example, it was suggested that sulfate formation on soot particles may be responsible for the observed larger cloud droplet concentrations in ship tracks [Radke et al., 1989]. Soot aerosols have complex effects on cloud properties. Smoke particles from biomass burning can increase cloud reflectance by reducing the droplet size [Kaufman and Fraser, 1997], and can change the dynamics of atmospheric circulation by suppressing the onset of precipitation and allowing invigoration of the updrafts [Andreae et al., 2004]; on the other hand, the high absorption by soot-containing cloud droplets enhances cloud absorption [Chylek and Hallett, 1992]. It was also found that dust particles passing over polluted areas often can be coated with sulfate due to chemical processes on their surface [Levin et al., 1996]. These particles then can serve as giant $\mathrm{CCN}$, which may enhance the collision and coalescence of droplets and therefore increase warm precipitation formation and decrease cloud albedo [Yin et al., 2000]. However, the contrary was shown using the satellite and aircraft observations that mineral dust could suppress precipitation through acting as $\mathrm{CCN}$ and forming small cloud droplets [Rosenfeld et al., 2001]. The formation of hygroscopic BC and mineral dust can also influence their burdens and lifetimes in the atmosphere through their wet scavenging by clouds and precipitation. If $\mathrm{BC}$ and dust particles are less hygroscopic, they can be transported into the upper troposphere by deep convection where they may have longer lifetimes and are exposed to long-range transport.

[7] The hygroscopic nature of carbonaceous aerosol in current global models is often tuned to give optimal agreement with observations. For BC, models used a fixed exponential decay lifetime (1.2-1.8 days) for the conversion of carbonaceous aerosol from hydrophobic to hydro- 
philic [Cooke et al., 1999], or an approach based on constant solubility [Koch, 2001] or on relating solubility to the gas phase oxidation of $\mathrm{SO}_{2}$ by $\mathrm{OH}$ to form sulfate [Koch, 2001]. Similar approaches exist for dust particle solubility using a constant solubility [e.g., Ginoux et al., 2001] or relating the aging rate of dust particles from hydrophobic to hydrophilic to gas phase $\mathrm{SO}_{2}$ concentrations [Fan et al., 2004]. All the above approaches are based on the empirical methods for the description of the hygroscopic properties of $\mathrm{BC}$ and dust particles, not on the sulfate amount coated on these particle surfaces.

[8] In this study, an aerosol dynamics module [Herzog et al., 2004] is incorporated into the framework of a global chemical transport model (IMPACT). The module includes the predictions of major atmospheric aerosol components (sulfate, OM, BC, dust and sea salt) and simulates the dynamics of sulfate aerosol and its interaction with nonsulfate aerosol components (OM, BC, dust and sea salt). Sulfate aerosol dynamics is based on the method of modes and moments. In the current implementation two modes are used for sulfate aerosol (nuclei and accumulation mode), and two moments are predicted within each mode (sulfate aerosol number and mass concentration). The aging of carbonaceous aerosol (BC and $\mathrm{OM}$ ) and dust particles from hydrophobic to hydrophilic depends on the surface coating of sulfate which occurs as a result of the condensation of sulfuric acid gas $\mathrm{H}_{2} \mathrm{SO}_{4}(\mathrm{~g})$ on their surface, and coagulation with sulfate aerosol. In-cloud sulfate production further increases sulfate amount on these aerosols after they become hygroscopic and act as CCN. Here we compare the model predicted mass concentrations of sulfate, $\mathrm{OM}, \mathrm{BC}$, dust and sea salt, $\mathrm{H}_{2} \mathrm{SO}_{4}$ (g) concentration, aerosol number and size distributions with measurement data, and examine the interaction between sulfate and nonsulfate aerosols. The model will be described in section 2. Model predictions of species distributions and global budgets will be presented in section 3. The model results will be compared with observations in section 4 . In section 5 we will discuss the model results for the amount of mixing of sulfate with carbonaceous and dust particles. In section 6 we will describe the model results from sensitivity tests. Section 7 presents our conclusions.

\section{Model Description}

\subsection{Model Framework}

[9] The LLNL/IMPACT model [Rotman et al., 2004; Penner et al., 1998a] was developed using a massively parallel computer architecture, and was extended in Liu and Penner [2002] to treat sulfate aerosol. For this study, IMPACT was driven by the meteorological fields available at a 6-h time interval from the NASA Goddard Data Assimilation Office (DAO) general circulation model (GCM) and interpolated to a 1-h time interval. The spatial resolution of IMPACT is the same as the DAO assimilated meteorological data, which has a horizontal resolution of $2^{\circ}$ latitude by $2.5^{\circ}$ longitude. The vertical resolution varies with different versions of the DAO Goddard Earth Observing System version 1 (GEOS-1). The meteorological data that we used was version GEOS-1.3 with data from 1997 to 1998. This data set has 46 levels with more than half of them in the stratosphere and a model top at $0.1 \mathrm{hPa}$. In our tropospheric simulations we have aggregated the top 23 levels (from $40 \mathrm{hPa}$ to $0.1 \mathrm{hPa}$ ) to 3 levels and kept the lowest 23 levels at the same resolution as in the original GEOS 1.3 data. The mean pressures of the 26 levels are $994,971,930,875,813,745,675,605,537,472,410,353$, $302,258,220,187,158,133,112,94.1,79.3,67.0,56.7$, $37.6,14.2$, and $2.5 \mathrm{hPa}$.

[10] The IMPACT model uses the flux-form semiLagrangian (FFSL) advection scheme [Lin and Rood, 1996]. Cumulus transport in the DAO meteorological fields was derived from the relaxed Arakawa-Schubert scheme, and its implementation in IMPACT was described in detail by Penner et al. [1998a]. Vertical diffusion is based on an implicit scheme [Walton et al., 1988] with the three-dimensional field of time-varying vertical diffusion coefficients supplied by the DAO meteorological fields.

[11] An aerosol module was added to the LLNL/IMPACT framework. It includes prognostic variables for sulfur species and related species: dimethylsulfide (DMS), $\mathrm{SO}_{2}$, and sulfuric acid gas $\left(\mathrm{H}_{2} \mathrm{SO}_{4}\right)$, sulfate aerosol and hydrogen peroxide $\left(\mathrm{H}_{2} \mathrm{O}_{2}\right)$; biomass burning $\mathrm{BC}$ and $\mathrm{OM}$, fossil fuel $\mathrm{BC}$ and $\mathrm{OM}$, natural $\mathrm{OM}$, mineral dust, and sea salt. The dynamic aerosol treatment for sulfate mass and number follows that described by Herzog et al. [2004] for the nuclei $(r<0.05 \mu \mathrm{m})$ and accumulation $(r>0.05 \mu \mathrm{m})$ modes. Mineral dust and sea salt are divided into four bins with radii varying from $0.05-0.63 \mu \mathrm{m}, 0.63-1.26 \mu \mathrm{m}, 1.26-$ $2.5 \mu \mathrm{m}$, and $2.5-10 \mu \mathrm{m}$. These size cuts are based on the consideration of the mass size distribution and thermodynamics of these aerosols as well as the CCN activation spectrum under typical supersaturations. In addition separate predictions of sulfate mass on each type of nonsulfate aerosols (biomass burning $\mathrm{BC}$ and $\mathrm{OM}$, fossil fuel $\mathrm{BC}$ and $\mathrm{OM}$, natural $\mathrm{OM}$, dust bins $1-4$, and sea salt bins $1-4$ ) are included in the model to describe the interactions between sulfate and nonsulfate aerosols in the atmosphere by aerosol dynamics as discussed below. We do not choose to separately keep track of different nonsulfate aerosols with different amount of attached sulfate. Thus, within one grid cell, each type of nonsulfate aerosol is assumed to have a single amount of sulfate coating. Although $\mathrm{BC}$ and $\mathrm{OM}$ from biomass burning and fossil fuel emissions are treated as distinct species in the model, we present model predicted $\mathrm{BC}$ and $\mathrm{OM}$ as "BC/OM" in our discussion, because their spatial distributions resemble each other very closely and also they have similar lifetimes (see section 3 ). In addition this is to reflect the general internal mixture of $\mathrm{BC}$ and $\mathrm{OM}$ when they are just emitted from biomass and fossil fuel sources.

\subsection{Sulfur Chemistry}

[12] The gas-phase chemistry included in the model is gas-phase oxidation of $\mathrm{SO}_{2}$ with $\mathrm{OH}$ radical to form $\mathrm{H}_{2} \mathrm{SO}_{4}$ (gas), and production and destruction of $\mathrm{H}_{2} \mathrm{O}_{2}$ (Table 1). Here we neglect the chemical source of $\mathrm{SO}_{2}$ from DMS + $\mathrm{NO}_{3}$ which can be important at night. However, this contribution to $\mathrm{SO}_{2}$ is generally small $(10-15 \%)$ compared to that from DMS + OH [e.g., Feichter et al., 1996; Chin et al., 2000a]. Within cloudy regions of the atmosphere, the aqueous phase oxidation of $\mathrm{SO}_{2}$ with $\mathrm{H}_{2} \mathrm{O}_{2}$ and $\mathrm{O}_{3}$ to produce sulfate ion $\left(\mathrm{SO}_{4}^{2-}\right)$ is considered. Within a cloud the partitioning of $\mathrm{SO}_{2}, \mathrm{H}_{2} \mathrm{O}_{2}$ and $\mathrm{O}_{3}$ is given by aqueous 
Table 1. Gas Phase Reactions Included in the Global Model

\begin{tabular}{|c|c|c|c|c|c|}
\hline \multicolumn{3}{|c|}{ Reactions } & $k_{298}{ }^{\mathrm{a}}$ & $E / R$ & Reference $^{b}$ \\
\hline (R1) & $\mathrm{DMS}+\mathrm{OH}$ & $\rightarrow \mathrm{SO}_{2}+\ldots$ & See footnote ${ }^{c}$ & & H86 \\
\hline (R2) & $\mathrm{SO}_{2}+\mathrm{OH}$ & $\rightarrow \mathrm{H}_{2} \mathrm{SO}_{4}+\ldots$ & $\begin{array}{l}k_{0}=3.0 \times 10^{-31}(300 / T)^{3.3} \\
k_{\infty}=1.5 \times 10^{-12}\end{array}$ & & D97 \\
\hline (R3) & $\mathrm{HO}_{2}+\mathrm{HO}_{2}$ & $\rightarrow \mathrm{H}_{2} \mathrm{O}_{2}+\mathrm{O}_{2}$ & See footnote ${ }^{\mathrm{d}}$ & & D97 \\
\hline (R4) & $\mathrm{HO}_{2}+\mathrm{HO}_{2}$ & $\rightarrow \mathrm{H}_{2} \mathrm{O}_{2}+\mathrm{O}_{2}+\mathrm{H}_{2} \mathrm{O}$ & See footnote ${ }^{e}$ & & D97 \\
\hline (R5) & $\mathrm{H}_{2} \mathrm{O}_{2}+h v$ & $\rightarrow \mathrm{OH}+\mathrm{OH}$ & see text & & \\
\hline (R6) & $\mathrm{H}_{2} \mathrm{O}_{2}+\mathrm{OH}$ & $\rightarrow \mathrm{H}_{2} \mathrm{O}+\mathrm{HO}_{2}$ & $1.7 \times 10^{-12}$ & 160 & D97 \\
\hline
\end{tabular}

${ }^{\mathrm{a}}$ Units for gas-phase reaction rate constants are $\mathrm{s}^{-1}$ for the first order reactions, molecules ${ }^{-1} \mathrm{~cm}^{3} \mathrm{~s}^{-1}$ for the second-order reactions, and molecules ${ }^{-2} \mathrm{~cm}^{6} \mathrm{~s}^{-1}$ for the third-order reactions. Reaction rate constants at temperatures other than $298 \mathrm{~K}$ are calculated from $k=k_{298} \exp \left[-\frac{E}{R}\left(\frac{1}{T}-\frac{1}{298}\right)\right]$.

${ }^{\mathrm{b}} \mathrm{H} 86$, Hynes et al. [1986]; D97, Demore et al. [1997].

${ }^{\mathrm{c}}$ Here $k=\frac{T e^{-234 / T}+8.46 \times 10^{-10} e^{7230 / T}+2.68 \times 10^{-10} e^{7810 / T}}{88.1 e^{7460 / T}+1.04 \times 10^{11} T}$, where $T$ is temperature in $\mathrm{K}$.

${ }^{\mathrm{d}}$ Here $k=2 \times 10^{-13} \exp (600 / T)+1.7 \times 10^{-33}[M] \exp (1000 / T)$, where $[\mathrm{M}]$ is air density in molecules $\mathrm{cm}^{-3}$.

${ }^{\mathrm{e}}$ Here $k=3.22 \times 10^{-34} \exp (2800 / T)+2.38 \times 10^{-54}[M] \exp (3200 / T)$.

phase equilibria based on Henry's law (aqueous phase dissociations are included for $\mathrm{SO}_{2}$ ). The aqueous phase reaction rate constants and the Henry's law coefficients are shown in Table 2. The hydrogen ion concentration in the droplet $\left[\mathrm{H}^{+}\right]$is required for the aqueous phase reaction calculations. Because we do not calculate the concentrations of all the ions that affect droplet $p \mathrm{H}$, we assumed a value for cloud droplets of 4.5. An increase to 5.5 or a reduction to 3.5 can significantly change the conversion rate of aqueous $\mathrm{SO}_{2}$ by $\mathrm{O}_{3}$ which is, however, of secondary importance to the global aqueous phase $\mathrm{SO}_{4}^{2-}$ production compared to that of $\mathrm{SO}_{2}$ (aq) by $\mathrm{H}_{2} \mathrm{O}_{2}$ [Feichter et al., 1996; Barth et al., 2000]. Indeed, a sensivity test with the GRANTOUR model which varied droplet $p \mathrm{H}$ (J. E. Penner et al., unpublished results) showed that the overall effect on $\mathrm{SO}_{2}$ and sulfate aerosol concentrations was limited $(<10 \%)$. In the control run of this model we have not included sulfate production on the surface of dust and sea salt through heterogeneous chemical reactions [e.g., Dentener et al., 1996; Carmichael et al., 1996; Sievering et al., 1992]. A sensitivity test with the heterogeneous chemical reactions included was undertaken and compared with the control run, which will be discussed in section 6 .
[13] The gas phase species involved in the sulfur chemistry, $\mathrm{OH}, \mathrm{HO}_{2}$, and $\mathrm{O}_{3}$, have prescribed concentrations taken from monthly averages in a simulation of photochemically active compounds by the GRANTOUR model [Penner et al., 1994]. The $\mathrm{H}_{2} \mathrm{O}_{2}$ concentration is predicted from prescribed $\mathrm{HO}_{2}$ concentration with losses from reactions by $\mathrm{OH}$ and by photolysis. The photolysis rate of $\mathrm{H}_{2} \mathrm{O}_{2}$ is determined via a look-up table method where the photolysis rate depends on the latitude and the height of the grid box, and the month of year. Diurnal variations of $\mathrm{OH}$ and $\mathrm{HO}_{2}$ concentrations and $\mathrm{H}_{2} \mathrm{O}_{2}$ photolysis rates are imposed by scaling the average fields to the cosine of solar zenith angle.

[14] The IMPACT model uses an operator splitting procedure with a one hour time step when advancing the solution in time for each operator. The differential equations with chemical sources and sinks of chemical species (DMS, $\mathrm{SO}_{2}$ and $\mathrm{H}_{2} \mathrm{O}_{2}$ ) are integrated in the clear portion of a grid box using an analytic solution. In the cloudy portion of each grid box, we use a simple predictor-corrector scheme with a variable time step for the integration of differential equations. Clear and cloudy region concentrations of each grid box are integrated separately for four hours. At the end of this time (a typical timescale for air residing within a

Table 2. Aqueous Phase Chemistry Included in the Global Model

\begin{tabular}{|c|c|c|c|c|c|}
\hline \multicolumn{3}{|c|}{ Reactions } & $k_{298}{ }^{\mathrm{a}}$ & $E / R$ & Reference $^{\mathrm{b}}$ \\
\hline (R7) & $\mathrm{SO}_{2}(\mathrm{aq})+\mathrm{H}_{2} \mathrm{O}_{2}(\mathrm{ac}$ & $\rightarrow \mathrm{SO}_{4}^{2-}+2 \mathrm{H}^{+}$ & See footnote ${ }^{c}$ & & MD81 \\
\hline (R8) & $\mathrm{SO}_{2}(\mathrm{aq})+\mathrm{O}_{3}(\mathrm{aq})$ & $\rightarrow \mathrm{SO}_{4}^{2-}+2 \mathrm{H}^{+}+\mathrm{O}_{2}$ & See footnote ${ }^{\mathrm{d}}$ & & M83 \\
\hline (R9) & $\mathrm{SO}_{2}(\mathrm{~g})$ & $\leftrightarrow \mathrm{SO}_{2}(\mathrm{aq})$ & 1.23 & -3020 & PS89 \\
\hline (R10) & $\mathrm{SO}_{2}(\mathrm{aq})$ & $\leftrightarrow \mathrm{HSO}_{3}^{-}+\mathrm{H}^{+}$ & $1.3 \times 10^{-2}$ & -1960 & SM76 \\
\hline (R11) & $\mathrm{HSO}_{3}^{-}$ & $\leftrightarrow \mathrm{SO}_{3}^{2-}+\mathrm{H}^{+}$ & $6.61 \times 10^{-8}$ & -1500 & SM76 \\
\hline (R12) & $\mathrm{H}_{2} \mathrm{O}_{2}(\mathrm{~g})$ & $\leftrightarrow \mathrm{H}_{2} \mathrm{O}_{2}(\mathrm{aq})$ & $7.45 \times 10^{4}$ & -6620 & LK86 \\
\hline (R13) & $\mathrm{O}_{3}(\mathrm{~g})$ & $\leftrightarrow \mathrm{O}_{3}(\mathrm{aq})$ & 0.011 & -2300 & PS89 \\
\hline
\end{tabular}

${ }^{\mathrm{a}}$ Units for aqueous-phase reaction rate constants are $\mathrm{M}^{-1} \mathrm{~s}^{-1}$ for the second-order reactions. Units for the Henry's law constants are $\mathrm{M} \mathrm{atm}^{-1}$, and for the dissociation rate constants are M. Reaction rate constants at temperatures other than $298 \mathrm{~K}$ are calculated from $k=k_{298} \exp \left[-\frac{E}{R}\left(\frac{1}{T}-\frac{1}{298}\right)\right]$.

${ }^{\mathrm{b}}$ MD81, Martin and Damschen [1981]; M83, Maahs [1983]; PS89, Pandis and Seinfeld [1989]; SM76, Smith and Martell [1976]; LK86, Lind and Kok [1986].




large scale stratiform cloud) the cloudy and clear air region concentrations are combined by weighting the cloudy concentration by the cloud fraction and the clear region concentration by the clear air fraction, producing a new grid-average concentration. A sensitivity test with a mixing time of one hour showed that this model choice is not crucial to determining the formation of sulfate (J. E. Penner et al., unpublished results).

[15] Cloud water content which is required for calculating the aqueous fractions of chemical species $\left(\mathrm{SO}_{2}, \mathrm{H}_{2} \mathrm{O}_{2}\right.$, and $\mathrm{O}_{3}$ ) in the cloudy region is not available in GEOS 1.3 . We calculated it from a parameterization used in the NCAR CCM [Hack, 1998]. We used relative humidity (RH) calculated from the DAO meteorological data to parameterize the large-scale stratiform cloud fraction according to Sundqvist et al. [1989]. For convective cloud fraction, a parameterization which uses the convective mass flux [Xu and Krueger, 1991] was adopted. We compared the model calculated liquid water path with observations [Weng and Grody, 1994; Greenwald et al., 1993]. The geographic pattern is reproduced well by the parameterizations, and the order of magnitude of liquid water path is also within the range of observational uncertainty. Model calculated cloud fraction was also compared with the International Satellite Cloud Climatology Project (ISCCP) observed cloud fraction. A detailed description can be found in Feng et al. [2004].

\subsection{Aerosol Dynamics}

[16] An aerosol dynamics module which describes the dynamics of sulfate aerosol and its interaction with primary emitted nonsulfate aerosol components [Herzog et al., 2004] was added to our model. Sulfate aerosol dynamics is based on the method of modes and moments. In our model we assume that each mode follows a lognormal distribution. Two modes are used for sulfate aerosol: a nuclei mode with $r<0.05 \mu \mathrm{m}$ and an accumulation mode with $r \geq 0.05 \mu \mathrm{m}$. The size distribution of the total sulfate aerosol population is a superposition of lognormal distributions with a constant geometric standard deviation. In the current implementation we predict two moments for the sulfate aerosol number and mass concentration.

[17] Binary homogeneous nucleation of $\mathrm{H}_{2} \mathrm{SO}_{4}$ (gas) is considered, which is one of the main drivers for the total aerosol number concentration. Four different nucleation parameterizations are implemented in our aerosol module [Zhao and Turco, 1995; Fitzgerald and Hoppel, 1998; Kulmala et al., 1998; Vehkamäki et al., 2002]. Sensitivity tests have been performed to examine the impact of these different schemes within the context of the GRANTOUR CTM [Penner and Herzog, 2002]. Therefore, here we do not examine the consequence of these different schemes, but use the Vehkamäki et al. [2002] scheme which was thought to have the best performance for simulating the aerosol number concentration in the upper troposphere. The sulfate aerosol composition is calculated from the Tabazadeh et al. [1997] parameterization for water uptake or release. The particle density for a given composition and temperature is calculated according to the parameterization given by Vehkamäki et al. [2002]. The particle size after water uptake can be derived from the particle mass including water and its density. This particle size is used in all size dependent processes in the model.

[18] The treatment of condensation and evaporation of $\mathrm{H}_{2} \mathrm{SO}_{4}$ (gas) to a particle surface assumes spherical particles that are in equilibrium with the surrounding water vapor. Condensational growth is limited by the diffusion of sulfate gas molecules to the particle surface. The equilibrium concentration of sulfate molecules in the gas phase includes solution and Kelvin effects. The condensation rate includes corrections for noncontinuum effects, imperfect surface accommodation and for the effect of the size distribution. Here we assume a unit accommodation coefficient for all particles. Only coagulation by Brownian motion is considered since it dominates coagulation for particles with radii in the submicron range [Seinfeld and Pandis, 1998]. We use the interpolation formula of Fuchs [1964] to describe coagulation in the continuum, the free molecular and the transition regime. Coagulation can occur between particles of the same mode (intramodal coagulation) and between particles of different modes (intermodal coagulation). Intramodal coagulation reduces the particles number per volume air of mode $i$, while intermodal coagulation removes particles from a mode $i$ with smaller volume mean radius and adds their mass to a mode $j$ with larger volume mean radius.

[19] The concentration of $\mathrm{H}_{2} \mathrm{SO}_{4}$ (gas) is predicted by the model. Gaseous $\mathrm{H}_{2} \mathrm{SO}_{4}$ is produced by gas phase chemistry of $\mathrm{SO}_{2}$ with $\mathrm{OH}$ (see Table 1). Condensation and nucleation are sinks for gaseous $\mathrm{H}_{2} \mathrm{SO}_{4}$. Wet scavenging by cloud and precipitation and dry deposition at surface are also included for gaseous $\mathrm{H}_{2} \mathrm{SO}_{4}$. The sulfate produced by the aqueous phase oxidation in clouds is equally distributed among all particles that have acted as CCN. In the model calculation we assume that all hygroscopic aerosol particles larger than $0.05 \mu \mathrm{m}$ in radius may act as a CCN. This includes pure sulfate aerosol in the accumulation mode, sea salt, and dust and $\mathrm{BC} / \mathrm{OM}$ particles with radius larger than $0.05 \mu \mathrm{m}$ which should also be internally mixed with sulfate. In order to maintain a good representation of the aerosol size distribution with the available number of modes and to enforce the ordering of modes by size, merging is implemented by using a table lookup. For example, if the size distribution of the nuclei mode contains a significant number of particles that are larger than a predefined limit radius for this mode $(0.05 \mu \mathrm{m})$, then the number and mass of particles larger than this limit are transferred to the next mode. Our merging process conserves aerosol mass and number.

[20] Nonsulfate aerosols are assumed to follow predefined background size distributions that do not change during the time integration. The size distribution parameters are given in Table 3. Particle size distribution for fossil fuel $\mathrm{BC} / \mathrm{OM}$ was based on measurements for the Hardiman fire by Radke et al. [1988]. The size distributions of organic and black carbon particles from fossil fuel combustion vary depending on the type of combustor and the phase of the cycle of combustion [Bond et al., 2002; Kerminen et al., 1997; McElroy et al., 1982]. Particles from most combustion processes are mainly submicron [Bond et al., 2002]. We chose to model the particles from combustion of fossil fuels using a size distribution that provides optical properties in the range of measured optical properties for particles from fossil fuel combustion [Penner et al., 1998b]. Alternative 
Table 3. Size Distribution Parameters for Nonsulfate Aerosols

\begin{tabular}{cccc}
\hline $\begin{array}{c}\text { Aerosol } \\
\text { Component }\end{array}$ & $N_{\mathrm{i}}^{\mathrm{a}}$ & $r_{\mathrm{i}}, \mu \mathrm{m}$ & $\sigma_{\mathrm{i}}$ \\
\hline Fossil fuel OM/BC & 0.428571 & 0.005 & 1.5 \\
& 0.571428 & 0.08 & 1.7 \\
& $1 \times 10^{-6}$ & 2.5 & 1.65 \\
Biomass OM/BC & 0.9987 & 0.0774 & 1.402 \\
and natural OM & & & \\
& $1.306 \times 10^{-3}$ & 0.3360 & 1.383 \\
Sea-salt & $2.830 \times 10^{-4}$ & 0.9577 & 1.425 \\
& 0.965 & 0.035 & 1.92 \\
Dust & 0.035 & 0.41 & 1.70 \\
& 0.854240 & 0.05 & 1.65 \\
& 0.145687 & 0.27 & 2.67 \\
& 0.000073 & 4.0 & 2.40 \\
\hline
\end{tabular}

${ }^{\mathrm{a}} N_{\mathrm{i}}$ is normalized by total number concentration of aerosols and is dimensionless.

size distributions may lead to somewhat different lifetimes in our model, but these changes would not be expected to be large, since these particles are only represented by a single submicron size bin in our model. For biomass burning $\mathrm{BC} /$ $\mathrm{OM}$ and natural $\mathrm{OM}$, the size distribution is fitted from measurements in the TRACE-A biomass experiment [Anderson et al., 1996]. Both the fossil fuel and biomass burning carbon size distributions can be described by the sum of three lognormal distributions with the geometric means and variance given in Penner et al. [1998b]. Mineral dust particles are assumed to follow the size distribution of d'Almeida et al. [1991] within each size bin while sea salt follows that of Quinn and Coffman [1998]. However, nonsulfate aerosol becomes mixed with sulfate when sulfuric acid condenses onto these aerosols, when pure sulfate aerosols coagulate with the nonsulfate aerosol, or when sulfate is formed through aqueous reactions in cloud drops that contain nonsulfate aerosols. Hygroscopic growth of sea salt and organic particles using the Gerber [1991] scheme and the particle growth due to sulfate associated with all particle types is included. Coagulation between nonsulfate aerosol particles of the same or of a different type is not included in the model at this point. Thus, although sulfate may become internally mixed with nonsulfate aerosols, carbonaceous aerosol, dust, and sea salt do not become mixed with each other. The assumption is justified by the low number concentrations of nonsulfate aerosols predicted within the grid size we are using (e.g., $2000 \mathrm{~cm}^{-3}$ ) which leads to coagulation lifetimes that are larger than 10 days [Seinfeld and Pandis, 1998]. The detailed aerosol dynamics and microphysics are shown in Figure 1.

[21] The coupling of the aerosol dynamics module with the CTM is implemented as follows. During one operator split time step of the CTM (one hour here) aerosol dynamics calculations are performed at every grid point. The CTM provides the dynamics module with the initial concentrations of $\mathrm{H}_{2} \mathrm{SO}_{4}$ (gas), sulfate aerosol mass and number in each mode, sulfate mass on the nonsulfate aerosols, and the mass of nonsulfate aerosols, and the source rates of gas and aqueous phase sulfate production (sulfate produced within one CTM time step divided by the CTM time step) along with the meteorological fields (temperature, pressure and relative humidity). The solution of the derivative equations in the aerosol dynamics module is advanced in time using a fourth-order Runge-Kutta scheme with a dynamically adjusted time step [Herzog et al., 2004]. The inner time step is calculated for each box individually and can be shorter than one second during a strong nucleation event. After the operator split time (one hour), changed species concentrations are fed back to the CTM.

\subsection{Emissions}

[22] The emissions specified for the model simulations reported here were as follows. Fossil fuel sulfur emission used the draft IPCC-specified 2000 scenario [Nakicenovic et al., 2000] and totaled $69 \mathrm{Tg}_{-} \mathrm{S} \mathrm{yr}^{-1}$. We assumed that $2 \%$ (by mole) of fossil fuel sulfur emissions occur as primary sulfate aerosol to account for fast conversion of $\mathrm{SO}_{2}$ to $\mathrm{SO}_{4}^{2-}$ in combustion plumes. This fraction is similar to the



Non -sulfate aerosols

(OM/BC/dust/sea salt)

Figure 1. Diagram of aerosol dynamics included in the model. 
fractions assumed in other global models [e.g., Chin et al., 2000a; Koch et al., 1999]. We further divided 15\% and $85 \%$ of the mass of the direct particle source into modes 1 and 2 , respectively, in accordance with the measurements of Whitby et al. [1978] and Cantrell and Whitby [1978]. The emission rates for number concentrations were determined by assuming the lognormal modes reported by Whitby [1978] with geometric mean diameters of 0.01 and $0.07 \mu \mathrm{m}$ and standard deviations of 1.6 and 2.0, respectively, similar to the approach used in regional models [e.g., Binkowski amd Shankar, 1995]. Volcanic $\mathrm{SO}_{2}$ sources were from Andres and Kasgnoc [1998]. It includes sporadic and continuously emitting volcanoes but they are averages over a 25 -year time period, so the total $\left(4.8 \mathrm{Tg}_{-} \mathrm{S} \mathrm{yr}^{-1}\right)$ includes only $1 \%$ from sporadic emissions. Marine DMS fluxes with a total of $26.1 \mathrm{Tg}-\mathrm{S} \mathrm{yr}{ }^{-1}$ were based on Kettle and Andreae [2000] using the ocean DMS field compiled by Kettle et al. [1999]. We used the average of the fluxes that they calculate based on the Liss and Merlivat [1986] parameterization (low estimate) and the Wanninkhof [1992] parameterization (high estimate).

[23] Natural OM fluxes were derived by assuming that $9 \%$ of the terpene emission of Guenther et al. [1995] was rapidly converted to $\mathrm{OM}$ and totaled $14.4 \mathrm{Tg} \mathrm{yr}^{-1}$. OM and $\mathrm{BC}$ from fossil fuels were developed from the inventories of Penner et al. [1993] and Liousse et al. [1996] for a calendar year representative of the mid-1980s. The biomass burning sources were taken from the inverse model study of Zhang et al. (Inverse modeling of biomass burning emissions using TOMS AI for 1997, submitted to Journal of Geophysical Research, 2005), who compared the modeled aerosol index (AI) with that measured by the EP TOMS instrument. The annual global source of biomass aerosols for the year 1997 is about $\sim 13 \%$ larger than that reported by Liousse et al. [1996] and has a factor of 8-10 increase for emissions from Indonesia due to the Indonesia fires in 1997. The total fossil fuel and biomass burning emissions for $\mathrm{OM}$ and $\mathrm{BC}$ are 96.8 $\mathrm{Tg} \mathrm{yr}^{-1}$ and $13.5 \mathrm{Tg} \mathrm{yr}^{-1}$, respectively. It is noted that there are still large uncertainties in the estimated emission fluxes for carbonaceous aerosol. Fossil fuel OM emissions used by different models range from $9.8 \mathrm{Tg}^{-1}$ [Cooke et al., 1999] and $14.7 \mathrm{Tg} \mathrm{yr}^{-1}$ [Chin et al., 2002] to $36.5 \mathrm{Tg} \mathrm{yr}^{-1}$ [Koch, 2001]. Biomass burning emissions range from 44.6 $\mathrm{Tg} \mathrm{yr}^{-1}$ [Liousse et al., 1996] to $107.8 \mathrm{Tg} \mathrm{yr}^{-1}$ [Chin et al., 2002] for OM, and from 5.6 $\mathrm{Tg}_{\mathrm{yr}}^{-1}$ [Liousse et al., 1996] to $11.0 \mathrm{Tg}^{-1}$ [Chin et al., 2002] for BC.

[24] Dust aerosol fluxes at every 6 hours were provided by Ginoux et al. [2001] which were generated using the DAO meteorological fields for year 1997. The original data were provided as fluxes in 4 size bins $(0.1-1 \mu \mathrm{m}, 1-1.8 \mu \mathrm{m}$, $1.8-3 \mu \mathrm{m}$, and $3-6 \mu \mathrm{m})$. Additionally the flux in the small bin $(0.1-1 \mu \mathrm{m})$ was divided into four subclasses $(0.1-0.18$, $0.18-0.3,0.3-0.6$, and $0.6-1 \mu \mathrm{m})$ by assuming a mass fraction for each class: $0.9,8.1,23.4$, and $67.6 \%$, respectively [Tegen and Lacis, 1996]. To get the mass flux in our size bins we lumped the fluxes in the first three subclasses $(0.1-0.18,0.18-0.3,0.3-0.6 \mu \mathrm{m})$ as the flux in our first bin $(0.05-0.63 \mu \mathrm{m})$ approximately (the mass flux in the size range of $0.05-0.1 \mu \mathrm{m}$ is negligibly small compared to flux in size range $0.1-0.6 \mu \mathrm{m})$. The flux in their fourth subclass $(0.6-1 \mu \mathrm{m})$ together with interpolations using the lognormal distribution from Ginoux et al. [2001] and Tegen and Lacis [1996] for particle sizes $1<r<10 \mu \mathrm{m}$ were used to derive the mass fluxes in our other three bins. It is noted that Ginoux et al.'s [2001] scheme may overestimate submicron dust emissions (C. Chuang, private communication, 2003). This was also confirmed by our own study, which found that the model calculated aerosol optical depth using the original Ginoux et al.'s [2001] dust fluxes is too high comparing with the satellite data (e.g., Multi-angle Imaging Spectro-Radiometer (MISR)) over dust source regions due to the larger extinction efficiency of submicron dust. Thus we further used the dust size distribution of d'Almeida et al. [1991] to scale the submicron dust fluxes from Ginoux et al. [2001]. The dust flux in the size bin $(0.05-0.63 \mu \mathrm{m})$ was reduced by almost a factor of 2 , and the model calculated aerosol optical depth now agrees well with satellite data over the dust source regions. The total dust flux is $1684{\mathrm{Tg} \mathrm{yr}^{-1}}^{-1}$ for $0.05 \mu \mathrm{m}<r<10 \mu \mathrm{m}$. Finally, sea salt emissions were provided from Gong et al. [1997]. An interpolation was made based on the algorithm of Monahan et al. [1986] to derive mass fluxes for our 4 size bins $(0.05-0.63 \mu \mathrm{m}, 0.63-$ $1.26 \mu \mathrm{m}, 1.26-2.5 \mu \mathrm{m}$, and $2.5-10 \mu \mathrm{m})$ and totaled $3768 \mathrm{Tg} \mathrm{yr}^{-1}$. Fossil fuel emissions of $\mathrm{SO}_{2}$, carbonaceous aerosol, natural emissions of DMS, OM, and sea salt emissions are injected in the model lowest layer, while mineral dust and biomass burning emissions of carbonaceous aerosol are uniformly injected in the boundary layer.

\subsection{Deposition}

[25] Dry deposition rates for gaseous species are calculated using a package developed at Harvard University based on the work of Jacob and Wofsy [1990], Wesely [1989], and Walcek et al. [1986]. For aerosols a surface resistance scheme based on Zhang et al. [2001] was used. Gravitational settling is also included for aerosols. The settling velocity and the slip correction factor for Stokes law are calculated from Seinfeld and Pandis [1998] using the mass-weighted average radius in each bin for each nonsulfate aerosol component based on the assumed size distribution in each bin. For sulfate aerosol the massweighted average sizes for mass and number are calculated from the model predicted mass and number in each mode. Sulfate mass accumulated on nonsulfate aerosols increase the sizes of nonsulfate particles. Hygroscopic growth also contributes to the increase in aerosol sizes.

[26] IMPACT uses the Harvard wet scavenging model [Mari et al., 2000; Liu et al., 2001] that is enhanced over previous models [Giorgi and Chameides, 1986; Balkanski et al., 1993]. Two types of scavenging are implemented: (1) scavenging in subgrid wet convective updrafts, and (2) first-order rainout and washout in precipitating columns. In the convective updrafts, the fraction of tracer scavenged is calculated based on the rate constant for conversion of cloud condensate (including liquid and ice) to precipitation (assumed to be $0.005 \mathrm{~s}^{-1}$ ) and the fraction of tracer present in the cloud condensate $f_{i}$ (scavenging efficiency). Highly soluble gas species such as $\mathrm{HNO}_{3}$ and $\mathrm{H}_{2} \mathrm{SO}_{4}(\mathrm{~g})$ are assumed to be $100 \%$ in the cloud condensate phase. For less soluble gas species scavenging efficiencies depend on their Henry's law coefficients. For aerosols scavenging efficiencies are gen- 
erally prescribed to be constants for different aerosol components $\left(f_{i}=1\right.$ for sulfate and sea salt; and $0<f_{i} \leq 1$ for BC/OM and mineral dust and depends on the amount of sulfate associated with these aerosols (see below)).

[27] Rainout, washout, and reevaporation are each calculated for stratiform and convective precipitation. The fraction of a tracer lost due to rainout depends on the wet scavenging efficiency of the tracer, the horizontal areafraction of the grid box experiencing precipitation, and conversion rate of cloud condensate to precipitation. The latter two parameters are calculated for both stratiform and convective precipitation from Giorgi and Chameides' [1986] scheme. Cloud liquid water content of $0.5 \mathrm{~g} \mathrm{~m}^{-3}$ for stratiform and of $2.0 \mathrm{~g} \mathrm{~m}^{-3}$ for convective precipitation is used in the scheme. Washout by large-scale and convective precipitation is computed as a first-order loss process using a washout rate constant of $0.1 \mathrm{~mm}^{-1}$ normalized to the precipitation rate in the precipitating fraction of the grid box [Balkanski et al., 1993]. Resuspension is calculated in any grid box where there is net evaporation of precipitation. A fraction (assumed to be half) or total of the tracer precipitating from above is released in the grid box to reflect the partial or total evaporation of precipitation, respectively.

[28] In our present model with aerosol dynamics we have set the scavenging efficiencies as follows. Wet scavenging efficiencies for the second (accumulation) mode sulfate aerosol and sea salt are assumed to be 1.0, but the first (nuclei) mode sulfate aerosol, which is not large enough to activate in most stratiform and convective clouds, can only be scavenged by its Brownian coagulation with cloud droplets. Therefore the scavenging efficiency is calculated from the Brownian coagulation coefficient [Seinfeld and Pandis, 1998], a cloud droplet number estimate and a cloud lifetime of 4 hours. The cloud droplet number is estimated from the second mode sulfate aerosol plus nonsulfate aerosols in the accumulation mode which are also hydrophilic depending on the surface sulfate coating (see below). Considering a dry radius of $0.02 \mu \mathrm{m}$ for the nuclei mode aerosols typically in the marine boundary layer [e.g., Raes et al., 2000, 1997] (see also section 4.3), the Brownian coagulation coefficient between aerosols with a wet size as calculated in section 2.3 and cloud droplets would be $\sim 2 \times$ $10^{-8} \mathrm{~cm}^{3} \mathrm{~s}^{-1}$. The scavenging efficiency of aerosols is estimated to be 0.09 assuming a cloud droplet number of $300 \mathrm{~cm}^{-3}$ and a cloud lifetime of 4 hours. The aging of $\mathrm{BC}$, $\mathrm{OM}$ and mineral dust particles from hydrophobic (with $f_{i}=$ 0 when they are just emitted without sulfate mixing) to hydrophilic (with $f_{i}=1$ ) depends on the surface coating by sulfate and other soluble components (e.g., nitrate). Here we calculate the fractional area coverage of a single nonsulfate particle surface by sulfate molecules (e.g., for carbonaceous aerosols) as

$$
f_{B C+O M}^{s o 4}=\frac{r_{s o 4 \min }^{2} N_{s o 4 \min }}{4\left(r_{B C+O M}+r_{s o 4 \min }\right)^{2}},
$$

where $r_{B C+O M}$ is the mass-weighted average radius for carbonaceous particles; $r_{\text {so4min }}$ the radius of a sulfate molecule; and $N_{\text {so4min }}$ the total sulfate molecules on a single carbonaceous particle. We assume here that when
$f_{B C+O M}^{s o 4}=10$ (layers), the particle becomes hygroscopic. The mass fraction of sulfate in the $\mathrm{BC} / \mathrm{OM} / \mathrm{SO}_{4}$ mixture with these layers of coating is $14 \%$. Since carbonaceous particles in the atmosphere are not purely spherical as assumed in equation (1), the specific surface area (surface area per unit mass) could be much higher than that of a spherical shape. Indeed the specific surface area of soot particles was measured to be from $75 \mathrm{~m}^{2} \mathrm{~g}^{-1}$ [Kärcher et al., 1996] up to more recent $400 \mathrm{~m}^{2} \mathrm{~g}^{-1}$ [Gierens, 2003] compared to $28 \mathrm{~m}^{2} \mathrm{~g}^{-1}$ for a spherical soot particle with a radius of $0.07 \mu \mathrm{m}$. Thus the ten-layer coating criterion in equation (1) would correspond to 0.67-3.6 layers on the soot particles with a higher specific surface area in the atmosphere. The above criterion for hygroscopicity is consistent with the laboratory measurements by Wyslouzil et al. [1994] and Lammel and Novakov [1995]. They found that when the $\mathrm{H}_{2} \mathrm{SO}_{4}$ mass fraction was greater than $10 \%$ for the coated $\mathrm{BC}$ aerosols, their droplet nucleation ability was the same as that for completely soluble $\left(\mathrm{NH}_{4}\right)_{2} \mathrm{SO}_{4}$ particles. This mass fraction corresponded to an $\mathrm{H}_{2} \mathrm{SO}_{4}$ surface coating of $0.1-1.5$ layers for different estimates of the specific surface area $\left(90-864 \mathrm{~m}^{2} \mathrm{~g}^{-1}\right)$. Since we are not aware of surface coating experiments similar to those for $\mathrm{BC}$ for mineral dust particles, we used the same criterion (i.e., a ten-layer coating) for mineral dust particles to become hydrophilic. This gives an $\mathrm{H}_{2} \mathrm{SO}_{4}$ mass fraction requirement of $3.5 \%, 0.7 \%, 0.4 \%$ and $0.2 \%$ for dust particles in bins 1 to 4 , respectively to become hygroscopic. Note that dust particles in bins $1-4$ have a mass mean radius of $0.2,0.9,1.7$ and $3.9 \mu \mathrm{m}$, respectively. Calculations based on the Köhler equation showed that the critical supersaturations required to activate mixed particles of the above 4-bin sizes containing the above sulfate mass fractions would be less than $0.2 \%$ [Seinfeld and Pandis, 1998]. If we consider a median supersaturation of $0.1-0.2 \%$ in stratiform clouds [Pruppacher and Klett, 1997], the above criterion is appropriate for mineral dust particles to become hydrophilic and to act as a nucleation site for new droplet formation in clouds. The scavenging efficiency is linearly interpolated between 0 and 1.0 for $0<f_{B C+O M}^{S O 4}<10$.

[29] In addition to the above specifications, for belowcloud washout we use the size-dependent washout rate constant from Dana and Hales [1976] for the two modes of sulfate aerosol and for nonsulfate aerosols instead of using a constant value of $0.1 \mathrm{~mm}^{-1}$ [Balkanski et al., 1993]. When reevaporation of precipitation occurs the scavenged $\mathrm{H}_{2} \mathrm{SO}_{4}(\mathrm{~g})$ and sulfate aerosol mass in modes 1 and 2 in precipitation are assumed to increase the sulfate mass in mode 2 . The contribution to the sulfate aerosol number is neglected from the reevaporation of the sulfate below cloud base because of a much smaller number of raindrops compared to aerosol number. Evaporation of scavenged nonsulfate aerosols and their associated sulfate increases the concentrations of nonsulfate aerosols and sulfate associated with them in the atmosphere.

\section{Model Results}

\subsection{Species Concentration Distributions}

[30] Figure 2 shows the model predicted zonal mean mass concentrations of pure sulfate aerosol in the nuclei and accumulation mode in January and July. Sulfate mass in the 



Figure 2. Model predicted zonal mean mass concentrations $\left(\mu \mathrm{g} \mathrm{m}^{-3}\right)$ of pure sulfate aerosol in the nuclei (upper panel) and accumulation mode (lower panel) in January (left) and July (right).

nuclei mode has a maximum in the upper troposphere which is associated with the source of sulfate aerosol by nucleation in the tropical upper troposphere [Clarke and Kapustin, 2002] and with a sink due to a poleward and downward transport by the Hadley circulation. Sulfate production in July in the Northern Hemisphere (NH) is stronger than that in January due to higher $\mathrm{OH}$ concentrations and temperatures there in July. The maximum near the surface in midlatitudes of the $\mathrm{NH}$ is due to direct sulfate particle emissions. Sulfate mass in the accumulation mode is much higher than those in the nuclei mode, because of the source associated with the condensation of $\mathrm{H}_{2} \mathrm{SO}_{4}$ (gas) onto these sulfate particles and the source associated with the aqueous phase sulfate production in droplets activated from accumulation mode sulfate particles. It has a maximum in its mass concentration in regions with high sulfur emissions for both months. The major contrast between January and July is the strong advection of pollutants (sulfate here) from the midlatitude source regions to the Arctic circle in January (which was confirmed by Chin et al. [2000a] using also the DAO meteorological data), and the production of sulfate from DMS oxidation in austral summer. Strong convection in July transports NH midlatitude sulfate to higher altitudes than in January.

[31] Figure 3 is the same as Figure 2 but for pure sulfate aerosol number concentrations. The very low temperature and high RH in the tropical upper troposphere [see Liu and Penner, 2002] result in very strong nucleation events there and sulfate number can reach over $10^{4} \mathrm{~cm}^{-3}$. This distribution pattern agrees with that reported by Clarke and Kapustin [2002] which was compiled from measurement data in the free troposphere. Accumulation mode sulfate number has a maximum in the lower troposphere which is associated with direct sulfate particle emissions. Accumulation mode sulfate number concentrations are generally within $50-400 \mathrm{~cm}^{-3}$ in most of free troposphere except in the Southern Hemisphere (SH) winter when accumulation mode sulfate number can be below $10 \mathrm{~cm}^{-3}$.

[32] Figure 4 shows the model predicted $\mathrm{SO}_{2}$ (upper panels) and $\mathrm{H}_{2} \mathrm{SO}_{4}(\mathrm{~g})$ (lower panels) concentrations at the surface in January and July, respectively. $\mathrm{SO}_{2}$ at the surface generally has the high concentrations in regions with anthropogenic sulfur emissions and in regions with high DMS oxidation near $60^{\circ}$ latitude during the $\mathrm{SH}$ summer. $\mathrm{H}_{2} \mathrm{SO}_{4}(\mathrm{~g})$ concentrations depend on the gas phase production from $\mathrm{SO}_{2}$ oxidation by $\mathrm{OH}$, and on nucleation losses and condensational losses to preexisting aerosols and cloud droplets. The seasonal dependence of $\mathrm{H}_{2} \mathrm{SO}_{4}(\mathrm{~g})$ concentrations at high latitudes is apparently due to $\mathrm{OH}$ concentration changes with the sun angle. $\mathrm{H}_{2} \mathrm{SO}_{4}(\mathrm{~g})$ concentrations in January are high in the tropics and subtropics in the SH over the oceans, but not in July due to much stronger DMS sources (by a factor of 3 ) there in January than in July. $\mathrm{H}_{2} \mathrm{SO}_{4}(\mathrm{~g})$ concentrations reach $10^{7}-10^{8}$ molecules $\mathrm{cm}^{-3}$ in January in the region near $60-70^{\circ} \mathrm{S}$ with high DMS emissions. $\mathrm{H}_{2} \mathrm{SO}_{4}(\mathrm{~g})$ concentrations in the 

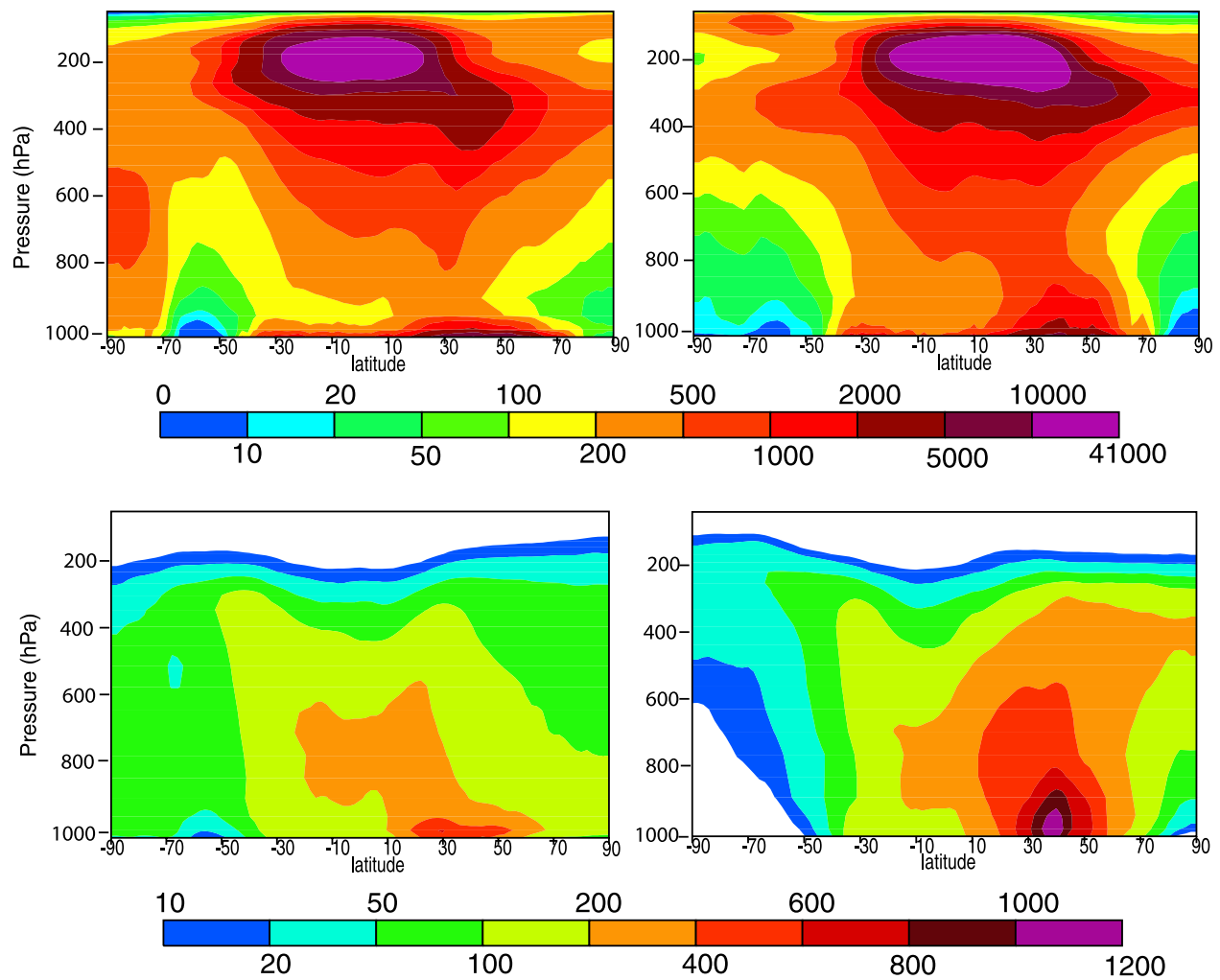

Figure 3. The same as Figure 2, but for pure sulfate aerosol number concentrations $\left(\mathrm{cm}^{-3}\right)$.


Figure 4. Model predicted $\mathrm{SO}_{2}$ (in units of pptv, upper panel) and gaseous $\mathrm{H}_{2} \mathrm{SO}_{4}$ (in units of molecules $\mathrm{cm}^{-3}$, lower panel) concentrations at the surface in January (left) and July (right). 



Figure 5. Annual averaged zonal mean distributions of $\mathrm{SO}_{2}$ (pptv), gaseous $\mathrm{H}_{2} \mathrm{SO}_{4}\left(\right.$ molecules cm ${ }^{-3}$ ), DMS (pptv), and $\mathrm{H}_{2} \mathrm{O}_{2}$ (pptv) predicted by the model.

most polluted regions in the $\mathrm{NH}$ midlatitudes are limited due to condensational loss on aerosol particles. Very high $\mathrm{H}_{2} \mathrm{SO}_{4}(\mathrm{~g})$ concentrations $\left(1-5 \times 10^{8}\right.$ molecules $\left.\mathrm{cm}^{-3}\right)$ in Northern Africa result from high $\mathrm{OH}$ concentrations, $\mathrm{SO}_{2}$ transported from Europe, and also from low cloud liquid water in this generally subsiding region, so that there is less cloud scavenging. Apart from the above regions, $\mathrm{H}_{2} \mathrm{SO}_{4}(\mathrm{~g})$ concentrations at the surface are generally within the range of $10^{5}-10^{7}$ molecules $\mathrm{cm}^{-3}$.

[33] The annual averaged zonal mean distribution of $\mathrm{SO}_{2}$, $\mathrm{H}_{2} \mathrm{SO}_{4}(\mathrm{~g})$, DMS, and $\mathrm{H}_{2} \mathrm{O}_{2}$ are shown in Figure 5. $\mathrm{SO}_{2}$ exhibits high concentrations in the $\mathrm{NH}$, as expected, but also significant concentrations in the $\mathrm{SH}$ midlatitudes in regions with high DMS emissions. $\mathrm{H}_{2} \mathrm{SO}_{4}(\mathrm{~g})$ has high concentrations in the subtropics in the $\mathrm{NH}$ and $\mathrm{SH}$, and in the high DMS emission regions in the $\mathrm{SH}$, a consequence of $\mathrm{H}_{2} \mathrm{SO}_{4}(\mathrm{~g})$ production and loss. $\mathrm{H}_{2} \mathrm{SO}_{4}(\mathrm{~g})$ concentrations generally reduce with increasing altitudes, which is consistent with $\mathrm{H}_{2} \mathrm{SO}_{4}(\mathrm{~g})$ production from $\mathrm{SO}_{2}$ which is mainly emitted near the surface and mixed upwards. $\mathrm{H}_{2} \mathrm{SO}_{4}(\mathrm{~g})$ concentration decreases with altitude faster than $\mathrm{SO}_{2}$ due to more efficient scavenging of $\mathrm{H}_{2} \mathrm{SO}_{4}(\mathrm{~g})$ by aerosols and clouds. We will see in section 3.2 that $\mathrm{H}_{2} \mathrm{SO}_{4}(\mathrm{~g})$ has a lifetime much shorter than that of $\mathrm{SO}_{2}$. In the tropics, DMS is pumped to the upper troposphere by deep convection, a feature which also appeared in the model simulations of Barth et al. [2000] and Chin et al. [2000a]. However, our calculated DMS concentrations near the surface in the $\mathrm{NH}$ and $\mathrm{SH}$ are much higher than their calculations because of the higher DMS emissions we used (total DMS emission of $26.1 \mathrm{Tg} \mathrm{S} \mathrm{yr}^{-1}$ in our work compared to $13.3-$
15.5 $\mathrm{Tg} \mathrm{S} \mathrm{yr}^{-1}$ in their studies). The annual averaged, zonal mean $\mathrm{H}_{2} \mathrm{O}_{2}$ concentrations are similar to those shown by Feichter et al. [1996], Barth et al. [2000], and Chin et al. [2000a] and reflect the input mixing ratio of $\mathrm{HO}_{2}$ and the losses of $\mathrm{H}_{2} \mathrm{O}_{2}$ by precipitation and photolysis.

[34] Annual averaged total sulfate mass (including sulfate mass on nonsulfate aerosols), pure sulfate number and total aerosol number concentrations at the surface and at $536 \mathrm{hPa}$ are shown in Figure 6. High surface mass concentrations of sulfate are found in regions of high anthropogenic emissions, as expected. Sulfate mass at $536 \mathrm{hPa}$ is better mixed zonally and the concentrations are one magnitude lower than those at the surface. The sulfate number concentration distribution at surface is generally correlated with that of the mass concentration with the highest values over the industrialized source regions due to direct sulfate particle emissions. However, sulfate number concentrations decrease faster than does sulfate mass with increasing distance from sources. Total aerosol number concentrations are dominated by pure sulfate aerosol over most of the continents at the surface and almost everywhere in the middle to upper troposphere. Peaks in modeled annual average total aerosol number occur over the eastern United States, eastern Europe, and China, and exceed $10,000 \mathrm{~cm}^{-3}$, consistent with the observations of rural and urban aerosols [e.g., Whitby, 1978; d'Almeida et al., 1991]. Modeled estimates of $1000-5000 \mathrm{~cm}^{-3}$ over remote land regions (e.g., northern Canada, northwestern Asia, and N. Africa) are similar to the range reported in the literature as compiled in Pruppacher and Klett [1997]. In polar regions, the model produces lower Arctic particle number concentrations 

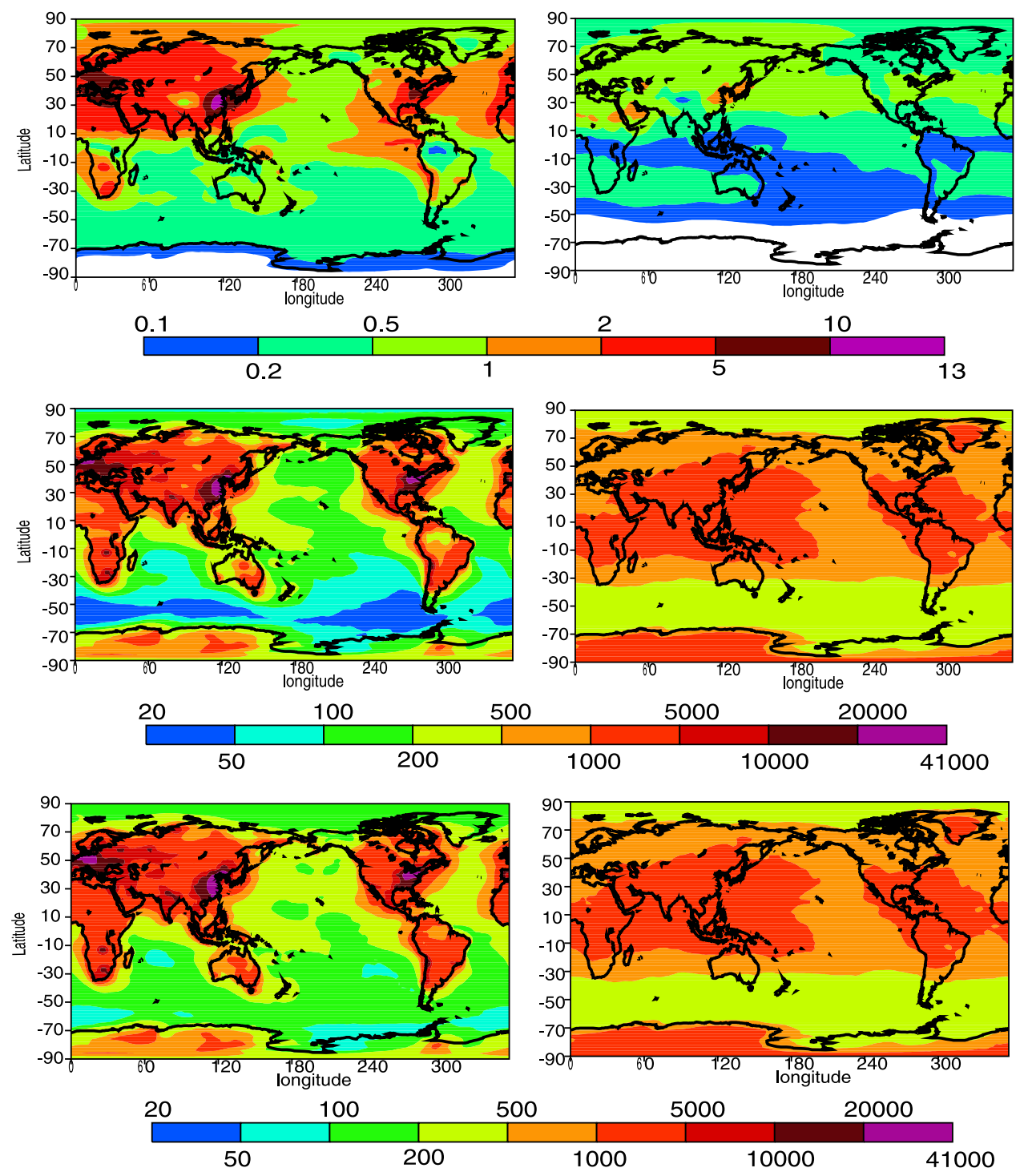

Figure 6. Annual averaged total sulfate mass (in units of $\mu \mathrm{g} \mathrm{m}^{-3}$, upper panel), pure sulfate number (in units of $\mathrm{cm}^{-3}$, middle panel) and total aerosol number (in units of $\mathrm{cm}^{-3}$, lower panel) concentrations at the surface (left) and at $536 \mathrm{hPa}$ (right) predicted by the model.

$\left(100-200 \mathrm{~cm}^{-3}\right)$ than those over remote land regions. However, much higher Antarctic number concentrations $\left(500-2000 \mathrm{~cm}^{-3}\right)$ are predicted even though the sulfate mass concentrations there are below $0.1 \mu \mathrm{g} \mathrm{m} \mathrm{m}^{-3}$. This higher concentration is consistent with the very low temperatures and high $\mathrm{RH}$ over Antarctic regions in the DAO meteorological data which favors new particle formation. A global model of aerosol processes (GLOMAP) by K. Carslaw et al. (unpublished results, 2003) using a sectional aerosol dynamics driven by the ECMWF meteorological fields also produced a high number concentrations $\left(1000-2500 \mathrm{~cm}^{-3}\right)$ of $2-10 \mathrm{~nm}$ sulfate aerosols at the surface of the Antarctic.

[35] Simulated total aerosol number concentrations over ocean regions are generally lower than those over continents. In general, higher number concentrations (200$500 \mathrm{~cm}^{-3}$ ) are found over the Atlantic Ocean and over most parts of the northern Pacific Ocean, as these regions are influenced by anthropogenic sources. The Southern
Ocean region has simulated marine aerosol number concentrations of $50-200 \mathrm{~cm}^{-3}$, and is generally considered one of the Earth's cleanest environments [Gras, 1990; Bates et al., 1998]. Sea salt particles constitute more than $50 \%$ of the total aerosol number in the DMS production region at $50-70^{\circ} \mathrm{S}$, and most of the sulfate generated from DMS oxidation is associated with sea salt there (see Figure 10). Compared to surface aerosol, aerosol number concentrations at $536 \mathrm{hPa}$ are less variable, which is mostly influenced by consistent $\mathrm{H}_{2} \mathrm{SO}_{4}$ nucleation rates in the free troposphere [e.g., Raes, 1995]. Again high Antarctic number concentrations $\left(1000-5000 \mathrm{~cm}^{-3}\right)$ are produced at this level.

[36] In order to address the interactions between sulfate and nonsulfate aerosols, the performance of the nonsulfate aerosol module is also important. Figures 7 and 8 present the vertically integrated (column burden) annual mean mass concentrations and zonal averaged annual mean plots for nonsulfate aerosols predicted by the model (OM, BC, dust, 
(a) OM



(c) Dust
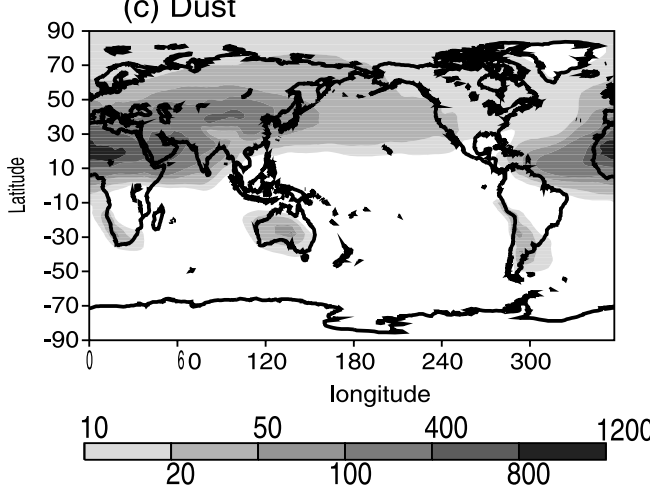

(b) $\mathrm{BC}$
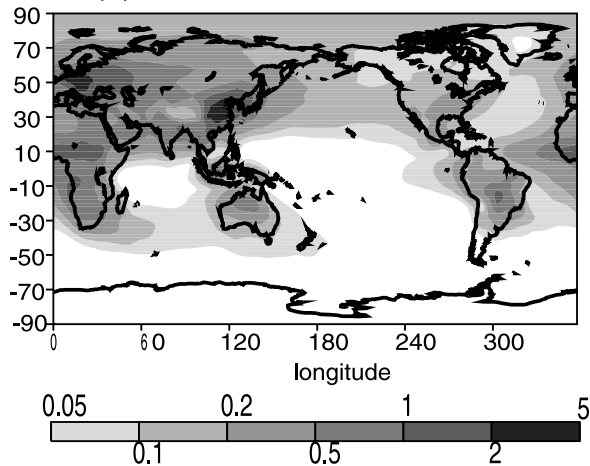

(d) Sea Salt


Figure 7. Vertically integrated annual mean concentrations $\left(\mathrm{mg} \mathrm{m}^{-2}\right)$ of $\mathrm{OM}, \mathrm{BC}$, dust, and sea salt predicted by the model.

(a) OM
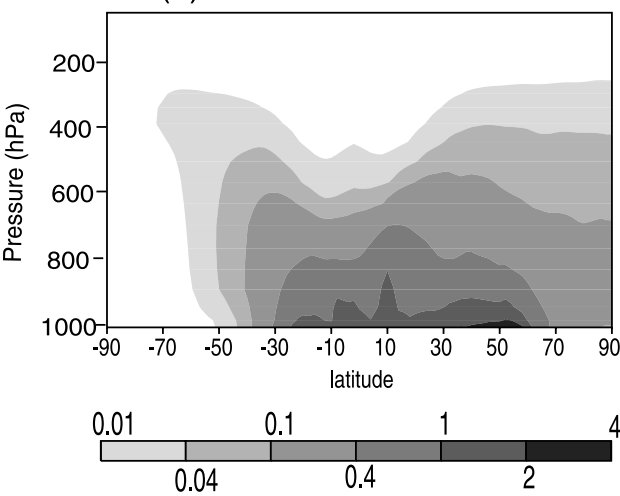

(c) Dust



(b) $\mathrm{BC}$


(d) Sea Salt

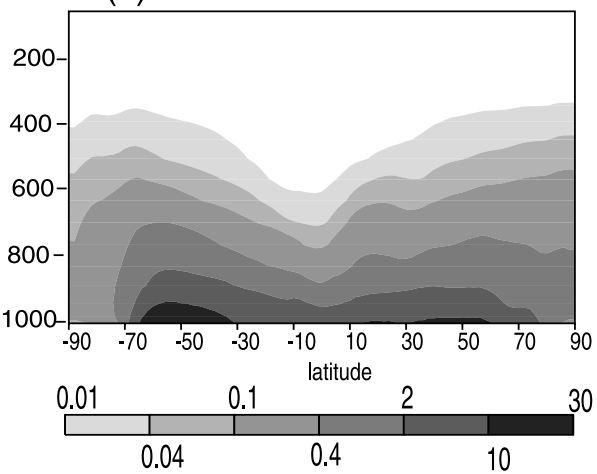

Figure 8. Annual averaged zonal mean concentrations $\left(\mu \mathrm{g} \mathrm{m}^{-3}\right)$ of $\mathrm{OM}, \mathrm{BC}$, mineral dust, and sea salt predicted by the model. 
(a) $\mathrm{OM} / \mathrm{BC}$

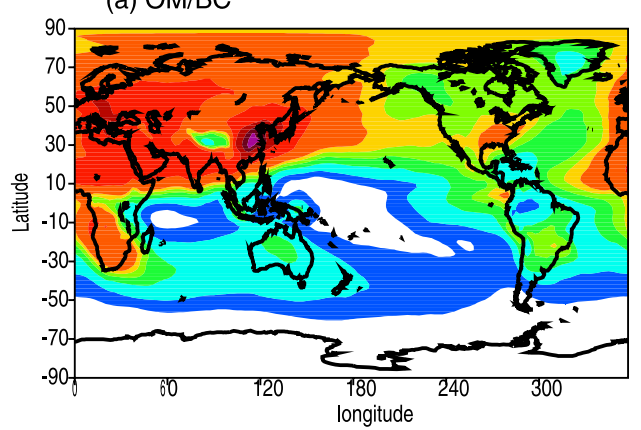

(b) Dust

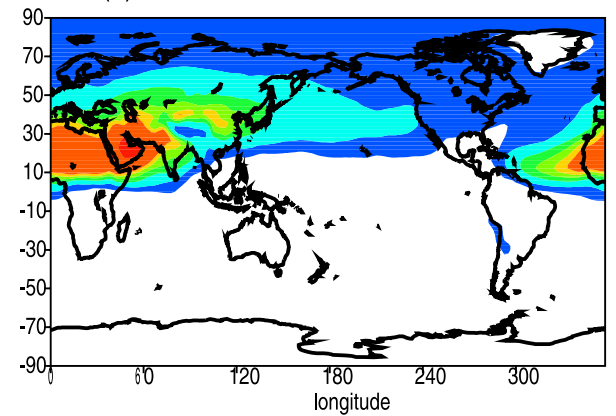

(c) Sea Salt

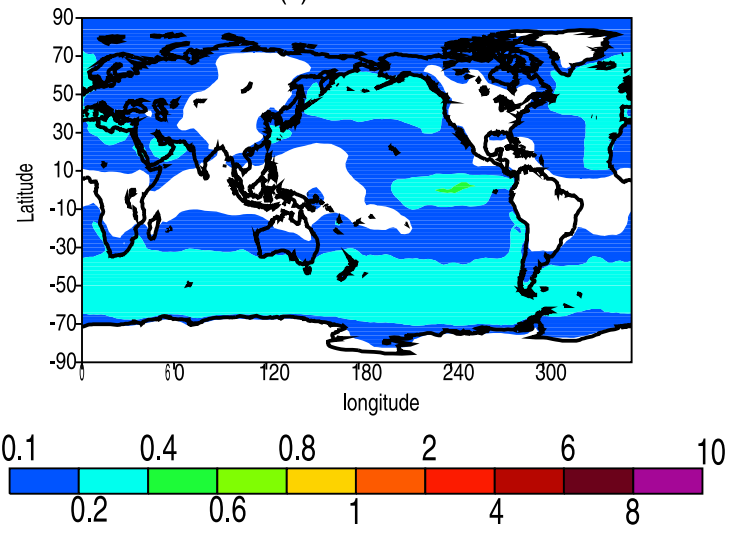

Figure 9. Vertically integrated annual mean sulfate mass $\left(\mathrm{mg} \mathrm{m}^{-2}\right)$ associated with $\mathrm{OM} / \mathrm{BC}$, dust, and sea salt as predicted by the model.

and sea salt), respectively. Not surprisingly, these column burden distributions essentially reflect the distributions of sources. Dust particles from Africa are transported over the North Atlantic and Caribbean [Prospero, 1999], and dust particles from Asia are transported over the North Pacific [Prospero et al., 1989; Arimoto et al., 1996]. Looking at the zonal distributions, $\mathrm{OM}$ and $\mathrm{BC}$ distributions resemble each other very closely, not surprisingly, and follow the proportion of $\mathrm{BC}$ and $\mathrm{OM}$ in the fossil fuel and biomass burning emissions. The distribution patterns of carbonaceous aerosol are similar to those predicted by Chung and Seinfeld [2002]. Dust particles are strongly transported vertically. The reason may be partly due to a uniform injection of dust flux in the boundary layer, and less cloud scavenging due to the lower scavenging efficiency of pure dust particles over the source regions. Measurements show that Sahara dust particles are transported at altitudes of 3-5 km [e.g., Karyampudi et al., 1999], and that dust particles emitted from Asian sources are lifted more efficiently to $8 \mathrm{~km}$ [e.g., Merrill et al., 1989; Ginoux et al., 2001]. Our modeled vertical distribution of dust is very similar to that predicted by Luo et al. [2003], while Ginoux et al. [2001] obtained a stronger meridional transport at lower altitude (around $800 \mathrm{hPa}$ ) in both the $\mathrm{NH}$ and $\mathrm{SH}$. Sea salt particles are mostly constrained to the lower atmosphere having a stronger decay rate with altitude due to their large settling velocity and effective wet removal.

[37] Figure 9 shows the vertically integrated annual mean sulfate mass on nonsulfate aerosols (carbonaceous aerosol, mineral dust and sea salt), which generally follows the mass distributions of nonsulfate aerosols (see Figure 7) and the gas- and aqueous-phase sulfate production. For example, while there are local maxima in the sulfate amount on carbonaceous aerosol in East Asia and central Europe because of both high anthropogenic carbonaceous aerosol sources and $\mathrm{SO}_{2}$ emissions there, the sulfate amount on carbonaceous particles in the South America biomass burning region is less noticeable because of the smaller $\mathrm{SO}_{2}$ emission and sulfate production there. The global average sulfate associated with carbonaceous aerosol is higher than that associated with mineral dust and sea salt because natural emissions of mineral dust and sea salt particles are not collocated with the industrialized regions where strong $\mathrm{SO}_{2}$ emission and sulfate production occurs. In addition, a lower number concentration of mineral dust and sea salt particles act as $\mathrm{CCN}$, and thus there is less sulfate coating from aqueous phase production (see below).

[38] Figure 10 compares the annual mean column burden of total sulfate mass on nonsulfate aerosols with that of pure sulfate aerosol. Most of the global sulfate mass exists as pure sulfate particles externally mixed from the nonsulfate aerosols. The rational for this is discussed as follows. Mineral dust particle concentrations near the surface are calculated in the model to be around $100-800 \mathrm{~cm}^{-3}$ in the Western Sahara and Asian Gobi deserts (results not shown). Away from these regions dust concentrations are rapidly reduced, and are generally less than $100 \mathrm{~cm}^{-3}$ in East Asia, less than $20 \mathrm{~cm}^{-3}$ in central Europe, and less than $1 \mathrm{~cm}^{-3}$ in most of the United States. Schütz and Jaenicke [1974] found dust particle concentrations near the ground over the Libyan Desert of $0.26,9.6$ and $8.8 \mathrm{~cm}^{-3}$ at mean wind speeds of $7.6 \mathrm{~m} \mathrm{~s}^{-1}, 8 \mathrm{~m} \mathrm{~s}^{-1}$, and $8.7 \mathrm{~m} \mathrm{~s}^{-1}$, respectively. Dust 
(a)



(b)



(d)


0

20

40

60

50 80

Figure 10. Annual mean column burden $\left(\mathrm{mg} \mathrm{m}^{-2}\right)$ of (a) pure sulfate aerosol, (b) sulfate associated with nonsulfate aerosols, (c) percentage of total sulfate mass associated with nonsulfate aerosols at the surface, and (d) the zonal mean distribution of this percentage.

particle concentrations were about $10 \mathrm{~cm}^{-3}$ in the size range between 0.1 and $10 \mu \mathrm{m}$ in small dust storms [e.g., Levin et al., 1980]. d'Almeida et al. [1991] reported 250 to $2600 \mathrm{~cm}^{-3}$ for various locations in the Sahara. A more recent measurement of dust plumes near the North African west coast in the free troposphere found that dust concentrations were in the range of $160-250 \mathrm{~cm}^{-3}$ [de Reus et al., 2000]. Thus our model calculated dust number concentrations are similar to those measured. Sea salt number concentrations near the surface are calculated in the model to be within the range of $40-140 \mathrm{~cm}^{-3}$ in the $\mathrm{SH}$ near $50^{\circ} \mathrm{S}$ and in $\mathrm{NH}$ extratropical cyclones with high wind speeds. Apart from these regions the average number concentrations are around $10-40 \mathrm{~cm}^{-3}$ over the ocean, consistent with observations [Blanchard and Cipriano, 1987; O'Dowd and Smith, 1993; Murphy et al., 1998]. The maximum number concentrations of carbonaceous aerosols in the boundary layer are calculated to be $1000-4000 \mathrm{~cm}^{-3}$ in the industrialized regions (e.g., East Asia and central Europe) with about half in the accumulation mode, and are 500$2000 \mathrm{~cm}^{-3}$ in biomass burning regions (e.g., southern Africa and southern America) with $90 \%$ in the accumulation mode. Biomass burning aerosol number concentrations in the boundary layer over Brazilian and African source regions have a median value of $1880 \mathrm{~cm}^{-3}$ and $936 \mathrm{~cm}^{-3}$, respectively [Anderson et al., 1996]. Compared to the sulfate aerosol number (shown in Figure 6), nonsulfate aerosol number concentrations are generally much less in both the continental and marine environments, and at the surface and in the upper troposphere. Since most of the global sulfate is produced through aqueous phase reactions in cloud droplets [e.g., Penner et al., 2001], the sulfate amount accumulated in this process is deposited on to the accumulation mode aerosols from each aerosol type in the proportions of their available numbers from which cloud droplets are formed.

[39] Figure 10 also shows the percentage of total sulfate which is associated with nonsulfate aerosols in the boundary layer, and the zonal mean distribution of this mass percentage fraction. Except over the United States and over part of the Pacific Ocean in the tropics, the percentage of total sulfate associated with nonsulfate aerosols in the boundary layer is generally larger than $20 \%$. Over most of Asia, part of Europe, and the Northern Sahara, the percentage is 30$40 \%$. The percentage in the biomass burning regions and the $\mathrm{NH}$ extratropical cyclones reaches up to $40-50 \%$. The model predicts a high percentage $(>60 \%)$ of sulfate that is associated with nonsulfate aerosol (i.e., sea salt) in the $\mathrm{SH}$ near $50^{\circ} \mathrm{S}$, which is consistent with measurements in the Southern Ocean marine boundary layer that show a significant number of sea salt aerosols contribute to the number concentrations of submicrometer particles $(>0.04 \mu \mathrm{m})$ that can act as CCN [Murphy et al., 1998]. It is noted that the absolute sulfate amount on sea salt particles in this region is quite low compared to sulfate amount on dust and $\mathrm{BC} / \mathrm{OM}$ in the NH (see Figure 9). Thus a higher fraction of sulfate on sea salt near $50^{\circ} \mathrm{S}$ as seen in Figures $10 \mathrm{c}$ and $10 \mathrm{~d}$ does not produce a similar maximum there in the column burden of sulfate associated with nonsulfate aerosols (Figure 10b). Analysis of the aerosol collected near the surface at Cheju 
Table 4. Global Budgets for DMS, $\mathrm{SO}_{2}$, and Sulfate ${ }^{\mathrm{a}}$

\begin{tabular}{|c|c|c|c|}
\hline & \multicolumn{2}{|c|}{ This Work } & \multirow[t]{2}{*}{$\begin{array}{c}\text { Other } \\
\text { Models }^{\mathrm{b}}\end{array}$} \\
\hline & $D M S$ & & \\
\hline Sources & & 26.1 & \\
\hline Emission & & 26.1 & $10.7-23.7$ \\
\hline Sinks & & 26.1 & \\
\hline Dry deposition & & 0.44 & \\
\hline Oxidation & & 25.6 & \\
\hline Burden & & 0.12 & $0.02-0.15$ \\
\hline \multirow[t]{2}{*}{ Lifetime } & & 1.8 & $0.5-3.0$ \\
\hline & $\mathrm{SO}_{2}$ & & \\
\hline Sources & & 98.0 & \\
\hline Anthropogenic emission & & 67.6 & $61.2-92.0$ \\
\hline Volcanic emission & & 4.8 & $3.4-9.2$ \\
\hline Biomass burning emission & & 0.0 & $2.2-2.9$ \\
\hline DMS oxidation & & 25.6 & $10.0-24.7$ \\
\hline Sinks & & 97.9 & \\
\hline Dry deposition & & 28.7 & $16.0-55.0$ \\
\hline Wet deposition & & 5.3 & $0.0-19.9$ \\
\hline Gas-phase oxidation & & 22.0 & $6.1-16.8$ \\
\hline Aqueous-phase oxidation & & 41.9 & $24.5-57.8$ \\
\hline Burden & & 0.69 & $0.20-0.61$ \\
\hline \multirow[t]{2}{*}{ Lifetime } & & 2.6 & $0.6-2.6$ \\
\hline & Sulfate & & \\
\hline Sources & & 65.3 & \\
\hline Emission & & 1.4 & $0-3.5$ \\
\hline $\begin{array}{l}\text { Gas-phase } \\
\mathrm{SO}_{2} \text { oxidation }\end{array}$ & & 22.0 & $6.1-16.8$ \\
\hline $\begin{array}{l}\text { Aqueous-phase } \\
\mathrm{SO}_{2} \text { oxidation }\end{array}$ & & 41.9 & $24.5-57.8$ \\
\hline Sinks & & 65.2 & \\
\hline Dry deposition & & 4.1 & $3.9-18.0$ \\
\hline Wet deposition & & 61.1 & $34.7-61.0$ \\
\hline Burden & & 0.89 & $0.53-1.07$ \\
\hline $\mathrm{H}_{2} \mathrm{SO}_{4}(\mathrm{~g})(\%)$ & & 0.05 & \\
\hline $\begin{array}{l}\text { Nuclei and accu. } \\
\text { mode sulfate }(\%)\end{array}$ & & $9.7,69.8$ & \\
\hline $\begin{array}{l}\text { On carbonaceous } \\
\text { aerosols }(\%)\end{array}$ & & 14.3 & \\
\hline On dust bins $1-4(\%)$ & $2.54,0.4$ & $7,0.28,0.01$ & \\
\hline On sea salt bins $1-4(\%)$ & $2.76,0.06$ & $0.01,0.0004$ & \\
\hline Lifetime & & 5.0 & $3.9-6.8$ \\
\hline
\end{tabular}

${ }^{\mathrm{a}}$ Units are sources and sinks, $\mathrm{Tg} \mathrm{S} \mathrm{yr}{ }^{-1}$; burden, $\mathrm{Tg} \mathrm{S}$; lifetime, days.

${ }^{\mathrm{b}}$ Including Langner and Rodhe [1991], Pham et al. [1995], Chin and Jacob [1996]; Feichter et al. [1996], Lohmann and Feichter [1997], Chuang et al. [1997], Roelofs et al. [1998], Koch et al. [1999], Lohmann et al. [1999b], Rasch et al. [2000], Chin et al. [2000a, 2000b], Chuang et al. [2002], Rotstayn and Lohmann [2002], and Easter et al. [2004].

Korea showed $10-20 \%$ of the sulfate mass was associated with the coarse particle mode [Carmichael et al., 1996, 1997]. The sulfate mass fraction in the coarse mode particles measured in the marine boundary layer at Barbados varied from $21 \%$ associated with the cleanest air masses from the central North Atlantic to $73 \%$ associated with strong dust events from North Africa [Li-Jones and Prospero, 1998]. With an increase of altitude the percentage of sulfate associated with nonsulfate aerosols is reduced in the model. This percentage falls in the range of $10-20 \%$ in the middle troposphere, and is below $10 \%$ in the upper troposphere. This result suggests that the majority of sulfate particles nucleated in the middle to upper troposphere are externally mixed from nonsulfate aerosols because of the low nonsulfate aerosol number there. It should be noted that we have not included sulfate production on the surface of dust and sea salt through heterogeneous chemical reactions here, which can be important for sulfate coating on dust and sea salt particles in the boundary layer [e.g., Dentener et al., 1996; Carmichael et al., 1996; Sievering et al., 1992]. See section 6 for an estimate of the importance of this process.

\subsection{Budgets}

[40] The global sulfur budgets for DMS, $\mathrm{SO}_{2}$ and sulfate are summarized in Table 4, together with a range of results from other models that were compiled by Rotstayn and Lohmann [2002]. Our global emission of DMS (26.1 $\mathrm{Tg} \mathrm{S} \mathrm{yr}{ }^{-1}$ ) is well within the range of 15 to $33 \mathrm{Tg} \mathrm{S} \mathrm{yr}{ }^{-1}$ suggested by Kettle and Andreae [2000], but is at the high end of the values used in other global models. Our $\mathrm{SO}_{2}$ and sulfate burdens are also high compared to most previous models (except others with prognostic $\mathrm{H}_{2} \mathrm{O}_{2}$ ), partly due to our higher DMS emissions. Looking at the $\mathrm{SO}_{2}$ budget, our gas-phase oxidation of $\mathrm{SO}_{2}$ is higher than the results of other models. Our model has $\sim 30 \%$ of the sulfate production by gas phase chemistry and $\sim 70 \%$ by aqueous phase chemistry. These ratios are similar to the values given by Koch et al. [1999] which also used a prognostic prediction of $\mathrm{H}_{2} \mathrm{O}_{2}$ in their model. This is a significantly slower aqueous conversion rate than the more highly parameterized models which convert 85 to $90 \%$ of the $\mathrm{SO}_{2}$ to $\mathrm{H}_{2} \mathrm{SO}_{4}$ by the aqueous pathway. As noted in Koch et al. [1999] and Roelofs et al. [1998], models that use prescribed $\mathrm{H}_{2} \mathrm{O}_{2}$ could overpredict the aqueous phase sulfate formation by $\mathrm{H}_{2} \mathrm{O}_{2}$ oxidation of $\mathrm{SO}_{2}$ when compared to models with prognostic $\mathrm{H}_{2} \mathrm{O}_{2}$. Less aqueous phase oxidation of $\mathrm{SO}_{2}$ in models with prognostic $\mathrm{H}_{2} \mathrm{O}_{2}$ may account for the higher $\mathrm{SO}_{2}$ burden in these models because the aqueous phase $\mathrm{SO}_{2}$ chemical conversion rate is much higher than that in the gas phase. In addition, higher gas-phase $\mathrm{SO}_{2}$ oxidation in those models with prognostic $\mathrm{H}_{2} \mathrm{O}_{2}$ could result in higher sulfate burdens because the sulfate thus produced is less easily scavenged by the rainout and washout compared to the sulfate produced in cloud droplets [Barth et al., 2000]. Therefore both $\mathrm{SO}_{2}$ and sulfate burdens are expected

Table 5. Global Budgets for $\mathrm{H}_{2} \mathrm{SO}_{4}(\mathrm{~g})$ and $\mathrm{H}_{2} \mathrm{O}_{2}$

\begin{tabular}{|c|c|c|}
\hline & This Work & Other Models ${ }^{\mathrm{a}}$ \\
\hline \multicolumn{3}{|c|}{$\mathrm{H}_{2} \mathrm{SO}_{4}(\mathrm{~g})$} \\
\hline Gas-phase production & 22.0 & 6.5 \\
\hline \multicolumn{3}{|l|}{ Sinks $\left(\mathrm{Tg} \mathrm{S} \mathrm{yr}^{-1}\right)$} \\
\hline Dry deposition & 0.011 & \\
\hline Wet deposition & 0.017 & \\
\hline Nucleation and condensation & 21.92 & \\
\hline Burden (Tg S) & 0.00044 & 0.00009 \\
\hline Lifetime (min) & 10.08 & 7.26 \\
\hline \multicolumn{3}{|l|}{ Sources $\left(\mathrm{Tg} \mathrm{H}_{2} \mathrm{O}_{2} \mathrm{yr}^{-1}\right)$} \\
\hline Gas-phase $\mathrm{HO}_{2}$ reactions & 1095.2 & 1125.0 \\
\hline Sinks $\left(\mathrm{Tg} \mathrm{H}_{2} \mathrm{O}_{2} \mathrm{yr}^{-1}\right)$ & 1095.3 & 1125.0 \\
\hline Dry deposition & 58.3 & 141.0 \\
\hline Wet deposition & 275.0 & 125.0 \\
\hline Gas-phase chemical sinks & 723.4 & 825.0 \\
\hline Aqueous-phase chemical sinks & 38.6 & 34.0 \\
\hline Burden $\left(\mathrm{Tg} \mathrm{H}_{2} \mathrm{O}_{2}\right)$ & 3.5 & 4.2 \\
\hline Lifetime (days) & 1.2 & 1.4 \\
\hline
\end{tabular}

${ }^{\mathrm{a}}$ Including Wilson et al. [2001] for $\mathrm{H}_{2} \mathrm{SO}_{4}$ (g) and Koch et al. [1999] for $\mathrm{H}_{2} \mathrm{O}_{2}$. 
Table 6. Global Budgets for Carbonaceous Aerosol ${ }^{\mathrm{a}}$

\begin{tabular}{lrr}
\hline & This Work & Other Models $^{\mathrm{b}}$ \\
\hline & $O M$ & \\
Sources & 111.2 & \\
Fossil fuel emission & 30.6 & $9.8-36.5$ \\
Biomass burning emission & 66.2 & $44.6-107.8$ \\
Photochemistry from terpenes & 14.4 & $7.8-17.8$ \\
Sinks & 111.2 & \\
Dry deposition & 11.3 & $19.0-29.8$ \\
Wet deposition & 99.9 & $60.1-113.3$ \\
Burden & 0.98 & $0.95-1.8$ \\
Lifetime & 3.2 & $3.9-6.4$ \\
& & \\
Sources & & \\
Fossil fuel emission & 13.5 & $5.1-8.0$ \\
Biomass burning emission & 6.7 & $5.6-11.0$ \\
Sinks & 6.8 & $2.7-4.6$ \\
Dry deposition & 13.5 & $7.8-13.7$ \\
Wet deposition & 1.6 & $0.13-0.29$ \\
Burden & 11.9 & $3.9-8.4$ \\
Lifetime & 0.12 & \\
\hline
\end{tabular}

${ }^{\mathrm{a}}$ Units are sources and sinks, $\mathrm{Tg}_{\mathrm{yr}}{ }^{-1}$; burden, $\mathrm{Tg}$; lifetime, days.

${ }^{\mathrm{b}}$ Range of the OM/BC results from Cooke and Wilson [1996], Liousse et al. [1996], Cooke et al. [1999], Koch [2001], Chin et al. [2002], Chuang et al. [2002], Chung and Seinfeld [2002], Cooke et al. [2002], Easter et al. [2004], and Wang [2004].

to be higher than in more highly parameterized models [Koch et al., 1999]. Our model has an efficient wet removal with $93 \%$ of total sulfate lost by wet deposition while $7 \%$ is lost by dry deposition. Our aerosol dynamics module predicts that $\sim 80 \%$ of sulfate exists as pure sulfate aerosol (9.7\% in the nuclei mode and $69.8 \%$ in the accumulation mode), while $14.3 \%$ of sulfate is mixed on carbonaceous aerosol, $3.3 \%$ on mineral dust (mostly in the smallest bin), and $2.7 \%$ on sea salt particles (nearly all in the smallest size bin). As noticed above, we have not included sulfate production on the surface of dust and sea salt through heterogeneous chemical reactions, which can be important for the amount of sulfate mass on dust and sea salt particles in the boundary layer.

[41] Table 5 shows the budgets for $\mathrm{H}_{2} \mathrm{SO}_{4}(\mathrm{~g})$ and $\mathrm{H}_{2} \mathrm{O}_{2}$. Almost all the $\mathrm{H}_{2} \mathrm{SO}_{4}(\mathrm{~g})$ is lost through nucleation and condensation (we do not have the separate contributions from the two processes from our present model runs). We have more gas-phase sulfate production (by a factor of 3 ) than that of Wilson et al. [2001], and a higher $\mathrm{H}_{2} \mathrm{SO}_{4}$ (g) burden. Our calculated $\mathrm{H}_{2} \mathrm{SO}_{4}$ (g) lifetime is $10 \mathrm{~min}$ compared to $\sim 7 \mathrm{~min}$ in Wilson et al. [2001]. For the $\mathrm{H}_{2} \mathrm{O}_{2}$ budget, gas-phase $\mathrm{H}_{2} \mathrm{O}_{2}$ losses, wet deposition, dry deposition, and aqueous-phase $\mathrm{H}_{2} \mathrm{O}_{2}$ chemistry constitute $66,25,5.5$, and $3.5 \%$ of the total $\mathrm{H}_{2} \mathrm{O}_{2}$ loss, respectively. Compared to the results of Koch et al. [1999], our model has higher wet deposition versus dry deposition for $\mathrm{H}_{2} \mathrm{O}_{2}$. Our calculated total $\mathrm{H}_{2} \mathrm{O}_{2}$ source $\left(1095 \mathrm{Tg} \mathrm{H}_{2} \mathrm{O}_{2} \mathrm{yr}^{-1}\right)$, burden $\left(3.5 \mathrm{Tg} \mathrm{H}_{2} \mathrm{O}_{2}\right.$ ) and lifetime (1.2 days) are close to those obtained by Koch et al. [1999].

[42] Table 6 presents the budgets for $\mathrm{OM}$ and $\mathrm{BC}$ predicted in this model along with the results from other global aerosol models. Our treatment of the hygroscopic properties of carbonaceous aerosol is directly related to the surface coating of the particle by sulfate as predicted in our model, and thus is more physically based than an approach that uses an exponential decay lifetime for the conversion of carbonaceous aerosol from hydrophobic to hydrophilic aerosol [Cooke et al., 1999], or an approach based on a constant solubility [Koch, 2001] or on relating the solubility to the gas phase oxidation of $\mathrm{SO}_{2}$ by $\mathrm{OH}$ [Koch, 2001]. Our results show that carbonaceous aerosol in most regions of the troposphere is internally mixed with sulfate and generally hygroscopic except near the source regions, and that on the global mean, $54 \%$ and $93 \%$ of carbonaceous aerosol are coated with sulfate in the boundary layer and in the upper troposphere, respectively (see section 5). (Of course, some of the organics near the source regions can be soluble by virtue of their chemical nature.) Thus we predict higher wet to dry deposition ratios, lower burdens, and shorter lifetimes for $\mathrm{OM}$ and $\mathrm{BC}$ than most other models. Our burden and lifetime for OM are similar to the results of Koch [2001] when they used a high scavenging efficiency $(70 \%)$ for OM.

[43] Table 7 gives our annual budget for dust in each size class along with a range of estimates from other models. Dust emissions and burdens vary by a factor of 5-8 in different models. Our budget for total dust $(0.05-10 \mu \mathrm{m})$ is within the middle of the ranges of different models. Dust particles in the first three bins are mainly scavenged by wet removal compared to the dominant effect of dry over wet scavenging in the largest size bin $(2.5-10 \mu \mathrm{m})$. The treatment of dust solubility in the model may not be as critical to its budget compared to that for carbonaceous aerosol because of the increased effect of dry deposition for dust particles. Our model predicts the highest loading $(13.6 \mathrm{Tg})$ in the size range of $1.25-2.5 \mu \mathrm{m}$, which is similar to that found by Luo et al. [2003] (12.5 Tg in the size range of 1-2.5 $\mu \mathrm{m})$ and by Ginoux et al. [2001] (14.5 Tg in the size range of $1-2 \mu \mathrm{m})$. Mass loadings are $6.6 \mathrm{Tg}(0.05-$ $1.25 \mu \mathrm{m})$ and $5.0 \mathrm{Tg}(2.5-10 \mu \mathrm{m})$ compared to $4.7 \mathrm{Tg}$ $(0.1-1 \mu \mathrm{m})$ and $6.0 \mathrm{Tg}(2.5-10 \mu \mathrm{m})$ from Luo et al. [2003] and $14.7 \mathrm{Tg}(0.1-1 \mu \mathrm{m})$ and $7.4 \mathrm{Tg}(2-6 \mu \mathrm{m})$ from Ginoux

Table 7. Global Budgets for Dust

\begin{tabular}{lrrrrr}
\hline \multicolumn{1}{c}{ Size, $\mu \mathrm{m}$} & $\begin{array}{c}\text { Emission, } \\
\mathrm{Tg} \mathrm{yr}^{-1}\end{array}$ & $\begin{array}{c}\text { Dry } \\
\text { Deposition, } \\
\mathrm{Tg} \mathrm{yr}^{-1}\end{array}$ & $\begin{array}{c}\text { Wet } \\
\text { Deposition, } \\
\mathrm{Tg} \mathrm{yr}^{-1}\end{array}$ & $\begin{array}{c}\text { Burden, } \\
\mathrm{Tg}\end{array}$ & $\begin{array}{c}\text { Lifetime, } \\
\text { days }\end{array}$ \\
\hline $0.05-0.63$ & 46 & 5.6 & 41 & 1.3 & 10.2 \\
$0.63-1.25$ & 191 & 28 & 163 & 5.3 & 10.1 \\
$1.25-2.5$ & 561 & 185 & 376 & 13.6 & 8.9 \\
$2.5-10$ & 886 & 824 & 62 & 5.0 & 2.1 \\
$0.05-10$ (this model) $_{\text {Total }(\text { other models }}^{\mathrm{a}}$ ) & 1684 & 1043 & 641 & 25.3 & 5.5 \\
\hline
\end{tabular}

${ }^{a}$ Range of the dust results from Tegen and Fung [1994], Tegen and Lacis [1996], Ginoux et al. [2001], Chin et al. [2002], Chuang et al. [2002], Tegen et al. [2002], Werner et al. [2002], Zender et al. [2003], Luo et al. [2003], and Easter et al. [2004]. 
Table 8. Global Budgets for Sea Salt

\begin{tabular}{lrrrrr}
\hline \multicolumn{1}{c}{ Size, $\mu \mathrm{m}$} & $\begin{array}{r}\text { Emission, } \\
\mathrm{Tg} \mathrm{yr}^{-1}\end{array}$ & $\begin{array}{r}\text { Dry Deposition, } \\
\mathrm{Tg} \mathrm{yr}^{-1}\end{array}$ & $\begin{array}{r}\text { Wet Deposition, } \\
\mathrm{Tg} \mathrm{yr}^{-1}\end{array}$ & $\begin{array}{c}\text { Burden, } \\
\mathrm{Tg}\end{array}$ & $\begin{array}{c}\text { Lifetime, } \\
\text { days }\end{array}$ \\
\hline $0.05-0.63$ & 220 & 27 & 193 & 0.79 & 1.32 \\
$0.63-1.25$ & 254 & 45 & 209 & 0.84 & 1.21 \\
$1.25-2.5$ & 453 & 2607 & 275 & 1.04 & 0.84 \\
$2.5-10$ & 2843 & 2857 & 913 & 0.74 & 0.096 \\
$0.05-10$ (this model) $_{\text {Total }(\text { other models }}^{\mathrm{a}}$ ) & 3770 & $940-7450$ & $74-2436$ & $4.3-12.0$ & 0.33 \\
\hline
\end{tabular}

${ }^{\mathrm{a}}$ Range of the sea salt results from Erickson and Duce [1988], Tegen et al. [1997], Chin et al. [2002], Chuang et al. [2002], Gong et al. [2002], and Easter et al. [2004].

et al. [2001]. Our model predicted lifetimes of 10.2 days $(0.05-0.63 \mu \mathrm{m})$ and 10.1 days $(0.63-1.25 \mu \mathrm{m})$ are close to those of 10.3 days $(0.1-1 \mu \mathrm{m})$ from Luo et al. [2003], but are less than that of 14 days $(0.1-1 \mu \mathrm{m})$ from Ginoux et al. [2001]. The lifetimes from our model for other size bins are 8.9 days $(1.25-2.5 \mu \mathrm{m})$ and 2.1 days $(2.5-10 \mu \mathrm{m})$ compared to 9.2 days $(1-2.5 \mu \mathrm{m})$ and 2.2 days $(2.5-10 \mu \mathrm{m})$ from Luo et al. [2003] and to 9 days $(1-2 \mu \mathrm{m})$ and 2.9 days $(2-6 \mu \mathrm{m})$ from Ginoux et al. [2001]. Therefore our mass loading and lifetime for different size classes of dust are close to Luo et al.'s [2003] results, and we both predict a much lower dust loading and a smaller lifetime for submicrometer dust particles compared to Ginoux et al. [2001]. Table 8 presents our budget for sea salt for each size class along with a range of estimates from other models. There are only a few global model estimates of sea salt budgets. Our model has a very high emission and dry deposition in the largest size bin $(2.5-10 \mu \mathrm{m})$ compared to that in the other three bins, while the wet deposition and mass loading are less variable for different bins compared to emission and dry deposition. Our model predicted burden and lifetime for total sea salt $(0.05-10 \mu \mathrm{m})$ are less than the results from


Figure 11. Comparison of modeled and observed monthly mean surface mass concentrations of sulfate at twelve sites in the SH. Model results are in solid lines, and observed data are in dots with one standard deviation. 



Figure 12. Same as Figure 11, but for eleven sites in the NH.

some other models [e.g., Tegen et al., 1997; Chin et al., 2002; Chuang et al., 2002], but are close to Easter et al.'s [2004] results.

\section{Comparison With Measurement Data}

\subsection{Aerosol Mass Concentrations}

[44] We compare our modeled seasonal cycles of sulfate, mineral dust and sea salt with aerosol concentrations measured at a number of locations that are part of an ocean network operated by a group at the University of Miami [Prospero et al., 1989; Arimoto et al., 1996; Savoie et al., 1989, 1993]. Direct comparison with point measurements is difficult, because the model results are interpreted as the average of each GCM grid cell $\left(2^{\circ}\right.$ latitude by $2.5^{\circ}$ longitude for our model) and the simulated wind direction and wind speed resolved by the DAO wind fields may not be consistent with those at the measurement site. However, these comparisons can serve as a reference to determine, in part, the accuracy of our simulated aerosol concentrations. Figure 11 shows a comparison of observed and modeled monthly mean surface concentrations of sulfate at twelve sites in the SH. The model is broadly able to capture the observed seasonal cycles at middle to high latitude oceanic sites in the SH. Sulfate is too high at sites (e.g., Palmer
Antarctica, Cape Grim) in the SH summer possibly because the DMS emissions that we used in the model are too high (globally $26.1 \mathrm{Tg}-\mathrm{S} \mathrm{yr}^{-1}$ ). This discrepancy was also present in the model results of Rotstayn and Lohmann [2002]. They have done a sensitivity test using the parameterization of Liss and Merlivat [1986] instead of that by Nightingale et al. [2000] for DMS emission. Their global

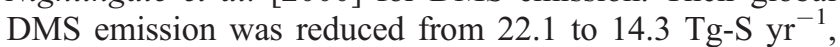
and the model results were remarkably improved at these $\mathrm{SH}$ sites. Our model predicts too low $\mathrm{SH}$ winter sulfate concentrations at Marsh King Island and Invercargill New Zealand while observations show weaker seasonal cycles. The model reproduces the peaks observed in February at several sites (e.g., Palmer Antarctica, Wellington New Zealand, Norfolk, and Yate New Caledonia). However, the maxima in the model results occur in February or March at some sites (Marsh King George, Reunion Island, and America Samoa), a little later than the observed maxima. A contributing factor to this discrepancy appears to be the month-to-month variations in the climatological seawater DMS concentrations from Kettle et al. [1999].

[45] Sulfate concentrations at eleven oceanic sites in the $\mathrm{NH}$ are shown in Figure 12. Observations at marine sites in the NH show strong seasonal enhancements of sulfate concentrations due to transport from the main anthropo- 
(a) North American sites


(b) European sites
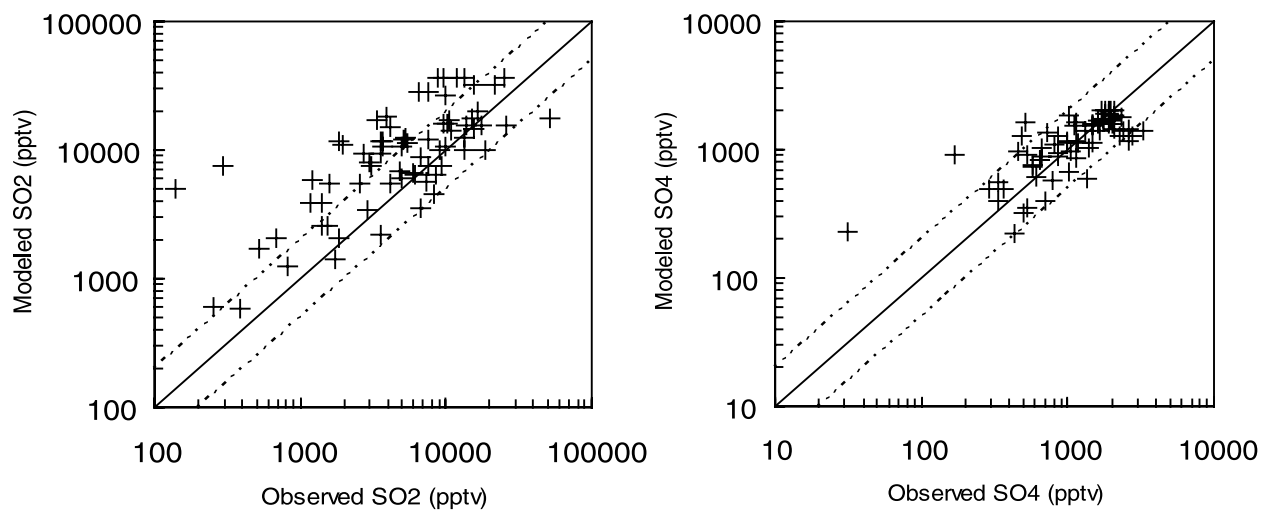

Figure 13. Comparison of annually averaged $\mathrm{SO}_{2}$ (left) and sulfate (right) mass concentrations at 75 North American (EMEFS) sites in 1989 and at 69 European (EMEP) sites in 1986. The solid lines are $1: 1$, and the dashed lines are $2: 1$ or $1: 2$.

genic source regions [Andreae et al., 1988; Savoie and Prospero, 1989; Savoie et al., 1993]. The summer maximum at Barbados is predicted by the model. The springtime maxima at Midway Island and Oahu Hawaii are also captured by the model, but the modeled concentrations in the summer and autumn are too high. The modeled peaks in October at Hedo Okinawa and in April at Cheju Island are also too high compared to observations. The springtime peak observed at Mace Head is captured by the model. The concentrations at Mace Head and Heimaey Iceland are too high in the summer, which can be due to too high DMS emissions in the storm track regions.

[46] We also compare modeled $\mathrm{SO}_{2}$ and sulfate concentrations over North America and Europe where extensive monitoring networks exist, as shown in Figure 13. North America observations are from the Eulerian Model Field Study (EMEFS) network [McNaughton and Vet, 1996], and European observations are from the European Monitoring and Evaluation Program (EMEP) [Hjellbrekke and Hanssen, 1998]. We have computed annual average $\mathrm{SO}_{2}$ and sulfate concentrations for 75 EMEFS sites in 1989 and 69 EMEP sites in 1986. From Figure 13, the major discrepancy between the modeled and the observed $\mathrm{SO}_{2}$ is that the model overestimates the $\mathrm{SO}_{2}$ levels by more than a factor of 2 at a large fraction of these sites, i.e., 1/3 of the EMEFS sites and 1/2 of the EMEP sites. High biases for $\mathrm{SO}_{2}$ over Europe and North America have been found in a number of global models [e.g., Barth et al., 2000; Chin et al., 2000b; Easter et al., 2004]. By contrast, the simulated sulfate concentrations agree well with the observations, especially for the North American sites, despite the overestimation of $\mathrm{SO}_{2}$. This is because the production of sulfate in the polluted regions is mainly controlled by the $\mathrm{H}_{2} \mathrm{O}_{2}$ concentrations in clouds, rather than by $\mathrm{SO}_{2}$. A number of reasons have been suggested for the overestimation of $\mathrm{SO}_{2}$ in the models, which include too weak boundary layer mixing [Lohmann et al., 1999b], too small $\mathrm{SO}_{2}$ dry deposition rates in the models [Easter et al., 2004], or the issue with sampling locations [Chin et al., 2000b].

[47] Figure 14 shows the observed and simulated surface concentrations of $\mathrm{OM}$ and $\mathrm{BC}$ at a number of locations compiled by Liousse et al. [1996] and Cooke et al. [1999]. Since the measured data are presented as OC, for comparison to measurements we assume that $\mathrm{OM} / \mathrm{OC}=1.4$ [Liousse et al., 1996]. Comparisons of carbonaceous aerosol to observations are more difficult because the measured concentrations are only available on a campaign basis so that the measured values are subject to short term variability. Such temporal variations may introduce a significant discrepancy between the observations and the monthly 

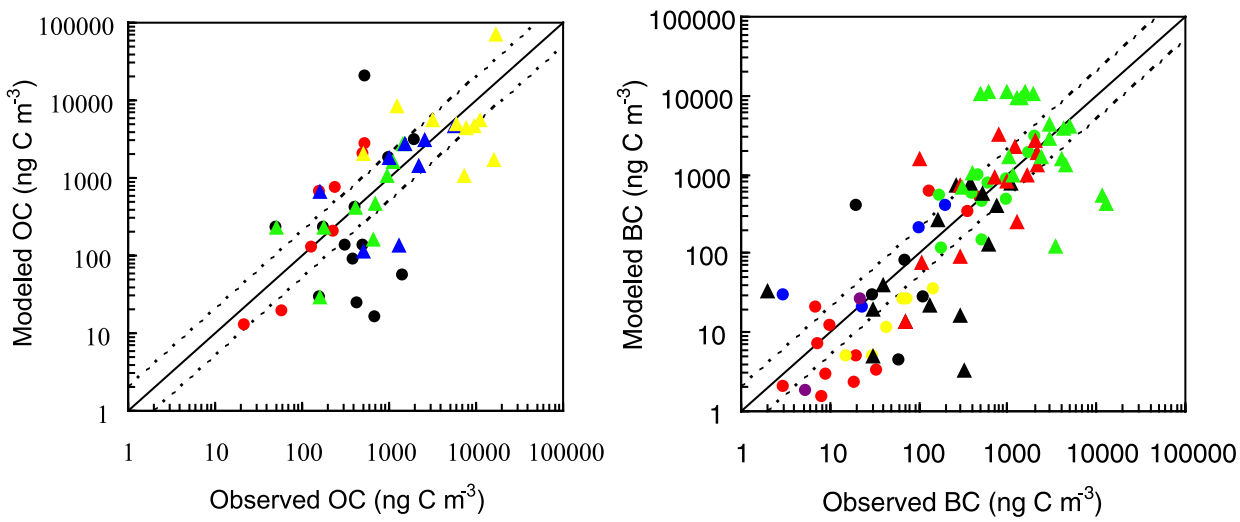

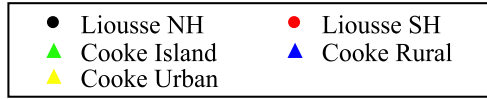

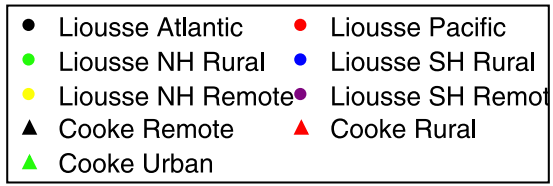

Figure 14. Comparison of observed and simulated mass concentrations of $\mathrm{OC}$ and $\mathrm{BC}$ at a number of locations. The solid lines are 1:1, and the dashed lines are 2:1 or 1:2. Observations refer to those summarized by Liousse et al. [1996] and Cooke et al. [1999].

averaged predictions from the model. Despite these facts, $\sim 50 \%$ of simulated values are within a factor of 2 , and $\sim 90 \%$ within a factor of 10 of $\mathrm{OC}$ and $\mathrm{BC}$ measurements, respectively. The model does a reasonable job of predicting the OC data for Liousse et al.'s [1996] SH locations, for Cooke et al.'s [1999] Island and Rural locations, and the BC data for Liousse et al.'s [1996] NH Rural locations and Cooke et al.'s [1999] Rural locations. For the comparisons with data at other locations, while model predictions are good compared with some of the data, there are some locations which are underpredicted or overpredicted. The discrepancies between our model results and observations at these locations appear to also occur in the model discussed by Chuang et al. [2002], which may imply a problem with the emissions used or may simply be due to the difficulty of comparing model results with these campaign based measurement data.

[48] Besides comparison with these campaign-based data, we compare the simulation results to the Inter-agency Monitoring of Protected Visual Environments (IMPROVE) database [Malm et al., 2000]. The IMPROVE network consists of aerosol and optical measurements at approximately 140 rural sites in the United States. The observation data for $\mathrm{OC}$ and $\mathrm{BC}$ from 48 sites are averaged over 3 years from March 1996 to February 1999. The comparison is shown in Figure 15. Simulated OC and BC concentrations are mostly within a factor of 2 of observed concentrations at these sites. However, the model tends to underpredict both $\mathrm{OC}$ and $\mathrm{BC}$ concentrations at this set of locations on average by about $40 \%$ and $20 \%$, respectively. The low biases have also been found in other model studies [Chung and Seinfeld, 2002; Easter et al., 2004]. This suggests a problem with local emissions or local complex terrain influences which a global model cannot reproduce.

[49] Figure 16 compares the modeled and observed seasonal cycle of $\mathrm{BC}$ concentrations at several sites in the $\mathrm{NH}$ and $\mathrm{SH}$. While the simulation exhibits a small seasonal variation which is also reflected in the observations, the simulated concentrations are much lower than the observed values at two Arctic sites (Alert and Barrow), and the peak in early spring is not reproduced. A similar underestimation was obtained by Liousse et al. [1996] and Chung and Seinfeld [2002]. Possible explanations include the underestimation of local sources and overestimation of wet scavenging. The model reproduces the seasonal cycle of $\mathrm{BC}$ concentrations at Jungfraujoch, Switzerland with a minimum in the winter months. The peaks in April and July are also captured. Figure 16d compares the modeled and observed BC concentrations at Mauna Loa, Hawaii. The model predicts a peak in BC in April and May, which is later than the observed one. The model also produces a peak in September which is absent from observations. The model captures the seasonal cycle of $\mathrm{BC}$ concentrations at Amsterdam Island with a maximum from June to September which results from biomass burning emissions. However the observed $\mathrm{BC}$ concentrations are underpredicted. Figure $16 \mathrm{f}$ shows a comparison of $\mathrm{BC}$ concentrations at Cape Grim, a remote site. The observation data include only the clean air sector [Heintzenberg and Bigg, 1990], and are severely overpredicted by the model. The simulation reflects the
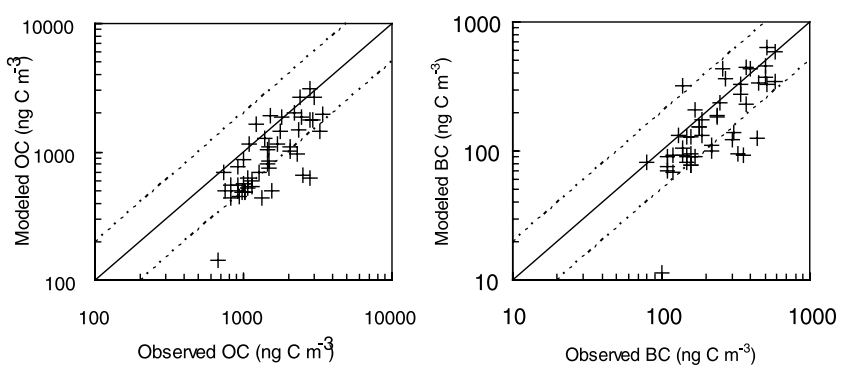

Figure 15. Simulated OC (left side) and BC (right side) concentrations versus observations from the IMPROVE network. The solid lines are 1:1, and the dashed lines are $2: 1$ or $1: 2$. 

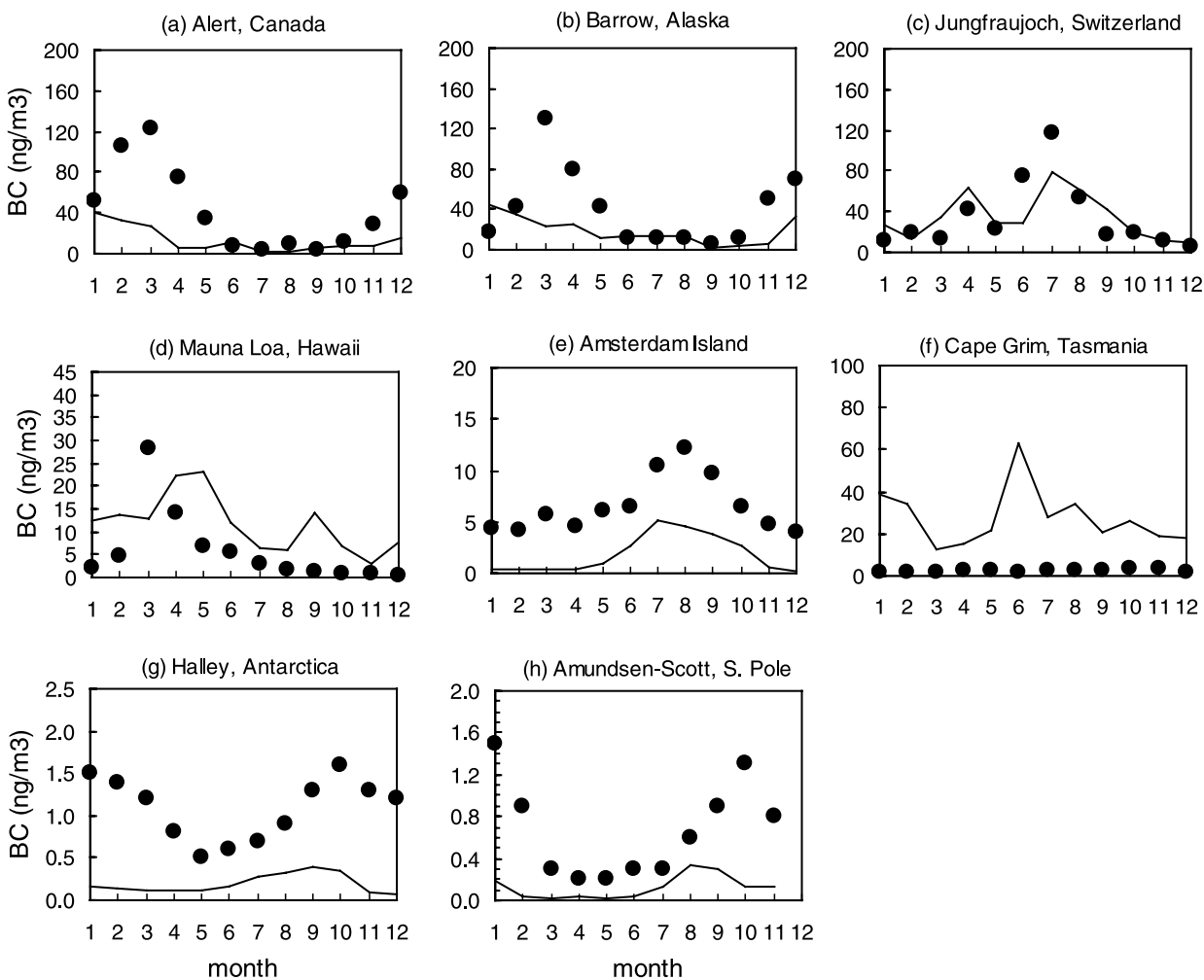

Figure 16. Comparison of modeled and observed seasonal variation of $\mathrm{BC}$ concentrations at various sites: (a) Alert, Canada $\left(82.5^{\circ} \mathrm{N}, 62.3^{\circ} \mathrm{W}\right)$ [Hopper et al., 1994], (b) Barrow, Alaska $\left(71.2^{\circ} \mathrm{N}, 156.3^{\circ} \mathrm{W}\right)$ [Bodhaine, 1995], (c) Jungfraujoch, Switzerland $\left(46.5^{\circ} \mathrm{N}, 9^{\circ} \mathrm{E}, 3.5 \mathrm{~km}\right.$ asl) [Nyeki et al., 1998], (d) Mauna Loa, Hawaii $\left(19.3^{\circ} \mathrm{N}, 155.4^{\circ} \mathrm{W}, 3.4 \mathrm{~km}\right.$ asl) [Bodhaine, 1995], (e) Amsterdam Island, France $\left(38^{\circ} \mathrm{S}, 77^{\circ} \mathrm{E}\right)$ [Wolff and Cachier, 1998], (f) Cape Grim, Tasmania $\left(40.7^{\circ} \mathrm{S}, 144.7^{\circ} \mathrm{E}\right)$ [Heintzenberg and Bigg, 1990], (g) Halley, Antarctica $\left(75.6^{\circ} \mathrm{S}, 26.2^{\circ} \mathrm{W}\right)[$ Wolff and Cachier, 1998], and (h) AmundsenScott, South Pole $\left(89^{\circ} \mathrm{S}, 102^{\circ} \mathrm{W}, 2.8\right.$ asl $)$ [Bodhaine, 1995]. Model results are in solid lines, and observed data are in dots.

seasonal trend of observed $\mathrm{BC}$ at the two Antarctic sites shown in Figures $16 \mathrm{~g}$ and $16 \mathrm{~h}$ with a peak in the austral spring. However, the observations are underpredicted. The low bias was also found by Chung and Seinfeld [2002], which suggests that emissions are too low, that wet deposition is too strong, or that advection towards the South Pole is inaccurately represented by the model.

[50] Figure 17 shows the modeled and observed seasonal variation of dust concentrations at fifteen ocean sites with seven sites in the $\mathrm{SH}$ and eight sites in the NH. In the remote region of the Antarctic (Mawson), the model reproduces the seasonal cycle of dust concentration, although the austral summer maximum is underpredicted (the measured standard deviation is particularly large during these months). The model also underpredicts the maximum in June at Palmer Antarctic which is influenced by dust emission from Patagonia. At Cape Grim, southeast of the Australian dust source, the model seems to reproduce the seasonal variation; however, it predicts too high concentrations in June and too low concentrations in December. At Cape Point, near the Namibian dust source, the model simulates the increase of concentration from March to July; however, it overpredicts the concentration in July by a factor of 4. This overprediction also appeared in Luo et al. [2003]. At Norfolk and New Caledonia, downwind of the Australian dust sources, the model predictions generally agree well with observations in both the concentrations and seasonal cycles, except the concentrations are too high in September and November at New Caledonia. In the NH, the model reproduces the concentrations and seasonal cycles at Izana Tenerife, Barbados and Bermuda, which are under the influence of the African dust source, although the model overpredicts the concentration in August at Izana and underpredicts the concentration in July and August at Bermuda by a factor of 2 . The model captures the seasonal cycles at Cheju Korea, Midway Island, Oahu, and Enewetak Atoll. However, the spring maximum is severely underpredicted at Cheju, which was also evident in Ginoux et al.'s [2001] results. Using a more efficient wet scavenging for dust particles in the model [i.e., $f_{i}=1$ ] would reduce dust concentrations by more than a factor of 2 in the most remote regions away from sources (e.g., Antarctica sites). In regions near the sources the impact of changing the scavenging efficiency is generally quite small (e.g., Izana Tenerife and Cape Point). The global dust burden was reduced by $\sim 12 \%$ in this sensitivity run.

[51] The model predicted sea salt surface concentrations are compared to observed data at seven $\mathrm{SH}$ sites and eight NH sites, in Figure 18. The model captures the seasonal cycle at an Antarctica site (Mawson). However, it under- 

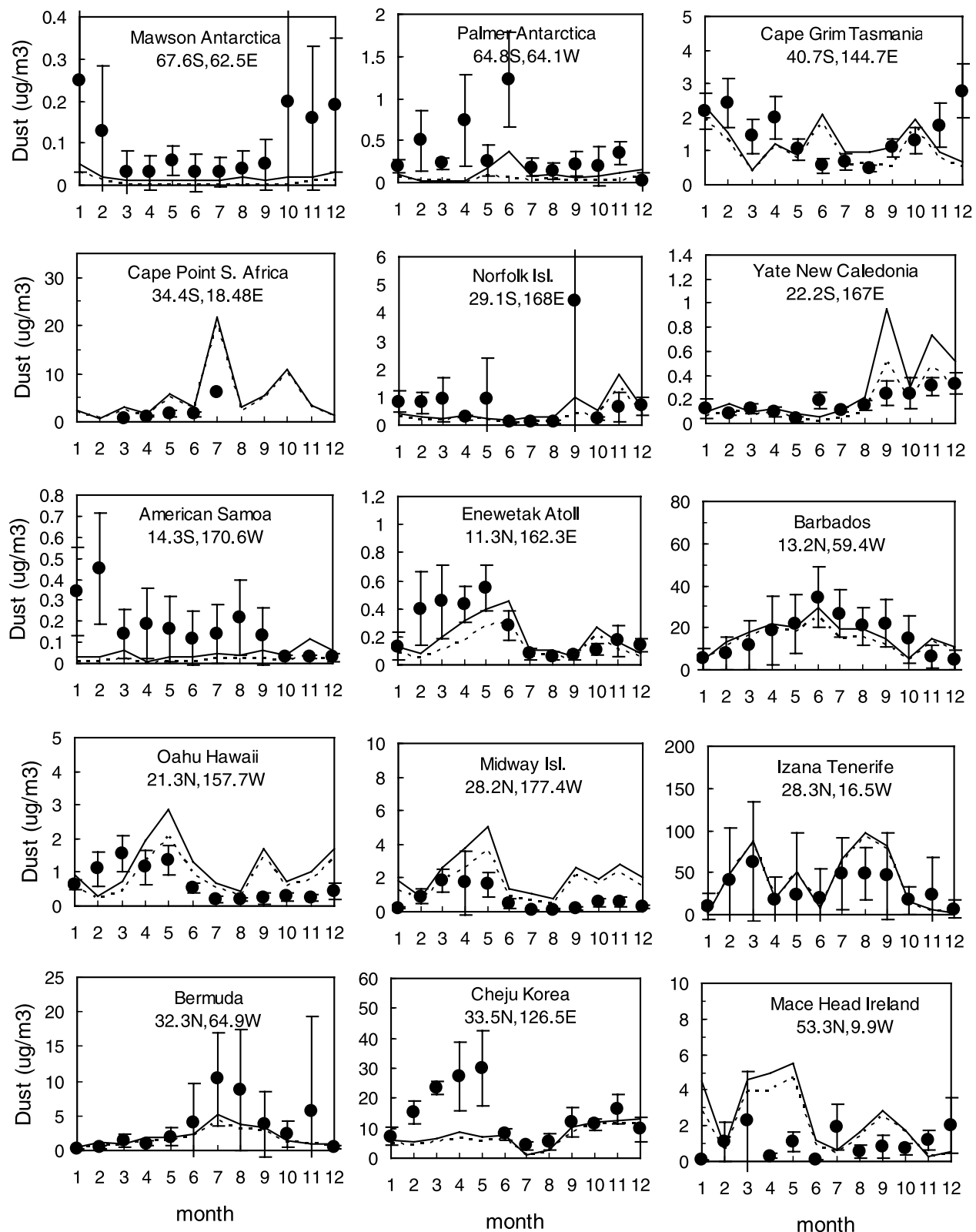

Figure 17. Comparison of modeled and observed monthly mean surface concentrations of dust at fifteen sites. Model results are in solid lines, and observed data are in dots with one standard deviation. Results from our model run with an assumed scavenging efficiency of 1.0 for dust as Ginoux et al. [2001] are shown in dashed lines.

predicts the concentrations. In the lower to middle latitude $\mathrm{SH}$ regions, the observed seasonal variations are small. However, the model produces concentrations that are too high in January or February (e.g., Cape Grim and Reunion Island). This may be caused by surface emissions that are too high or by removal of sea salt that is too low, though the latter possibility seems less likely, given that the removal of the other aerosol species appears adequate. In the NH sites, the model predictions agree well with observations in terms of both concentrations and seasonal cycles for America Samoa, Oahu, Midway, and Heimaey Iceland. While the model reproduces the seasonal variation (summer minimum and winter maximum) at Hedo Okinawa, Bermuda, and
Mace Head Ireland, the concentrations in January or wintertime are too high.

\subsection{Sulfuric Acid Gas Concentrations}

[52] A limited number of observations of $\mathrm{H}_{2} \mathrm{SO}_{4}(\mathrm{~g})$ concentrations exist, as these measurements are a relatively recent innovation [Eisele and Tanner, 1991, 1993]. Concentrations measured at surface generally range from 0.01 to 1 pptv (equivalently $2 \times 10^{5}-2 \times 10^{7}$ molecules $\mathrm{cm}^{-3}$ ) in clean regions, while the model predicted concentrations (see Figure 4) are generally within the range of $10^{5}$ $10^{7}$ molecules $\mathrm{cm}^{-3}$. Table 9 shows a comparison of simulated $\mathrm{H}_{2} \mathrm{SO}_{4}(\mathrm{~g})$ concentrations with observations 

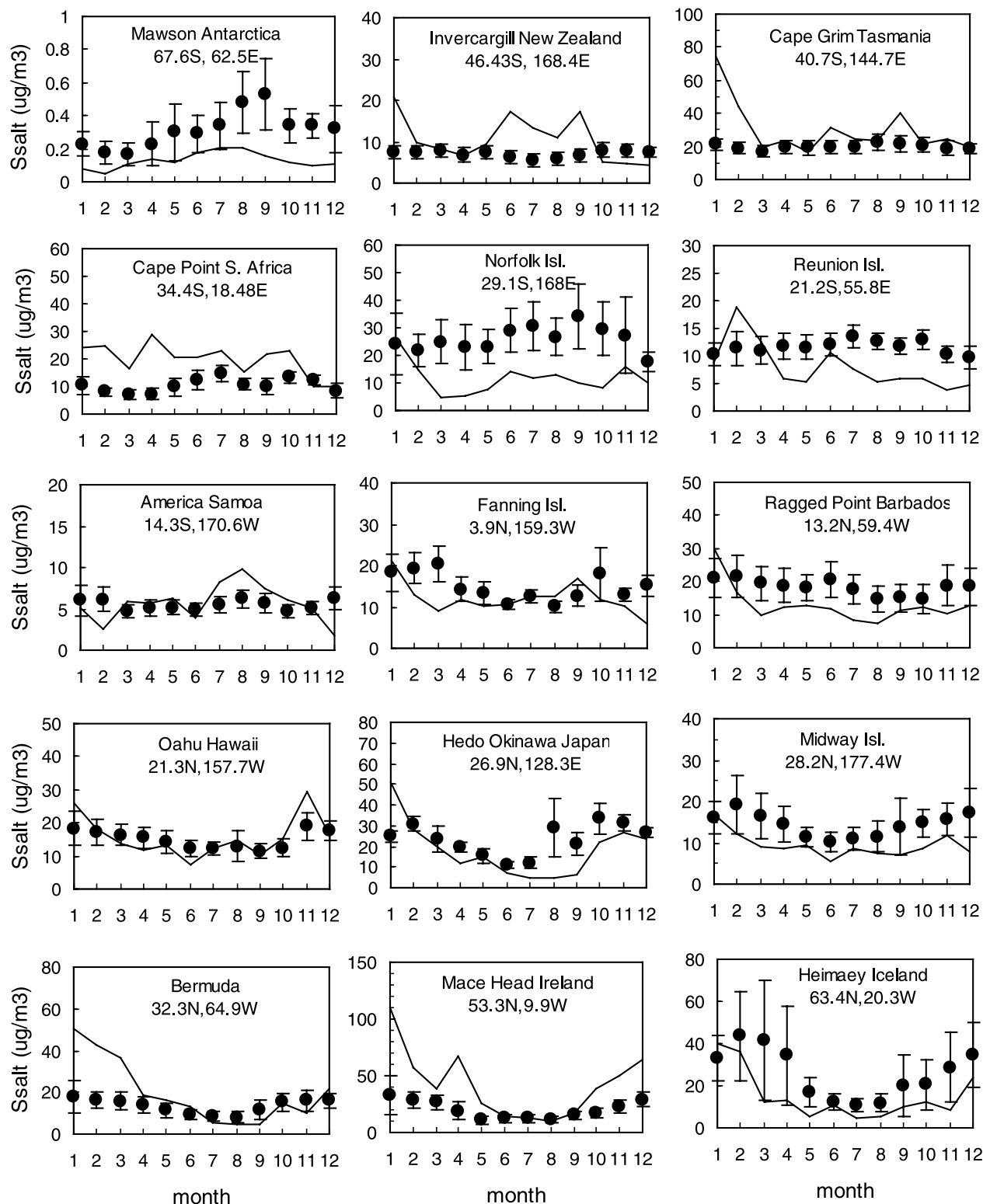

Figure 18. Comparison of modeled and observed monthly mean surface concentrations of sea salt at fifteen sites. Model results are in solid lines, and observed data are in dots with one standard deviation.

Table 9. Comparison of Simulated and Observed $\mathrm{H}_{2} \mathrm{SO}_{4}(\mathrm{~g})$ Concentrations From Several Field Campaigns ${ }^{\mathrm{a}}$

\begin{tabular}{|c|c|c|c|c|}
\hline Location & Time & Observed & Simulated & References \\
\hline $\begin{array}{l}\text { Pacific tropics, } \\
<0.5 \mathrm{~km}\end{array}$ & $\begin{array}{c}\text { Aug-Sep } \\
1996\end{array}$ & $1-10 \times 10^{6}$ & $1-5 \times 10^{6}$ & $\begin{array}{c}\text { Mauldin et al. } \\
\text { [1999] }\end{array}$ \\
\hline $\begin{array}{l}\text { South Pole, } \\
\text { at surface }\end{array}$ & $\begin{array}{r}\text { Nov } 1998- \\
\text { Jan } 1999\end{array}$ & $3 \times 10^{5}$ & $7 \times 10^{5}$ & $\begin{array}{l}\text { Mauldin et al. } \\
\text { [2001] }\end{array}$ \\
\hline $\begin{array}{l}\text { North America, } \\
<2 \mathrm{~km}\end{array}$ & $\begin{array}{l}\text { Feb-May } \\
2000\end{array}$ & $\begin{array}{l}1-12 \times 10^{6} \\
\left(39.9-57^{\circ} \mathrm{N}\right) \\
0.5-2 \times 10^{6} \\
\left(57-85.1^{\circ} \mathrm{N}\right)\end{array}$ & $\begin{array}{l}0.5-5 \times 10^{6} \\
\quad\left(39.9-57^{\circ} \mathrm{N}\right) \\
0.1-0.5 \times 10^{6} \\
\left(57-85.1^{\circ} \mathrm{N}\right)\end{array}$ & $\begin{array}{l}\text { Mauldin et al. } \\
\text { [2003] }\end{array}$ \\
\hline $\begin{array}{l}\text { Yellow Sea and Sea of Japan } \\
\left(20-45^{\circ} \mathrm{N}\right) \\
<2 \mathrm{~km}\end{array}$ & $\begin{array}{c}\text { Feb-Apr } \\
2001\end{array}$ & $\begin{array}{l}1-6 \times 10^{7} \text { (polluted } \\
\text { plume); } \\
3 \times 10^{6} \text { (mean value, } \\
\text { clean plume) }\end{array}$ & $0.2-1 \times 10^{7}$ & $\begin{array}{c}\text { Weber et al. } \\
\text { [2003] }\end{array}$ \\
\hline
\end{tabular}

${ }^{\mathrm{a}}$ Units are in molecules $\mathrm{cm}^{-3}$. 
available from several field campaigns. Model predicted $\mathrm{H}_{2} \mathrm{SO}_{4}$ (g) concentrations agree generally well with the limited observations. Higher $\mathrm{H}_{2} \mathrm{SO}_{4}(\mathrm{~g})$ concentrations can be found in the polluted plumes and in the regions with high DMS emissions, while those in the polar regions and in the higher latitudes of North America are much lower. Our model result for the decrease in $\mathrm{H}_{2} \mathrm{SO}_{4}(\mathrm{~g})$ concentrations with increasing altitude (see Figure 5) is consistent with aircraft measurements by Mauldin et al. [2003]. $\mathrm{H}_{2} \mathrm{SO}_{4}(\mathrm{~g})$ concentrations respond strongly to the representation of the vapor-pressure dependence of the condensation and nucleation rates. More observations of tropospheric $\mathrm{H}_{2} \mathrm{SO}_{4}(\mathrm{~g})$ concentrations will permit more quantitative comparisons between simulations and measurements.

\subsection{Aerosol Number and Size Distributions}

[53] Model predictions of aerosol number concentrations $N_{\mathrm{T}}$ are compared with a number of observations at the surface and at other levels in Figure 19. It should be noted that different observations of $N_{\mathrm{T}}$ have different lower cutoff sizes depending on the instrument that was used. The total sulfate number concentrations shown in Figure 6 are the sum of the number concentrations predicted in both modes, regardless of the mass mean diameters. For comparison with observations having various lower size detection limits, the size distribution of the aerosol should be taken into account. Since each sulfate mode is assumed to follow a lognormal distribution, we used the predicted two moments (mass and number) in each mode to define the mass mean diameter, and then to determine the number median diameter using the relation between the mass mean diameter and number median diameter [Seinfeld and Pandis, 1998] assuming the geometric standard deviations of 1.514 and 1.776 , respectively, for the nuclei and accumulation modes of the pure sulfate particles [Herzog et al., 2004]. We used the lognormal function with derived parameters to integrate the distribution over the appropriate size range of the observation. These assumptions also permit us to display the twomoment model results as an aerosol size distribution. Since observed $N_{\mathrm{T}}$ normally represents all aerosol components, the number concentrations of nonsulfate aerosol particles were calculated from the predicted mass with the assumed

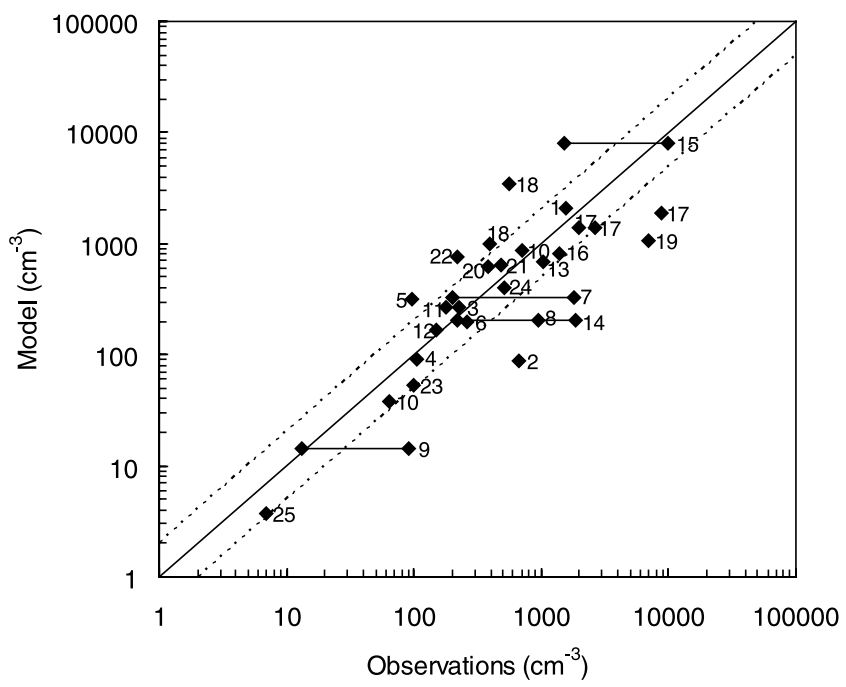

size distributions for different aerosol types, and then added to the pure sulfate number concentrations to get the total aerosol number. However, our calculated nonsulfate particle concentrations are generally smaller than the pure sulfate number at these observation sites.

[54] We can see from the comparison that the best agreement between simulations and observations was in the marine regions (e.g., Pacific and Atlantic Oceans). The overprediction in the central Pacific Ocean [Quinn et al., 1990] may be due to the fact that the measurement only collected clean marine sample. Harvey et al. [1991] observed a high $N_{\mathrm{T}}\left(\sim 1000 \mathrm{~cm}^{-3}\right)$ in the Antarctic summer for particle size $D \mathrm{p}>0.0025 \mu \mathrm{m}$. While our simulation under-

Figure 19. Comparison of model predictions of particle number concentrations with observations. Observational sites with locations, altitudes, measurement time, and aerosol cutoff sizes are as follows: (1) Cape Grim (41S, 145E), surface, annual cycle, $D_{\mathrm{p}}>0.01 \mu \mathrm{m}$ [Gras, 1990]; (2) Macquarie Island (54.4S, 159E), surface, November/ December, $D_{\mathrm{p}}>0.015 \mu \mathrm{m}$ [Brechtel et al., 1997]; (3) Pacific Ocean (20N-55S, 150W), surface, March-April, $D_{\mathrm{p}}>$ $0.01 \mu \mathrm{m}$ [Hoppel and Frick, 1990]; (4) Pacific Ocean (20N55S, 150W), surface, March-April, $D_{\mathrm{p}}>0.12 \mu \mathrm{m}$ [Hoppel and Frick, 1990]; (5) central Pacific Ocean (14N-11S, 170W), shipboard, May, clean marine only, 0.02-0.5 $\mu \mathrm{m}$ [Quinn et al., 1990]; (6) NE Atlantic (63N, 8W), shipboard, November, modified marine, 0.1-3.0 $\mathrm{m}$ [O'Dowd and Smith, 1993]; (7) N. Atlantic (30-35N, 20-30W), shipboard, June, 0.012-0.5 $\mu \mathrm{m}$ [Jensen et al., 1996]; (8) Ross Island, Antarctic (78S, 164E), $67 \mathrm{~m}$, November, $D_{\mathrm{p}}>$ $0.0025 \mu \mathrm{m}$ [Harvey et al., 1991]; (9) Ross Island, Antarctic (78S, 164E), $67 \mathrm{~m}$, November, 0.12-3.12 $\mu \mathrm{m}$ [Harvey et al., 1991]; (10) Mawson, Antarctic (67S, 63E), surface, February and July, $D_{\mathrm{p}}>0.01 \mu \mathrm{m}$ [Gras, 1993]; (11) Ny Alesund (79N, 12E), surface, March/April, 0.02-1 $\mu \mathrm{m}$ [Covert and Heintzenberg, 1993]; (12) Ny Alesund (79N, 12E), surface, March/April, accumulation mode [Covert and Heintzenberg, 1993]; (13) central United States (2941N, 91.5W), $1450 \mathrm{~m}$, July, 0.1-16 $\mu \mathrm{m}$ [Kim et al., 1988]; (14) Canada (46N, 78.5W), $950 \mathrm{hPa}$, July, 0.17-3 $\mu \mathrm{m}$ [Isaac et al., 1986]; (15) Great Smoky Mountains National Park (36N, 84W), $793 \mathrm{~m}$, July-August, $D_{\mathrm{p}}>0.015 \mu \mathrm{m}$ [Sherman et al., 1997]; (16) S. California (34N, 118W), surface, June-August, 0.05-2.5 $\mathrm{m}$ [John et al., 1990]; (17) Reno, NV (40N, 120W), surface, April-June, September, and November, $D_{\mathrm{p}}>0.01 \mu \mathrm{m}$ [Hudson and Da, 1996]; (18) Budapest (47.5N, 19E), surface, JuneAugust, November-January, 0.04-0.6 $\mu \mathrm{m}$, sulfate only [Meszaros, 1978]; (19) Lake Baikal, Siberia (53N, 107E), $500 \mathrm{~m}$, July, $D_{\mathrm{p}}>0.01 \mu \mathrm{m}$ [Jaenicke and Koutsenogii, 1992]; (20) Mauna Loa Observatory (MLO) (19N, $155.1 \mathrm{~W}), 3.4 \mathrm{~km}$, July, 0.017-0.231 $\mu \mathrm{m}$ [Weber and McMurry, 1996]; (21) MLO (19N, 155.1W), 3.4 km, July, 0.016-0.5 $\mathrm{m}$ [Weber and McMurry, 1996]; (22) MLO $(19 \mathrm{~N}, 155.1 \mathrm{~W}), 3.4 \mathrm{~km}$, annual cycle, $D_{\mathrm{p}}>0.01 \mu \mathrm{m}$ [Bodhaine et al., 1992]; (23) Canada $(46 \mathrm{~N}, 78.5 \mathrm{~W})$, $600 \mathrm{hPa}$, July, 0.17-3 $\mu \mathrm{m}$ [Isaac et al., 1986]; (24) central United States $(29-41 \mathrm{~N}, 91.5 \mathrm{~W}), 2450 \mathrm{~m}$, July, 0.1-16 $\mu \mathrm{m}$ [Kim et al., 1988]; (25) Laramie, WY (41N, 106W), 2 km,

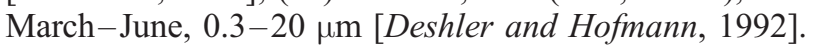




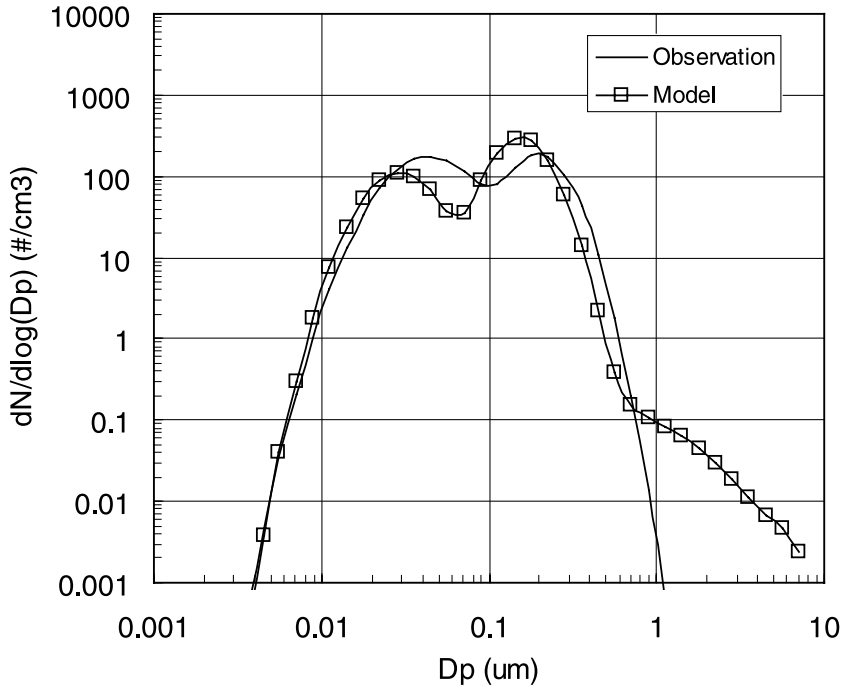

Figure 20. Comparison of modeled aerosol size distribution with an observation obtained in a clean air mass over the North Atlantic [Dingenen et al., 1995]. The observation does not include particles greater than $1 \mu \mathrm{m}$.

estimates these small size particles, the agreement is generally good for the larger size range particles at both the Antarctic and Arctic sites. The number concentrations in the accumulation mode over the United States (e.g., central United States, S. California, Reno, NV, and Laramie, WY) and Canada are underpredicted, but are mostly within a factor of 2. While the modeled $N_{\mathrm{T}}$ agrees well with one data set obtained in Mauna Loa Observatory (MLO) [Weber and McMurry, 1996], the model overpredicts $N_{\mathrm{T}}$ compared to earlier measurements at MLO with a similar aerosol size range [Bodhaine et al., 1992]. The model underpredicts observation data at two remote sites in the $\mathrm{NH}$ and $\mathrm{SH}$ extratropical regions (Siberia and Masquarie Island), which may imply stronger local nucleation events in these regions.

[55] Model predicted aerosol size distributions are compared with several observations in Figures 20, 21, and 22. Figure 20 shows the comparison of modeled aerosol size distribution with observations obtained in a clean air mass over the North Atlantic [Dingenen et al., 1995]. Figure 21 compares aerosol size distributions for observations at two sites on Tenerife Island (one in the marine boundary layer $(50 \mathrm{~m}$ asl) and another in the lower free troposphere $(2360 \mathrm{~m}$ asl)) [Raes et al., 2000, 1997]. Our model successfully predicts the bimodal shape of typical marine aerosol distributions in the boundary layer (Figures 20 and 21a) which is due to the processing of activated aerosol particles through nonprecipitating clouds [Hoppel et al., 1986]. However, the predicted mode radii in the two modes are somewhat less than the measured sizes, and the model tends to overpredict number concentrations in the accumulation mode. The measurement has a cutoff size at $1 \mu \mathrm{m}$, so coarse sea-salt particles are not included in the measurement data. Our model predicts the unimodal structure of the aerosol size distribution that is typical of the free troposphere (Figure $21 \mathrm{~b})$, and the predicted mode diameter $(\sim 0.05 \mu \mathrm{m})$ agrees with the measurement. Figure 22 compares model predictions with aerosol measurements in the middle and upper troposphere during the CRYSTAL-FACE field experiment in Florida [Fridlind et al., 2004]. The aerosol number concentrations in the free troposphere are overpredicted by the model. The model simulates a mode diameter of $0.02 \mu \mathrm{m}$ in the upper troposphere which is close to the measurement. It should be noted that the representation of the predicted variables (mass and number) as size distributions depends on the assumptions of the functional form within each mode and the standard deviation, and the comparisons with data would be modified under different assumptions. However, some of the differences between the model results and observations would remain. While the two-mode aerosol dynamics model is capable of capturing the variability of aerosol size distributions, the three-mode version of our aerosol dynamics module performed better when compared to a sectional module [Herzog et al., 2004]. A three-moment aerosol dynamics model will also improve the comparison with data. In addition, the treatment of direct aerosol particle emissions (which represent conversion to particles on sub-
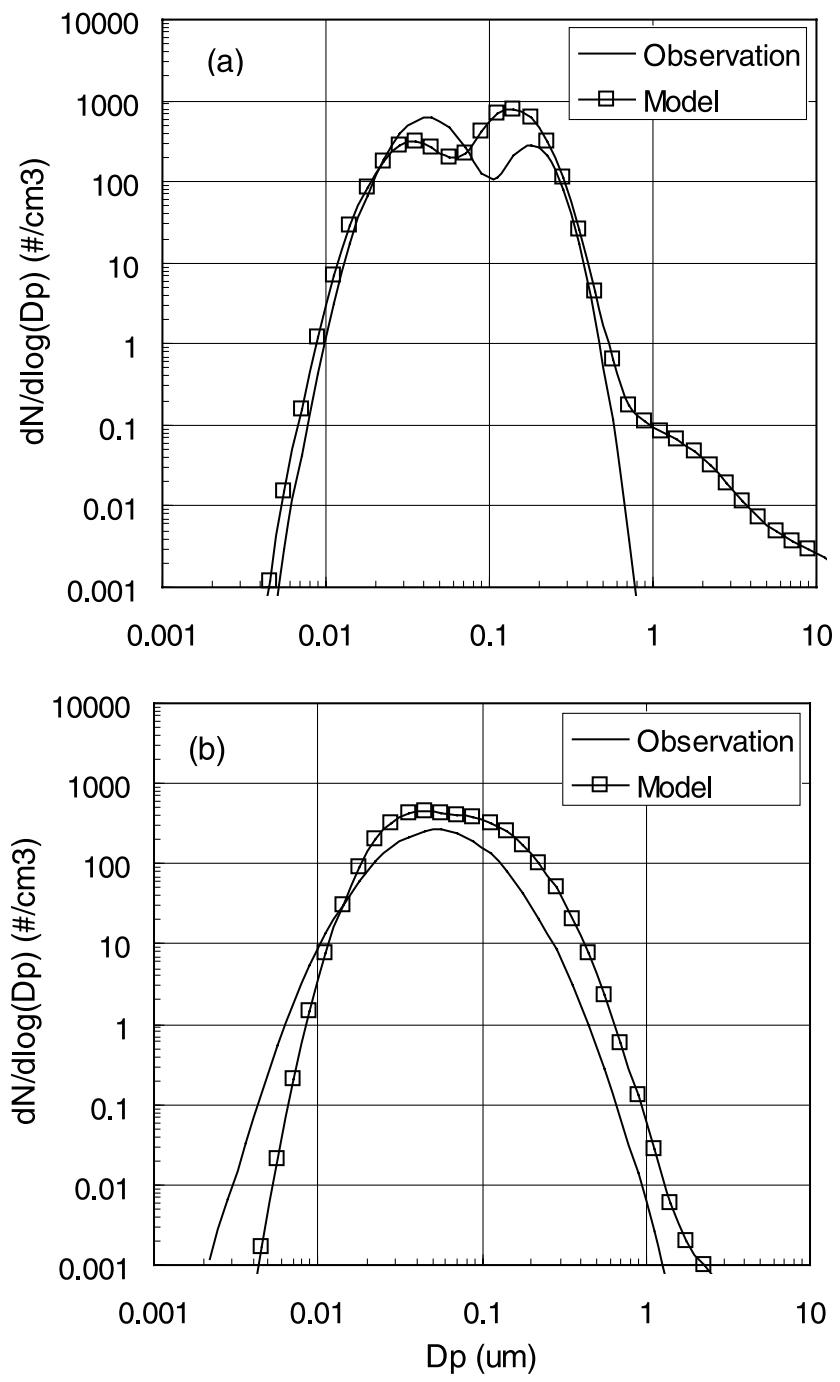

Figure 21. Comparison of modeled aerosol size distributions with observations at two sites on Tenerife Island: (a) a site in the marine boundary layer (50 $\mathrm{m}$ asl); (b) a site in the lower free troposphere $(2360 \mathrm{~m}$ asl) [Raes et al., 1997, 2000]. 

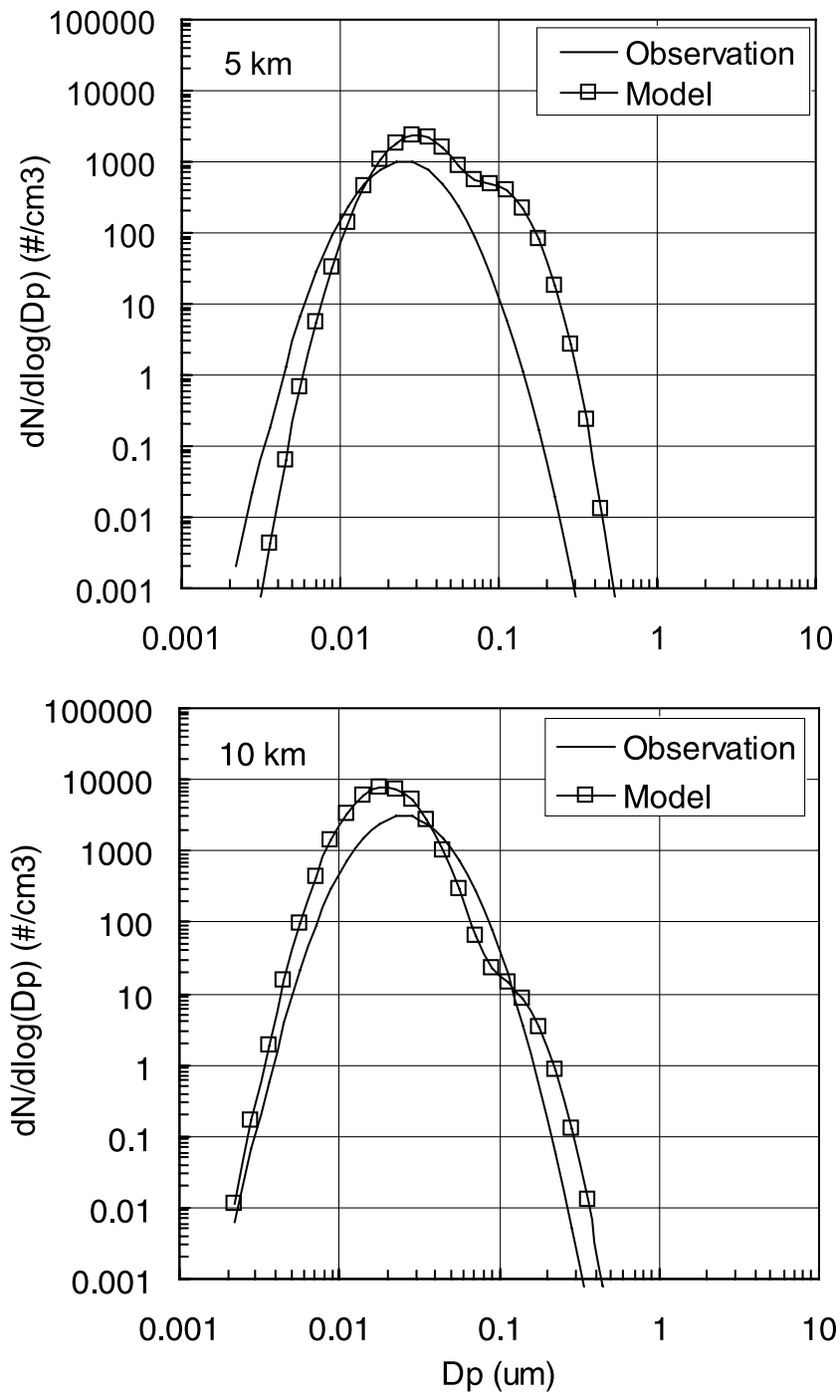

Figure 22. Comparison of modeled aerosol size distributions with observations in the middle $(5 \mathrm{~km})$ and upper troposphere $(10 \mathrm{~km})$ during the CRYSTAL-FACE field experiment in Florida [Fridlind et al., 2004].

grid-scales, e.g., within power plant plumes) will also play a role.

\section{Mixing States of Nonsulfate Aerosols With Sulfate}

[56] In this section we will present our model results on the mixing of nonsulfate aerosols with sulfate, and comparisons with available observations. Figure 23 shows model predicted mass fraction of sulfate on carbonaceous aerosol (sulfate mass on $\mathrm{BC} / \mathrm{OM}$ relative to sulfate mass on $\mathrm{BC} / \mathrm{OM}$ plus $\mathrm{BC} / \mathrm{OM}$ mass) at the surface and in the middle to upper troposphere $(536-187 \mathrm{hPa})$. In the biomass source regions (southern Africa and southern America) where carbonaceous aerosol mass concentrations in the boundary layer are high, the mass fraction of sulfate on the carbonaceous aerosol is smaller than 5\%. Over central Europe the mass fraction is $5-10 \%$ at the surface. In the fossil fuel source regions over most parts of Asia and the United States, the mass fraction can reach 10-20\%. Away from source regions over the ocean and poles the mass fraction reaches $40-60 \%$. Sulfate mass fractions in the middle to upper troposphere are more uniformly distributed than those in the boundary layer. The lower mass fractions $(10-20 \%)$ in the biomass source regions are still evident, however. Other than these regions mass fractions are generally within $20-$ $50 \%$ in the middle to upper troposphere. These model results suggest that carbonaceous aerosol in most of the troposphere might be internally mixed with sulfate except near biomass burning source regions where the mass fractions are less than $10 \%$. We calculated the global mean fraction of carbonaceous aerosol that is internally mixed with sulfate (with sulfate mass fraction larger than $14 \%$ ). For the global mean, $54 \%$ and $93 \%$ of carbonaceous aerosol is internally mixed in the boundary layer and in the upper troposphere $(536-187 \mathrm{hPa})$, respectively. We also calculated the change in the sulfate amount on hydrophobic carbonaceous aerosol (determined by sulfate mass fractions $<14 \%$ ) in two adjacent time steps, and then determined the lifetime of carbonaceous aerosol for conversion from freshly emitted particles (with a sulfate mass fraction equal to zero) to hydrophilic (with a sulfate mass fraction of 14\%). The global mean aging time is estimated to be 1.8 days. An

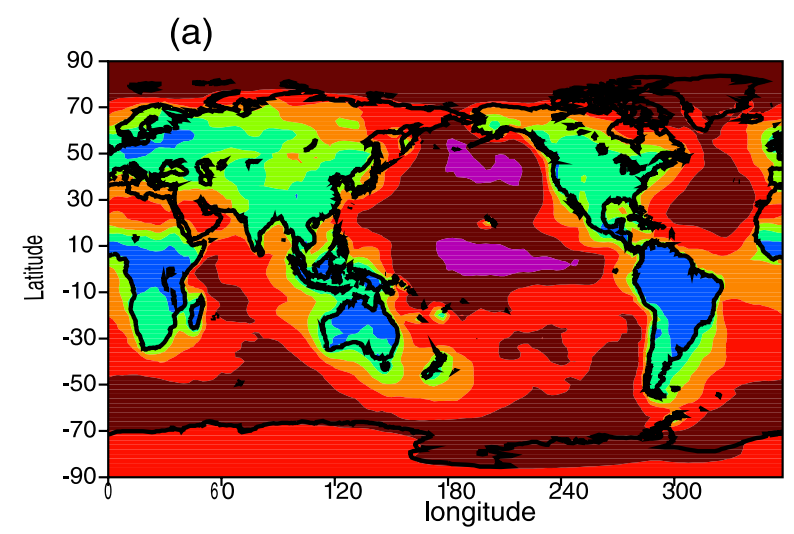

(b)

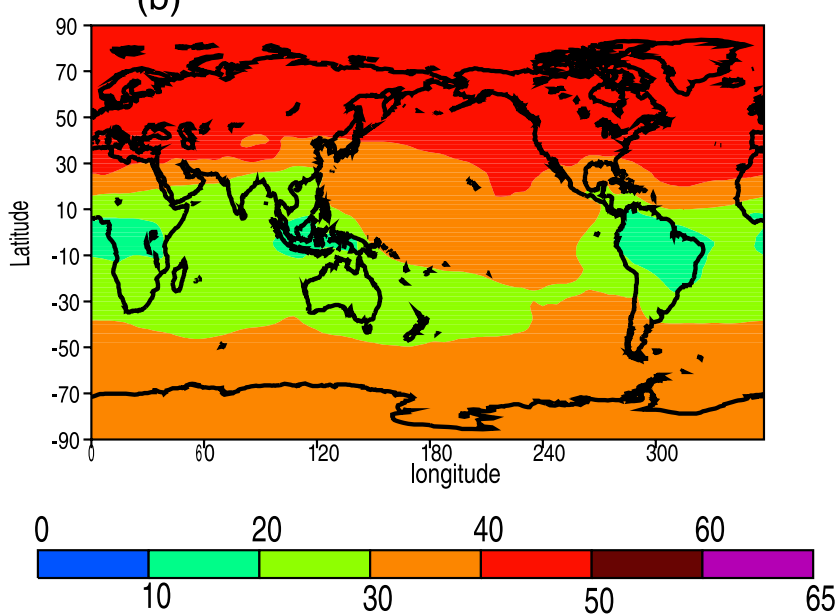

Figure 23. Annual mean mass fraction (\%) of sulfate on carbonaceous aerosol (sulfate mass on $\mathrm{OM} / \mathrm{BC}$ relative to sulfate mass on $\mathrm{OM} / \mathrm{BC}$ plus $\mathrm{OM} / \mathrm{BC}$ mass) (a) at the surface and (b) in the middle to upper troposphere (536$187 \mathrm{hPa})$. 


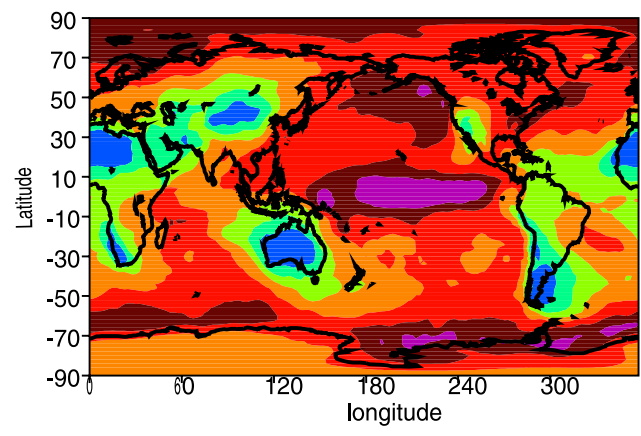

0 6

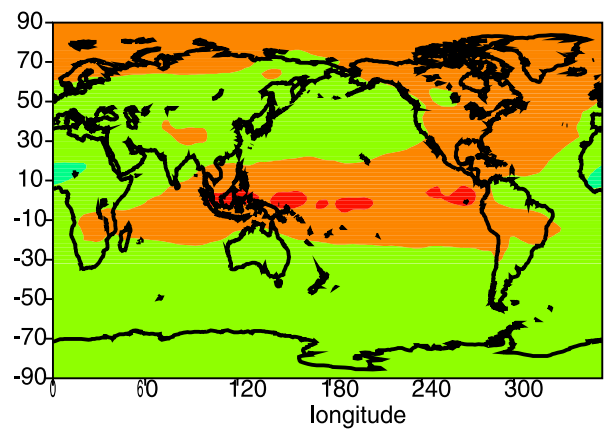

12
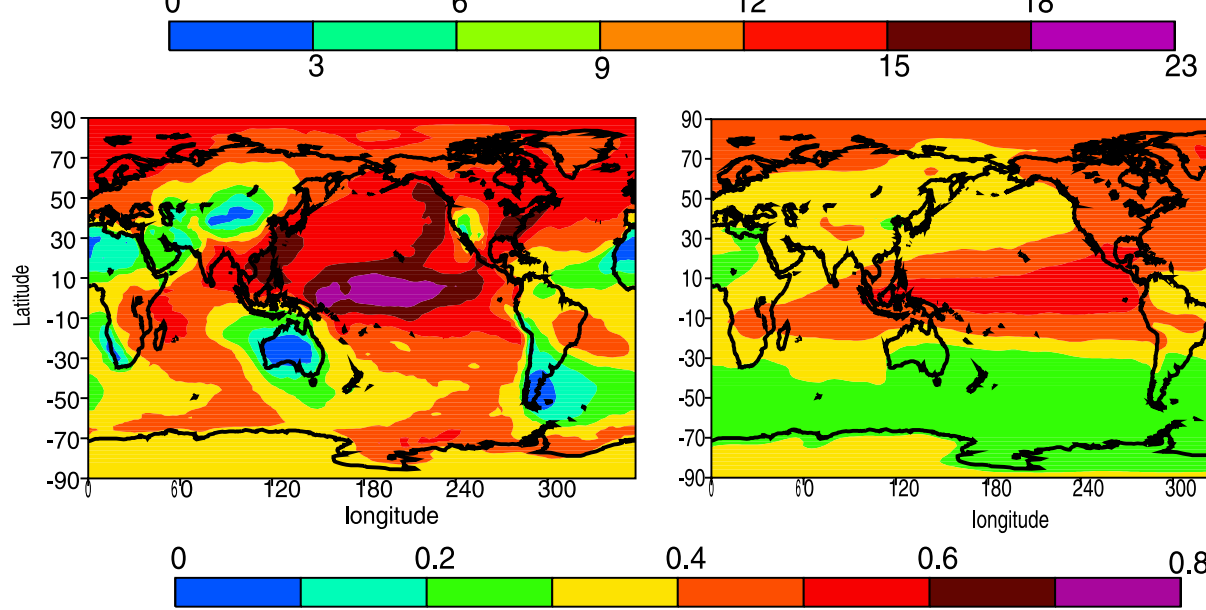

0.2

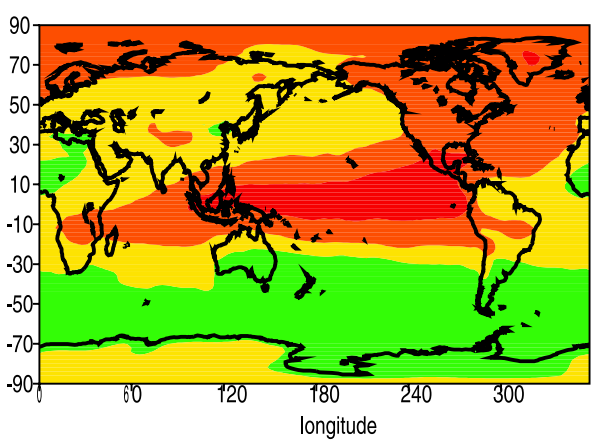

0.1

0.3 0.4

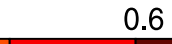

0.6 0.5

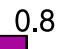

Figure 24. Annual mean mass fraction (\%) of sulfate on mineral dust particles in size bin 1 (upper panel) and size bin 2 (lower panel) (sulfate mass on dust relative to sulfate mass on dust plus dust mass) at the surface (left) and in the middle to upper troposphere (536-187 hPa) (right).

$e$-folding time of $1.2-1.8$ days as used by some global aerosol models would suggest a timescale of 2.8-4.0 days for $90 \%$ of hydrophobic particles to become hydrophilic.

[57] Our model prediction of low mass fraction of sulfate on carbonaceous aerosol over the source regions and an internal mixing state between sulfate and $\mathrm{BC} / \mathrm{OM}$ over remote and oceanic regions away from sources is consistent with available measurements. For example, $\mathrm{BC}$ aerosol was reported to be externally mixed with sulfate in an industrialized site in France through a comparison of measurement derived single scattering albedo of aerosol with retrievals from independent AERONET Sun-photometric measurements [Mallet et al., 2004]. The BC scavenging efficiency in clouds observed at a midlevel mountain site in central Europe was 0.54 [Hitzenberger et al., 2001] comparing to 0.74 observed at a high-level mountain site [Hitzenberger et al., 2000]. The number fractions of internally mixed soot particles compared to all soot-containing particles were only $5-7 \%$ over Sapporo (an urban site in Japan), whereas 19$72 \%$ were observed at a rural site (Fukue Island, Japan) and $56 \%$ at Poker Flat, Alaska [Hasegawa and Ohta, 2002]. In Asian outflow during the TRACE-P and ACE-Asia experiments, $\mathrm{BC}$ was found to be internally mixed with volatile aerosol in $\sim 85 \%$ of accumulation mode particles [Clarke et al., 2004]. In the North Atlantic marine boundary layer it was found that almost all soot particles in the samples occurred within sulfates [Pósfai et al., 1999]. Individual aerosol particles from biomass burning in southern Africa were measured to be externally mixed with sulfate in young smoke plumes in the boundary layer, whereas a large number of internally mixed organic/sulfate and soot/sulfate particles were found in the regional haze after aging of the smoke [Pósfai et al., 2003].

[58] Figure 24 shows the mass fraction of sulfate on dust particles in size bin $1(0.05-0.63 \mu \mathrm{m})$ and size bin $2(0.63-$ $1.25 \mu \mathrm{m}$ ) (sulfate mass on dust relative to sulfate mass on dust plus dust mass) at the surface and in the middle to upper troposphere $(536-187 \mathrm{hPa})$. The sulfate mass fraction on dust particles in size bin 1 is less than $3 \%$ at the surface and in the vicinity of source regions (e.g., western Sahara and the Sahel, Taklimakan and Gobi deserts, most of the Australia, and Patagonia of Argentina). Dust particles in these source regions are normally insoluble because of less covering by sulfate molecules. Away from source regions after long range transport of dust in the atmosphere, the sulfate mass fraction associated with dust increases and reaches more than $10 \%$ over the ocean. A higher mass fraction $(>15 \%)$ at the surface is predicted in the tropical Pacific, the northern Pacific, at $50-70^{\circ} \mathrm{S}$ in the $\mathrm{SH}$, and in the Arctic. The mass fraction in the middle to upper troposphere is uniformly distributed and is within $6-15 \%$. Thus dust particles in size bin $1(0.05-0.63 \mu \mathrm{m})$ are probably hygroscopic except near source regions. Sulfate mass fractions in dust particles in size bin $2(0.63-1.25 \mu \mathrm{m})$ are much smaller than those in dust size bin 1 because of less sulfate accumulation, which also corresponds to a 
(a)

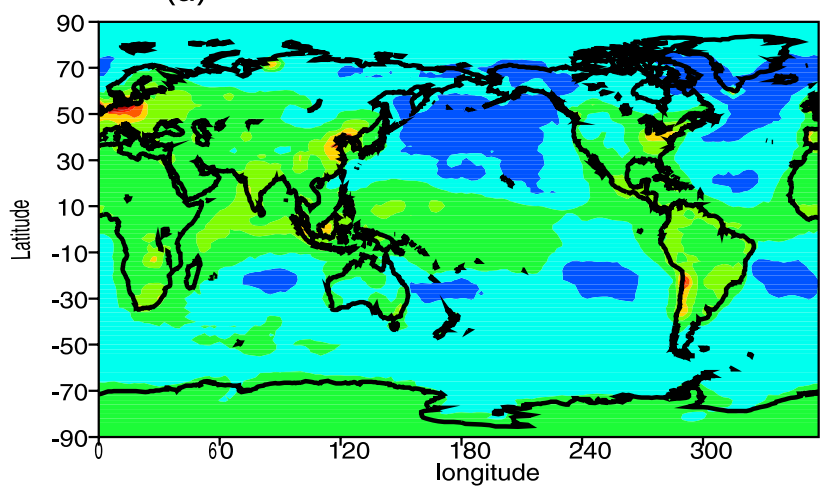

(b)

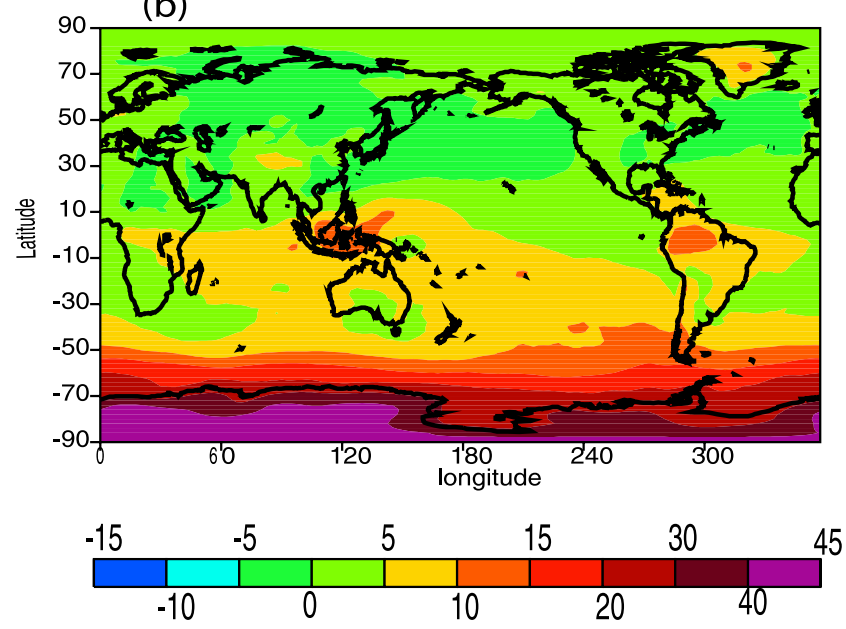

Figure 25. Annual mean percentage change (\%) of (a) sulfate concentration in the boundary layer, and of (b) sulfate column burden between the model run with aerosol dynamics and a model run which only predicts bulk sulfate mass (without sulfate size resolution and interactions between sulfate and nonsulfate aerosols).

decreasing area-to-volume ratio. Sulfate mass fractions on dust in this size range are less than $0.7 \%$ except in some regions (e.g., the tropics over the Pacific) in both the surface layer and the free troposphere. Therefore dust particles in size bin 2 probably have little sulfate on their surface. Sulfate mass fractions are even less for dust particles in size bin $3(1.5-2.5 \mu \mathrm{m})$ and size bin $4(2.5-10 \mu \mathrm{m})$ (figures not shown).

[59] There have been some observations to assess the model predictions of the mixing states of sulfate with dust particles. Individual particle analysis on dust collected at a coastal site of Qingdao, China found mineral dust particles were often coated with sulfate [Parungo et al., 1995]. However, measurements during dust storm events in spring in this same region found that only $3.3-12.2 \%$ of the dust particles contained sulfate because the mineral dust particles transported from source regions did not have time to become coated with sulfate and nitrate in the continental atmosphere [Zhang et al., 2003]. After transport of mineral dust over the ocean, $5-40 \%$ of the particles larger than $0.5 \mu \mathrm{m}$ had sulfate associated with them from size-resolved measurements in spring in Japan [Horai et al., 1993].
Analysis on single mineral dust particles collected in a dust storm over Israel starting from North Africa found that the sulfate that was on dust particles was part of the source soil and was present in gypsum [Falkovich et al., 2001]. However, in another pattern of dust storms that reached Israel, mineral dust particles were coated with sulfate from atmospheric processing during the longer period over the sea where they interacted with polluted air masses from Europe [Levin et al., 1996]. The measured ratios of non-seasalt sulfate to dust mass in the marine boundary layer at Barbados were 0.04-0.08 for the particle radius range of $0.3-0.65 \mu \mathrm{m}$, and varied from 0.01 to 0.04 with size range above $0.65 \mu \mathrm{m}$, and the ratio in the coarse size range generally decreased with increasing size [Li-Jones and Prospero, 1998]. As noted above in the model simulations described thus far, we did not include sulfate production on the surface of dust and sea salt through heterogeneous chemical reactions which can be important for sulfate mass accumulation on dust and sea salt particles.

\section{Sensitivity Tests}

[60] The impact of aerosol dynamics as determined above is studied by comparing the present model run with a run that predicts only bulk sulfate mass (without sulfate size resolution and interactions between sulfate and nonsulfate aerosols). Both model runs are performed under the same emissions and driven by the same meteorological data. The relative difference in total sulfate mass concentrations in the boundary layer and in the sulfate column burden is shown in Figure 25. Sulfate mass concentrations in the boundary layer differ by less than $5 \%$ in most continental regions, which suggests that the interaction between sulfate and dust/ carbonaceous aerosol has a relatively small effect on the total sulfate mass concentrations. In most of the oceanic regions, however, sulfate mass concentrations are reduced by $>5 \%$ due to sulfate coating on sea salt. There is a relatively larger increase $(>10 \%)$ in the sulfate column burden south of $50^{\circ} \mathrm{S}$ when aerosol dynamics are included. Small sulfate particles nucleated over the South Pole due to the low temperature there accumulate more mass compared to the run without aerosol dynamics. It is also noted that the absolute sulfate mass burden over the South Pole is very small. The impact of aerosol dynamics is generally not critical for sulfate mass concentrations. The global mass burden difference is $2 \%$. Figure 26 further compares the total sulfate number and sulfate number concentrations in the accumulation mode between the two runs. In the bulk sulfate run, sulfate number is calculated from sulfate mass assuming a fixed sulfate size distribution [Chuang et al., 1997]. The distribution pattern in the total sulfate number (upper panel of Figure 26) is remarkably different. In the bulk sulfate run, the pattern of sulfate number follows that of sulfate mass with a maximum near the Earth's surface. In the case of sulfate number in the accumulation mode, both the absolute number and distribution pattern differ greatly between the two runs, especially in the SH. This suggests the problem of using a fixed sulfate size distribution to derive number from mass for the bulk sulfate run. The biases in sulfate number especially in the accumulation mode will produce large biases in the estimation of aerosol indirect effects. 
(a) Total sulfate number
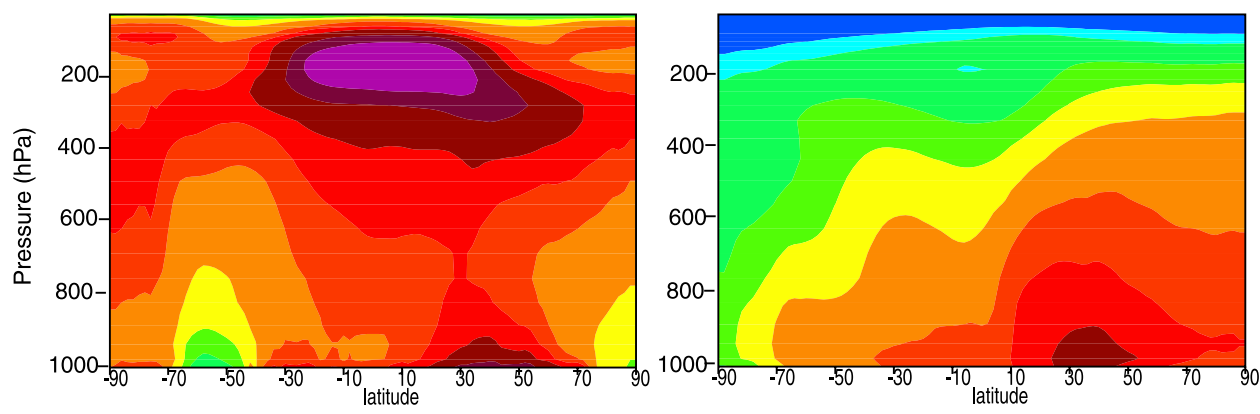

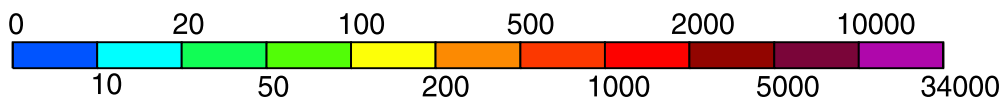

(b) Accumulation mode number

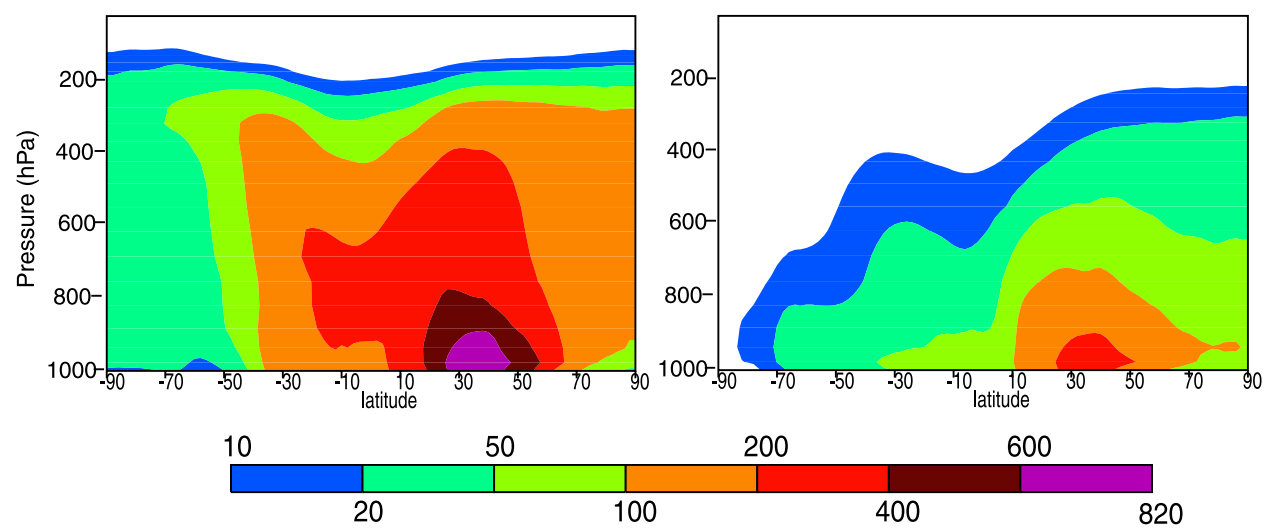

Figure 26. A comparison of annual mean number concentrations of total sulfate (upper panel) and sulfate in the accumulation mode (lower panel) between two model runs: control run with aerosol dynamics (left) and a model run which predicts only bulk sulfate mass (without sulfate size resolution and interactions between sulfate and nonsulfate aerosols) (right).

[61] Our model predicts an internal mixture with sulfate on dust particles in the size bin with radii between 0.05 and $0.63 \mu \mathrm{m}$ except near the source regions. Smaller sulfate mass fractions on dust particles in the larger size bins are predicted. We have conducted a sensitivity test to include heterogeneous sulfate reactions on the surface of dust and sea salt particles [cf. Dentener et al., 1996; Clegg and Toumi, 1997]. Sulfate can accumulate on dust and sea salt particles through condensation, coagulation, in-cloud sulfate production, and heterogeneous reactions on dust and sea salt. Heterogeneous sulfate production mainly takes place through the dissolved $\mathrm{SO}_{2}$ reaction with $\mathrm{O}_{3}$ in wetted particles, and the $\mathrm{SO}_{2}$ solubility and thus the reaction with $\mathrm{O}_{3}$ is strongly $p \mathrm{H}$ dependent, being fast only for $p \mathrm{H}>8$. Therefore we assume that the uptake of $\mathrm{SO}_{2}$ to the dust surface only takes place if the alkalinity from the dust aerosol (determined by the calcium content of soils) exceeds the acidity from the dust-associated sulfate [Dentener et al., 1996]. In our calculations we assumed an average $\mathrm{Ca}^{2+}$ content of $5 \%$ in the dust aerosol. Similarly, we limit the total reaction of $\mathrm{SO}_{2}$ with sea salt to form fewer than 0.005 moles $\mathrm{SO}_{4}^{2-}$ for each mole of Na present in the sea salt particle in accord with the study by Clegg and Toumi [1997]. Figure 27 shows the annual mean percentage change of the total sulfate mass concentrations in the boundary layer and of the total sulfate column burden after including heterogeneous reactions on dust and sea salt. Compared to the control run, the sulfate amount produced through heterogeneous reactions on dust and sea salt particles contributes $2-3 \%$ to the total sulfate burden, and the additional sulfate is mainly on larger dust and sea salt particles. This is because submicron dust and sea salt particles have accumulated enough sulfate from condensation and coagulation to neutralize the alkalinity from dust and salt aerosol, and thus any further uptake of $\mathrm{SO}_{2}$ and reaction with $\mathrm{O}_{3}$ in the submicron particles is inhibited. Heterogeneous reactions increase the fraction of sulfate that is associated with nonsulfate aerosols from $20.5 \%$ to $22.6 \%$. On a regional scale, these reactions can significantly increase boundary layer sulfate mass concentrations in dust and sea salt source regions: by $20-30 \%$ in the Gobi deserts, and by $\sim 10 \%$ near $50^{\circ} \mathrm{S}$ in the SH. Sulfate mass accumulated on the dust particles through heterogeneous reactions will increase their solubility and thus wet scavenging. In comparison to the control run, dust burdens in the four size bins are reduced by $\sim 0.2,4,10$, and $19 \%$, respectively. Thus including heterogeneous reactions on dust and sea salt particles shifts several percents of total sulfate mass to larger 
(a)

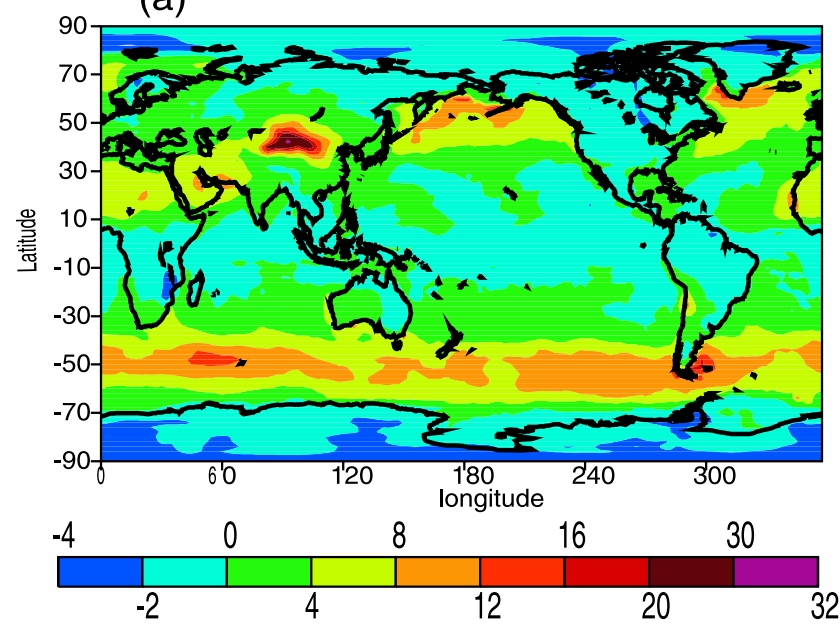

(b)

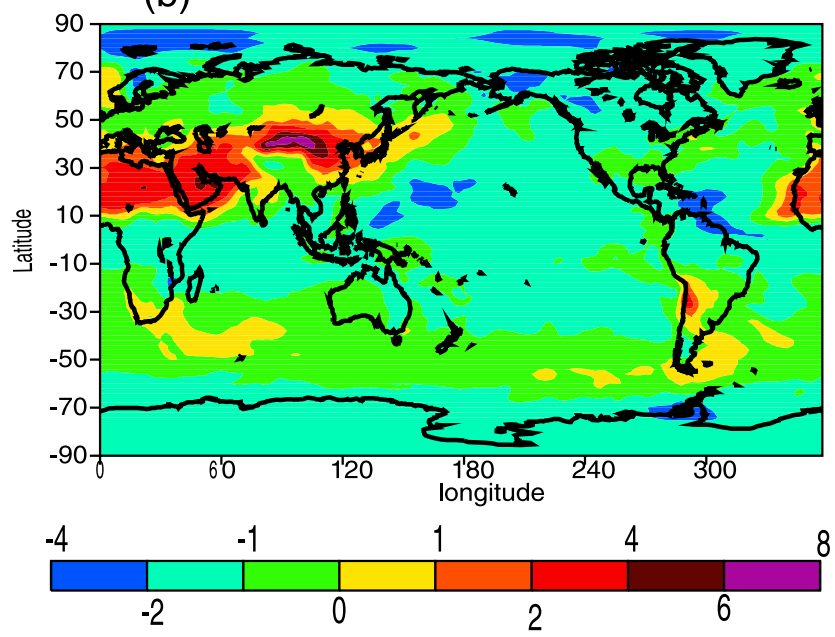

Figure 27. Annual mean percentage change (\%) of (a) total sulfate mass concentration in the boundary layer and (b) total sulfate column burden after including heterogeneous reactions on dust and sea salt.

dust and sea salt particles. However, the impact on the dust burden and lifetime is not significant because for dust particles dry deposition is an important sink.

[62] This study only considers binary nucleation of $\mathrm{H}_{2} \mathrm{SO}_{4}-\mathrm{H}_{2} \mathrm{O}$ when, in fact, other species can also be involved in nucleation. For example, ammonia can be included in a ternary system, especially in the boundary layer. Such a system will result in nucleation rates that are several orders of magnitude higher than those of binary nucleation [e.g., Coffman and Hegg, 1995]. In order to examine the uncertainties in predicted particle number due to a limited understanding of nucleation, we have conducted sensitivity tests using different nucleation schemes within the context of the GRANTOUR CTM [Penner and Herzog, 2002]. Penner and Herzog [2002] compared pure sulfate number concentrations for two different nucleation schemes [Vehkamäki et al., 2002; Zhao and Turco, 1995]. Although the Zhao and Turco scheme produces in general larger nucleation rates than the Vehkamäki et al. scheme, there are two noticeable exceptions: for temperatures below
$190 \mathrm{~K}$; and for low relative humidities $(<5 \%)$ at relative high temperatures $(285-300 \mathrm{~K})$. Interestingly, the Vehkamäki et al. scheme produces overall somewhat more particles than the Zhao and Turco scheme near the surface. In the $\mathrm{NH}$ and in continental regions of the $\mathrm{SH}$ where surface particle number concentrations are high the differences between the two schemes are relatively small with the Vehkamäki et al. scheme producing $10-20 \%$ more particles than the Zhao and Turco scheme. The number concentrations in the upper troposphere between these two schemes are vastly different. We used the Vehkamäki et al. [2002] scheme in the IMPACT aerosol dynamics runs presented here, which is thought to have the best performance for simulating aerosol number concentrations in the upper troposphere [Penner and Herzog, 2002]. It is noted that the role of ammonia in the ternary $\mathrm{H}_{2} \mathrm{SO}_{4}-\mathrm{NH}_{3}-\mathrm{H}_{2} \mathrm{O}$ system will arise even higher uncertainties in the aerosol nucleation. In the future we plan to add nitrate and ammonium aerosols to the model and explicitly treat ternary nucleation.

[63] In this study, hygroscopic particles that can act as $\mathrm{CCN}$ include pure sulfate aerosol in the accumulation mode, sea salt, and dust and $\mathrm{BC} / \mathrm{OM}$ aerosols with radius larger than $0.05 \mu \mathrm{m}$ which are also internally mixed with sulfate. In the case of carbonaceous aerosol, when mass fraction of sulfate in the sulfate/BC/OM mixture is $14 \%$, the particle becomes hydroscopic, in accordance with the laboratory measurements of Wyslouzil et al. [1994] and Lammel and Novakov [1995]. According to the Köhler equation, however, a median supersaturation of $0.15 \%$ in stratiform clouds would require mixed particles (with $86 \%$ of the mass insoluble) of $\sim 0.1 \mu \mathrm{m}$ radius to be activated [Seinfeld and Pandis, 1998]. To address this question we have conducted a sensitivity test in which the critical radius for carbonaceous aerosol to be activated in clouds increases from 0.05 to $0.1 \mu \mathrm{m}$, while the sulfate mass fraction requirement remains at $14 \%$. Compared to the control run, the global average fraction of total sulfate associated with $\mathrm{BC} / \mathrm{OM}$ is reduced slightly from $14.3 \%$ to $12.5 \%$. The $\mathrm{OM}$ and $\mathrm{BC}$ global burdens are increased by $9.5 \%$ and $7.8 \%$, respectively, due to larger size requirement for $\mathrm{BC} / \mathrm{OM}$ to act as $\mathrm{CCN}$ and the smaller amount of sulfate coating on these particles, which causes less wet removal by precipitation. On the regional scale, the difference in carbonaceous aerosol concentrations is less than $10 \%$ over most of continents, and can reach $20-40 \%$ over remote regions.

\section{Discussion and Conclusions}

[64] In this study an aerosol dynamics module was incorporated into the IMPACT model framework. It includes prognostic variables for sulfur species and related species: DMS, $\mathrm{SO}_{2}$, and $\mathrm{H}_{2} \mathrm{SO}_{4}(\mathrm{~g})$, sulfate aerosol and $\mathrm{H}_{2} \mathrm{O}_{2}$; biomass burning $\mathrm{BC}$ and $\mathrm{OM}$, fossil fuel $\mathrm{BC}$ and $\mathrm{OM}$, natural OM, mineral dust, and sea salt. Mineral dust and sea salt are divided into four size bins $(0.05-0.63 \mu \mathrm{m}$, $0.63-1.26 \mu \mathrm{m}, 1.26-2.5 \mu \mathrm{m}$, and $2.5-10 \mu \mathrm{m})$. The sulfate aerosol dynamics model is based on the method of modes and moments. In the current implementation two modes are used for sulfate aerosol (nuclei and accumulation mode), and two moments are predicted within each mode (sulfate aerosol number and mass concentration). Aerosol dynamical processes include sulfate nucleation, condensation, and 
coagulation, as well as cloud processing and deposition. These processes determine the aerosol size distributions and number concentrations. Interactions between sulfate and nonsulfate aerosols in the atmosphere are included and the amount of sulfate mass on each type of nonsulfate aerosol resulting from the condensation of sulfuric acid gas $\mathrm{H}_{2} \mathrm{SO}_{4}$ (g) on their surface, coagulation with pure sulfate aerosol, and in-cloud sulfate production after these particles can act as $\mathrm{CCN}$ is predicted.

[65] Our model predicts a maximum of sulfate number concentration in the tropical upper troposphere, which is controlled by strong nucleation events in this region due to the low temperatures and high RH. Sulfate number concentrations in the boundary layer over the industrialized regions is controlled mainly by the direct emission of sulfate particles from surface sources. Accumulation mode sulfate number concentrations are predicted to be within $50-$ $400 \mathrm{~cm}^{-3}$ in most regions of free troposphere. Total aerosol number concentrations (for sulfate plus nonsulfate aerosol particles) at the surface are predicted to range from over $10,000 \mathrm{~cm}^{-3}$ in the urban areas to $1000-5000 \mathrm{~cm}^{-3}$ over remote land regions in the continent. Over oceans, total aerosol number concentrations vary from $200-500 \mathrm{~cm}^{-3}$ over the Atlantic and over most of the Pacific, to 50$200 \mathrm{~cm}^{-3}$ over the Sourthern Ocean. Our model results generally reflect observed changes of aerosol number concentrations at the surface and at other levels in different environments, and agree with most of the observations within a factor of 2. Our model captures the bimodal shape of typical marine aerosol distributions in the boundary layer. However, the predicted mode radii in the two modes are too small. The model also reproduces the observed unimodal structure typical of the free troposphere with the correct mode radius; however, it tends to overpredict aerosol number concentrations in the upper troposphere.

[66] Our model predicted $\mathrm{H}_{2} \mathrm{SO}_{4}$ (g) concentrations at the surface are generally within the range of $10^{5}-$ $10^{7}$ molecules $\mathrm{cm}^{-3}$, and are smaller at increasing altitudes. The model predicted $\mathrm{H}_{2} \mathrm{SO}_{4}(\mathrm{~g})$ concentrations agree with available measurements obtained in several field campaigns. Our calculated global mass distributions and budgets of sulfate and nonsulfate aerosols (OM, BC, dust, and sea salt) are compared with other model results, and also compared to the observations obtained at the surface. The modeled concentrations are consistent to within a factor of 2 with most of the observation data. The discrepancies between model results and observations reflect the deficiencies of chemical transport models in emissions, transport, and scavenging of species, and also the difficulty of comparing large-scale model results with in situ measurement data.

[67] In this study we have looked at the interactions between sulfate and nonsulfate aerosols. Our model predicts that about $80 \%$ of global sulfate exists as pure sulfate aerosol $(9.7 \%$ in nuclei and $69.8 \%$ in accumulation mode), with $14.3 \%$ on carbonaceous aerosol, $3.3 \%$ on dust and $2.7 \%$ on sea salt. In the boundary layer, over $40 \%$ of sulfate is associated with nonsulfate aerosols in many regions of world whereas less than $10 \%$ of sulfate is associated with these aerosols in the upper troposphere. A high percentage $(>60 \%)$ of sulfate is associated with sea salt in the remote Southern Ocean marine boundary layer which is consistent with measurements showing a significant contribution of sea salt to the number concentrations of submicrometer particles $(>0.04 \mu \mathrm{m})$ that can act as CCN [Murphy et al., 1998]. It is noted that the fraction of sulfate associated with nonsulfate aerosols depends very much on the number concentration of emitted primary sulfate aerosol compared to the number concentrations of emitted nonsulfate aerosols. Most global models for the sulfur cycle assume that $0-5 \%$ of anthropogenic sulfur is emitted directly as sulfate aerosol [Penner et al., 2001]. This small amount of sulfur emission does not matter much for models that predict only sulfate mass, but this fraction as well as the assumed size distribution for emitted sulfate particles will determine the sulfate number concentration over most continental regions in the boundary layer [Adams and Seinfeld, 2002]. This sulfate aerosol number concentration will further influence the fraction of total sulfate mass associated with nonsulfate aerosols. Thus more accurate estimations of direct sulfate emission and the size distribution of these aerosols are crucially needed.

[68] In this study, scavenging efficiencies for carbonaceous and dust particles are based on the surface coating of these aerosols by sulfate. Our model results suggest that carbonaceous aerosol in most of the troposphere is internally mixed with sulfate except near source regions, where the mass fraction of sulfate contained in these particles is less than $5 \%$. The absorption by $\mathrm{BC}$ in particles that are internally mixed with sulfate will be a factor of 2-2.5 greater than that by externally mixed BC [Chylek et al., 1995]. Sato et al. [2003] also suggested that BC in the atmosphere may be internally mixed through the comparison of model calculated aerosol absorption with that observed by the AERONET (Aerosol Robotic Network). However, an internal mixture of $\mathrm{BC}$ with sulfate would also have a higher scavenging efficiency of $\mathrm{BC}$ by clouds and precipitation. Indeed our model predicts a shorter $\mathrm{BC}$ lifetime than most present models. The OC burden and lifetime are similar to those from Koch [2001] when they assumed a high scavenging efficiency for OC $(70 \%)$.

[69] In our aerosol model, coagulation between nonsulfate aerosols is not considered. The nonsulfate aerosols within each size bin are assumed to follow size distributions suggested by measurements. The characteristic time for Brownian coagulation between nonsulfate aerosols is 12 days [Seinfeld and Pandis, 1998] for a nonsulfate aerosol number concentration of $2000 \mathrm{~cm}^{-3}$ in the source regions compared to $2-3$ days for a sulfate number concentration of $10^{4} \mathrm{~cm}^{-3}$. This characteristic time becomes longer with the lower number concentrations predicted over remote areas and thus is much larger than the lifetimes of nonsulfate aerosols associated with wet scavenging and dry deposition (see section 3.2). In our model, the size distribution of the total sulfate aerosol population is represented by a superposition of lognormal distributions with fixed width parameters. We compared the results from our aerosol model with those from a sectional model [Herzog et al., 2004] and found good agreement between the predicted size distributions. In addition, most observations are reported as a superposition of usually up to three lognormal distributions [e.g., Whitby, 1978; Raes et al., 2000]. Such observed size distributions can be represented well with our aerosol model (see section 4.3). In future work, we plan to predict the width parameter instead of prescribing it by introducing 
an additional moment (the surface area) as a prognostic variable for each mode.

[70] Acknowledgment. The authors acknowledge the support of the DOE Atmospheric Chemistry Program, the DOE Atmospheric Radiation Measurement (ARM) Program, and the NASA Global Modeling Initiative (GMI) Program.

\section{References}

Ackerman, A. S., and O. S. Toon (1981), Absorption of visible radiation in atmospheric containing mixtures of absorbing and non absorbent particles, Appl. Opt., 20, 3661-3668.

Adams, P. J., and J. H. Seinfeld (2002), Predicting global aerosol size distributions in general circulation models, J. Geophys. Res., 107(D19), 4370, doi:10.1029/2001JD001010.

Anderson, B. E., Jr., G. W. Sachse, D. R. Bagwell, C. H. Hudgins, D. R Blake, and N. J. Blake (1996), Aerosols from biomass burning over the tropical South Atlantic region: Distributions and impacts, J. Geophys. Res., 101, 24,117-24,138.

Andreae, M. O., H. Berresheim, T. W. Andreae, M. A. Kritz, T. S. Bates, and J. T. Merrill (1988), Vertical distribution of dimethylsulfide, sulfur dioxide, aerosol ions, and radon over the northeast Pacific Ocean, J. Atmos. Chem., 6, 149-173.

Andreae, M. O., D. Rosenfeld, P. Artaxo, A. A. Costa, G. P. Frank, K. M. Longo, and M. A. F. Silva-Dias (2004), Smoking rain clouds over the Amazon, Science, 303, 1337-1342.

Andres, R. J., and A. D. Kasgnoc (1998), A time-averaged inventory of subaerial volcanic sulfur emissions, J. Geophys. Res., 103, 25,25125,262

Arimoto, R., R. A. Duce, D. L. Savoie, J. M. Prospero, R. Talbot, J. D. Cullen, U. Tomza, N. F. Lewis, and B. J. Ray (1996), Relationships among aerosol constituents from Asia and the North Pacific during PEM-West A, J. Geophys. Res., 101, 2011-2024.

Balkanski, Y. J., D. J. Jacob, G. M. Gardner, W. C. Graustein, and K. K. Turekian (1993), Transport and residence times of tropospheric aerosols inferred from a global three-dimensional simulation of ${ }^{210} \mathrm{~Pb}, J$. Geophys. Res., 98, 20,573-20,586.

Barth, M. C., P. J. Rasch, J. T. Kiehl, C. M. Benkovitz, and S. E. Schwartz (2000), Sulfur chemistry in the National Center for Atmospheric Research Community Climate Model: Description, evaluation, features, and sensitivity to aqueous chemistry, J. Geophys. Res., 105(D1), 13871416.

Bates, T. S., B. J. Huebert, J. L. Gras, F. B. Griffiths, and P. A. Durkee (1998), International Global Atmospheric Chemistry (IGAC) Project's First Aerosol Characterization Experiment (ACE 1): Overview, J. Geophys. Res., 103, 16,297-16,318.

Binkowski, F. S., and U. Shankar (1995), The regional particulate matter model: 1. Model description and preliminary results, J. Geophys. Res., 100, 26,191-26,209.

Blanchard, D. C., and R. J. Cipriano (1987), Biological regulation of climate, Nature, 330, 526.

Bodhaine, B. A. (1995), Aerosol absorption measurements at Barrow, Mauna-Loa, and the South-Pole, J. Geophys. Res., 100, 8967-8975.

Bodhaine, B. A., J. M. Harris, J. A. Ogren, and D. J. Hofmann (1992), Aerosol optical properties at Mauna Loa Observatory: Long-range transport from Kuwait?, Geophys. Res. Lett., 19, 581-584.

Bond, T. C., D. S. Covert, J. C. Kramlich, T. V. Larson, and R. J. Charlson (2002), Primary particle emissions from residential coal burning: Optical properties and size distributions, J. Geophys. Res., 107(D21), 8347, doi:10.1029/2001JD000571.

Boucher, O., and U. Lohmann (1995), The sulfate-CCN-cloud albedo effect: A sensitivity study with two general circulation models, Tellus, Ser $B, 47,281-300$.

Brechtel, F., S. M. Kreidenweis, L. M. McInnes, and H. Swan (1997), Aerosol characteristics at Macquarie Island, Tasmania, during ACE-1, Rep. 633, Dep of Atmos. Sci. Colo. State Univ, Fort Collins.

Cantrell, B. K., and K. T. Whitby (1978), Aerosol size distributions and aerosol volume formation for a coal-fired power-plant plume, Atmos. Environ., 12, 323-333.

Carmichael, G. R., Y. Zhang, L.-L. Chen, M.-S. Hong, and H. Ueda (1996), Seasonal variation of aerosol composition at Cheju Island, Korea, Atmos Environ., 30, 2407-2416.

Carmichael, G. R., M.-S. Hong, H. Ueda, L.-L. Chen, K. Murano, J. K. Park, H. Lee, Y. Kim, C. Kang, and S. Shim (1997), Aerosol composition at Cheju Island, Korea, J. Geophys. Res., 102(D5), 6047-6062.

Charlson, R. J., S. E. Schwartz, J. M. Hales, R. D. Cess, J. A. Coakley, J. E. Hansen, and D. J. Hofmann (1992), Climate forcing by anthropogenic aerosols, Science, 255, 423-430.
Chin, M., and D. J. Jacob (1996), Anthropogenic and natural contributions to tropospheric sulfate: A global model analysis, J. Geophys. Res., 101(D13), 18,691-18,700.

Chin, M., R. B. Rood, S.-J. Lin, J.-F. Muller, and A. M. Thompson (2000a), Atmospheric sulfur cycle simulated in the global model GOCART: Model description and global properties, J. Geophys. Res., 105, 24,671-24,687

Chin, M., D. L. Savoie, B. J. Huebert, A. R. Bandy, D. C. Thornton, T. S. Bates, P. K. Quinn, E. S. Saltzman, and W. J. De Bruyn (2000b), Atmospheric sulfur cycle simulated in the global model GOCART: Comparison with field observations and regional budgets, J. Geophys. Res., 105, 24,689-24,712.

Chin, M., P. Ginoux, S. Kinne, O. Torres, B. N. Holben, B. N. Duncan, R. V. Martin, J. A. Logan, A. Higurashi, and T. Nakajima (2002), Tropospheric aerosol optical thickness from the GOCART model and comparisons with satellite and sun photometer measurements, J. Atmos. Sci., 59, 461-483.

Chuang, C. C., J. E. Penner, K. E. Taylor, A. S. Grossman, and J. J. Walton (1997), An assessment of the radiative effects of anthropogenic sulfate, J. Geophys. Res., 102(D3), 3761-3778.

Chuang, C. C., J. E. Penner, J. M. Prospero, K. E. Grant, G. H. Rau, and K. Kawamoto (2002), Cloud susceptibility and the first aerosol indirect forcing: Sensitivity to black carbon and aerosol concentrations, J. Geophys. Res, 107(D21), 4564, doi:10.1029/2000JD000215.

Chung, S. H., and J. H. Seinfeld (2002), Global distribution and climate forcing of carbonaceous aerosols, J. Geophys. Res., 107(D19), 4407, doi:10.1029/2001JD001397.

Chylek, P., and J. Hallett (1992), Enhanced absorption of solar radiation by cloud droplets containing soot particles in their surface, Q. J. R. Meteorol. Soc., 118, 167-172.

Chylek, P., G. Videen, D. Ngo, R. G. Pinnick, and J. D. Klett (1995), Effect of black carbon on the optical properties and climate forcing of sulfate aerosols, J. Geophys. Res., 100(D8), 16,325-16,332.

Clarke, A. D., and V. N. Kapustin (2002), A Pacific aerosol survey. Part I: A decade of data on particle production, transport, evolution, and mixing in the troposphere, J. Atmos. Sci., 59, 363-382.

Clarke, A. D., et al. (2004), Size distributions and mixtures of dust and black carbon aerosol in Asian outflow: Physiochemistry and optical properties, J. Geophys. Res., 109, D15S09, doi:10.1029/ 2003JD004378.

Clegg, N. A., and R. Toumi (1997), Sensitivity of sulphur dioxide oxidation in sea salt to nitric acid and ammonia gas phase concentrations, J. Geophys. Res., 102(D19), 23,241-23,250.

Coffman, D. J., and D. A. Hegg (1995), A preliminary study of the effect of ammonia on nucleation in the marine boundary layer, J. Geophys. Res., 100(D4), 7147-7160.

Cooke, W. F., and J. J. N. Wilson (1996), A global black carbon aerosol model, J. Geophys. Res., 101(D14), 19,395-19,410.

Cooke, W. F., C. Liousse, H. Cachier, and J. Feichter (1999), Construction of a $1^{\circ} \times 1^{\circ}$ fossil fuel emission data set for carbonaceous aerosol and implementation and radiative impact in the ECHAM4 model, J. Geophys. Res., 104(D18), 22,137-22,162.

Cooke, W. F., V. Ramaswamy, and P. Kasibhatla (2002), A general circulation model study of the global carbonaceous aerosol distribution, J. Geophys. Res., 107(D16), 4279, doi:10.1029/2001JD001274.

Covert, D. S., and J. Heintzenberg (1993), Size distributions and chemical properties of aerosol at Ny Alesund, Svalbard, Atmos. Environ., Part A, 27, 2989-2997.

d'Almeida, G. A., P. Koepke, and E. P. Shettle (1991), Atmospheric Aerosols: Global Climatology and Radiative Characteristics, A. Deepak, Hampton, Va.

Dana, M. T., and J. M. Hales (1976), Statistical aspects of the washout of polydisperse aerosols, Atmos. Environ., 10, 45-50.

Demore, W. B., S. P. Sander, C. J. Howard, A. R. Ravishankara, D. M. Gloden, C. E. Kolb, R. F. Hampson, M. J. Kurylo, and M. J. Molina (1997), Chemical kinetics and photochemical data for use in stratospheric modeling, Evaluation number 12, JPL Publ., 97-4.

Dentener, F. J., G. R. Carmichael, Y. Zhang, J. Lelieveld, and P. J. Crutzen (1996), Role of mineral aerosol as a reactive surface in the global troposphere, J. Geophys. Res., 101(D17), 22,869-22,890.

de Reus, M., F. Dentener, A. Thomas, S. Borrmann, J. Ström, and J. Lelieveld (2000), Airborne observations of dust aerosol over the North Atlantic Ocean during ACE 2: Indications for heterogeneous ozone destruction, J. Geophys. Res., 105, 15,263-15,275.

Deshler, T., and D. J. Hofmann (1992), Measurements of unusual aerosol layers in the upper troposphere over Laramie, Wyoming in the spring of 1991: Evidence for long range transport from the oil fired in Kuwait, Geophys. Res. Lett., 19, 385-388.

Dingenen, R. V., F. Raes, and N. R. Jensen (1995), Evidence for anthropogenic impact on number concentration and sulfate content of cloud- 
processed aerosol particles over the North Atlantic, J. Geophys. Res., 100(D10), 21,057-21,067.

Easter, R. C., S. J. Ghan, Y. Zhang, R. D. Saylor, E. G. Chapman, N. S. Laulainen, H. Abdul-Razzak, L. R. Leung, X. Bian, and R. A. Zaveri (2004), MIRAGE: Model description and evaluation of aerosols and trace gases, J. Geophys. Res., 109, D20210, doi:10.1029/2004JD004571.

Eisele, F. L., and D. J. Tanner (1991), Ion-assisted tropospheric OH measurements, J. Geophys. Res., 96, 9295-9308.

Eisele, F. L., and D. J. Tanner (1993), Measurement of the gas phase concentration of $\mathrm{H}_{2} \mathrm{SO}_{4}$ and methane sulfonic acid and estimates of $\mathrm{H}_{2} \mathrm{SO}_{4}$ production and loss in the atmosphere, J. Geophys. Res., 98, 9001-9010.

Erickson, D. J., and R. A. Duce (1988), On the global flux of atmospheric sea salt, J. Geophys. Res., 93(C11), 14,079-14,088.

Falkovich, A. H., E. Ganor, Z. Levin, P. Formenti, and Y. Rudich (2001) Chemical and mineralogical analysis of individual mineral dust particles, J. Geophys. Res., 106(D16), 18,029-18,036.

Fan, S.-M., L. W. Horowitz, H. Levy II, and W. J. Moxim (2004), Impact of air pollution on wet deposition of mineral dust aerosols, Geophys. Res. Lett., 31, L02104, doi:10.1029/2003GL018501.

Feichter, J., E. Kjellstroem, H. Rodhe, F. Dentener, J. Lelieveld, and G.-J. Roelofs (1996), Simulation of the tropospheric sulfur cycle in a global climate model, Atmos. Environ., 30, 1693-1707.

Feng, Y., J. E. Penner, S. Sillman, and X. Liu (2004), Effects of cloud overlap in photochemical models, J. Geophys. Res., 109, D04310, doi:10.1029/2003JD004040.

Fitzgerald, J. W., and W. A. Hoppel (1998), A one-dimensional sectional model to simulate multicomponent aerosol dynamics in the marine boundary layer: 1. Model description, J. Geophys. Res., 103(D13), $16,085-16,102$.

Fridlind, A. M., et al. (2004), Evidence for the predominance of midtropospheric aerosols as subtropical anvil nuclei, Science, 304, 718-722.

Fuchs, N. A. (1964), Mechanics of Aerosols, Elsevier, New York.

Gerber, H. (1991), Supersaturation and droplet spectral evolution in fog, J. Atmos. Sci., 48, 2569-2588.

Ghan, S. J., R. C. Easter, E. G. Chapman, H. Abdul-Razzak, Y. Zhang, L. R. Leung, N. S. Laulainen, R. D. Saylor, and R. A. Zaveri (2001a), A physically based estimate of radiative forcing by anthropogenic sulfate aerosol, J. Geophys. Res., 106(D6), 5279-5294.

Ghan, S., R. Easter, J. Hudson, and F.-M. Bréon (2001b), Evaluation of aerosol indirect radiative forcing in MIRAGE, J. Geophys. Res., 106(D6), $5317-5334$

Gierens, K. (2003), On the transition between heterogeneous and homogeneous freezing, Atmos. Chem. Phys., 3, 437-446.

Ginoux, P., M. Chin, I. Tegen, J. M. Prospero, B. Holben, O. Dubovik, and S.-J. Lin (2001), Sources and distributions of dust aerosols simulated with the GOCART model, J. Geophys. Res., 106, 20,255-20,274.

Giorgi, F., and W. L. Chameides (1986), Rainout lifetimes of highly soluble aerosols and gases as inferred from simulations with a general circulation model, J. Geophys. Res., 91, 14,367-14,376.

Gong, S. L., L. A. Barrie, and J.-P. Blanchet (1997), Modeling sea-salt aerosols in the atmosphere: 1. Model development, J. Geophys. Res., 102, 3805-3818.

Gong, S. L., L. A. Barrie, and M. Lazare (2002), Canadian Aerosol Module (CAM): A size-segregated simulation of atmospheric aerosol processes for climate and air quality models: 2. Global sea-salt aerosol and its budgets, J. Geophys. Res., 107(D24), 4779, doi:10.1029/2001JD002004.

Gras, J. L. (1990), Baseline atmospheric condensation nuclei at Cape Grim 1977-1987, J. Atmos. Chem., 11, 89-106.

Gras, J. L. (1993), Condensation nucleus size distribution at Mawson, Antarctica: Seasonal cycle, Atmos. Environ., Part A, 27, 1417-1425.

Greenwald, T. J., G. L. Stephens, T. H. Vonder Haar, and D. L. Jackson (1993), A physical retrieval of cloud liquid water over the global oceans using special sensor microwave/imager (SSI/I) observations, J. Geophys. Res., 98, 18,471-18,488.

Guenther, A., et al. (1995), A global model of natural volatile organic compound emissions, J. Geophys. Res., 100, 8873-8892.

Hack, J. J. (1998), Sensitivity of the simulated climate to a diagnostic formulation for cloud liquid water, J. Clim., 11, 1497-1515.

Harvey, M. J., G. W. Fisher, I. S. Lechner, P. Issac, N. E. Flower, and A. L. Dick (1991), Summertime aerosol measurements in the Ross Sea region of Antarctica, Atmos. Environ., Part A, 25, 569-580.

Hasegawa, S., and S. Ohta (2002), Some measurements of the mixing state of soot-containing particles at urban and nonurban sites, Atmos. Environ. 36, 3899-3908.

Haywood, J. M., and K. P. Shine (1995), The effect of anthropogenic sulfate and soot aerosol on the clear sky planetary radiation budget, Geophys. Res. Lett., 22(5), 603-606.

Haywood, J. M., D. L. Roberts, A. Slingo, J. M. Edwards, and K. P. Shine (1997), General circulation model calculations of the direct radiative forcing of tropospheric sulphate and fossil-fuel soot aerosol, J. Clim., $10,1562-1577$

Heintzenberg, J., and E. K. Bigg (1990), Tropospheric transport of trace substances in the Southern Hemisphere, Tellus, Ser. B, 42, 355-363.

Herzog, M., D. K. Weisenstein, and J. E. Penner (2004), A dynamic aerosol module for global chemical transport models: Model description and impact of nonsulfate aerosol particles, J. Geophys. Res., 109, D18202, doi:10.1029/2003JD004405.

Hitzenberger, R., A. Berner, R. Kromp, A. Kasper-Giebl, A. Limbeck, W. Tscherwenka, and H. Puxbaum (2000), Black carbon and other species at a high-elevation European site (Mount Sonnblick, 3106 $\mathrm{m}$, Austria): Concentrations and scavenging efficiencies, J. Geophys. Res., 105(D20), 24,637-24,646.

Hitzenberger, R., A. Berner, H. Giebl, K. Drobesch, A. Kasper-Giebl, M. Loeflund, H. Urban, and H. Puxbaum (2001), Black carbon (BC) in alpine aerosols and cloud water-concentrations and scavenging efficiencies, Atmos. Environ., 35, 5135-5141.

Hjellbrekke, A.-G., and J. E. Hanssen (1998), Data report 1996, 1, Annual summaries, EMEP/CCC Rep. 1/98, 85 pp., Norw. Inst. for Air Res., Lillestrom

Hoppel, W. A., and G. M. Frick (1990), Submicron aerosol size distributions measured over the tropical and south Pacific, Atmos. Environ., Part A, 24, 645-659.

Hoppel, W. A., F. M. Frick, and R. E. Larson (1986), Effect of nonprecipitating clouds on the aerosol size distribution in the marine boundary layer, Geophys. Res. Lett., 13, 125-128.

Hopper, J. F., D. E. J. Worthy, L. A. Barrie, and N. B. A. Trivett (1994), Atmospheric observations of aerosol black carbon, carbon-dioxide, and methane in the high Arctic, Atmos. Environ., 28, 3047-3054.

Horai, S., T. Minari, and Y. Migita (1993), Aerosols composition in Kagoshima, annual report, Environ. Sci. 9, Kagoshima Prefect. Inst., Kagoshima, Japan.

Hudson, J. G., and X. Da (1996), Volatility and size of cloud condensation nuclei, J. Geophys. Res., 101(D2), 4435-4442.

Hynes, A. J., P. H. Wine, and D. J. Semmes (1986), Kinetics and mechanisms of $\mathrm{OH}$ reactions with organic sulfides, J. Phys. Chem., 90, 41484156.

Intergovernmental Panel on Climate Change (IPCC) (2001), Third Assessment Report, Cambridge Univ. Press, New York.

Isaac, G. A., W. R. Leaitch, J. W. Strapp, and K. G. Anlauf (1986), Summer aerosol profiles over Algonquin Park, Canada, Atmos. Environ., 20, $157-$ 172

Jacob, D. J., and S. C. Wofsy (1990), Budgets of reactive nitrogen, hydrocarbons, and ozone over the Amazon forest during the wet season, J. Geophys. Res., 95, 16,737-16,754.

Jacobson, M. Z. (2001), Strong radiative heating due to the mixing state of black carbon in atmospheric aerosols, Nature, 409, 695-697.

Jaenicke, R, and P. K. Koutsenogii (1992), Measurements of atmospheric aerosol in Siberia, in Nucleation and Atmospheric Aerosols, edited by N. Fukuta and P. E. Wagner, pp. 435-438, A. Deepak, Hampton, Va. Jensen, T. L., S. M. Kreidenweis, Y. Kim, H. Sievering, and A. Pszenny (1996), Aerosol distributions measured in the North Atlantic marine boundary layer during ASTEX/MAGE, J. Geophys. Res., 101(D2), $4455-4467$.

John, W., S. M. Wall, J. L. Ondo, and W. Winklmyr (1990), Modes in the size distribution of atmospheric inorganic aerosol, Atmos. Environ., Part A, 24, 2349-2359.

Jones, A., D. L. Roberts, and A. Slingo (1994), A climate model study of indirect radiative forcing by anthropogenic sulfate aerosols, Nature, 370 , $450-453$

Kärcher, B., T. Peter, U. M. Biermann, and U. Schumann (1996), The initial composition of jet condensation trails, J. Atmos. Sci., 53, 3066-3083.

Karyampudi, M. V., et al. (1999), Validation of the Saharan dust plume conceptual model using lidar, Meteosat, and ECMWF data, Bull. Am. Meteorol. Soc., 80, 1045-1076.

Kasibhatla, P., W. L. Chameides, and J. St. John (1997), A threedimensional global model investigation of seasonal variations in the atmospheric burden of anthropogenic sulfate aerosols, J. Geophys. Res., 102(D3), 3737-3760.

Kaufman, Y. J., and R. S. Fraser (1997), The effect of smoke particles on cloud and climate forcing, Science, 277, 1636-1639.

Kerminen, V.-M., T. E. Makela, C. H. Ojanen, R. E. Hillamo, J. K. Vilhunen, L. Rantanen, N. Havers, A. Von Bohlen, and D. Klockow (1997), Characterization of the particulate phase in the exhaust from a diesel car, Environ. Sci. Technol., 31, 1883-1889.

Kettle, A. J., and M. O. Andreae (2000), Flux of dimethylsulfide from the oceans: A comparison of updated data sets and flux models, J. Geophys. Res., 105, 26,793-26,808.

Kettle, A. J., et al. (1999), A global database of sea surface dimethylsulfide (DMS) measurements and a procedure to predict sea surface DMS as a 
function of latitude, longitude, and month, Global Biogeochem. Cycles, $13,399-444$.

Kiehl, J. T., and B. P. Brieglieb (1993), The relative role of sulfate aerosols and greenhouse gases in climate forcing, Science, 260, $311-314$

Kim, Y. J., H. Sievering, and J. F. Boatman (1988), Airborne measurements of atmospheric aerosol particles in the lower troposphere over the central United States, J. Geophys. Res., 93, 12,631-12,644.

Koch, D. (2001), Transport and direct radiative forcing of carbonaceous and sulfate aerosols in the GISS GCM, J. Geophys. Res., 106, 20,31120,332.

Koch, D., D. Jacob, I. Tegen, D. Rind, and M. Chin (1999), Tropospheric sulfur simulation and sulfate direct radiative forcing in the Goddard Institute for Space Studies general circulation model, J. Geophys. Res. 104, 23,799-23,822.

Kulmala, M., A. Laaksonen, and L. Pirjola (1998), Parameterizations for sulfuric acid/water nucleation rates, J. Geophys. Res., 103(D7), 83018308 .

Lammel, G., and T. Novakov (1995), Water nucleation properties of carbon black and diesel soot particles, Atmos. Environ., 29, 813-823.

Langner, J., and H. Rodhe (1991), A global three-dimensional model of the tropospheric sulfur cycle, J. Atmos. Chem., 13, 225-263.

Levin, Z., J. H. Joseph, and Y. Mekler (1980), Properties of Sharav (Khamsin) dust-Comparison of optical and direct sampling data, J. Atmos. Sci., 37, 882-891.

Levin, Z., E. Ganor, and V. Gladstein (1996), The effects of desert particles coated with sulfate on rain formation in the eastern Mediterranean, J. Appl. Meteorol., 35, 1511-1523.

Li-Jones, X., and J. M. Prospero (1998), Variations in the size distribution of non-sea-salt sulfate aerosol in the marine boundary layer at Barbados: Impact of African dust, J. Geophys. Res., 103, 16,073-16,084.

Lin, S.-J., and R. B. Rood (1996), Multidimensional flux-form semiLagrangian transport schemes, Mon. Weather Rev., 124, 2046-2070.

Lind, J. A., and G. L. Kok (1986), Henry's law determination for aqueous solutions of hydrogen peroxide, methyl hydroperoxide, and peroxyacetic acid, J. Geophys. Res., 91, 7889-7896.

Liousse, C., J. E. Penner, C. Chuang, J. J. Walton, H. Eddleman, and H. Cachier (1996), A global three-dimensional model study of carbonaceous aerosols, J. Geophys. Res., 101, 19,411-19,432.

Liss, P. S., and L. Merlivat (1986), Air-sea gas exchange rates: Introduction and synthesis, in The Role of Air-Sea Gas Exchange in Geochemical Cycling, edited by P. B. Menard, pp. 113-127, Springer, New York.

Liu, H., D. J. Jacob, I. Bey, and R. M. Yantosca (2001), Constraints from ${ }^{210} \mathrm{~Pb}$ and ${ }^{7} \mathrm{Be}$ on wet deposition and transport in a global three-dimensional chemical tracer model driven by assimilated meteorological fields, J. Geophys. Res., 106(D11), 12,109-12,128.

Liu, X., and J. E. Penner (2002), Effect of Mount Pinatubo $\mathrm{H}_{2} \mathrm{SO}_{4} / \mathrm{H}_{2} \mathrm{O}$ aerosol on ice nucleation in the upper troposphere using a global chemistry and transport model (IMPACT), J. Geophys. Res., 107(D12), 4141, doi:10.1029/2001JD000455.

Lohmann, U., and J. Feichter (1997), Impact of sulfate aerosols on albedo and lifetime of clouds: A sensitivity study with the ECHAM4 GCM, J. Geophys. Res., 102(D12), 13,685-13,700

Lohmann, U., J. Feichter, C. C. Chuang, and J. E. Penner (1999a), Prediction of the number of cloud droplets in the ECHAM GCM, J. Geophys. Res., 104(D8), 9169-9198.

Lohmann, U., K. von Salzen, N. McFarlane, H. G. Leighton, and J. Feichter (1999b), Tropospheric sulfur cycle in the Canadian general circulation model, J. Geophys. Res., 104(D21), 26,833-26,858.

Luo, C., N. M. Mahowald, and J. del Corral (2003), Sensitivity study of meteorological parameters on mineral aerosol mobilization, transport, and distribution, J. Geophys. Res., 108(D15), 4447, doi:10.1029/ 2003JD003483.

Maahs, H. G. (1983), Kinetics and mechanisms of the oxidation of S (IV) by ozone in aqueous solution with particular reference to $\mathrm{SO}_{2}$ conversion in nonurban clouds, J. Geophys. Res., 88, 10,721-10,732.

Mallet, M., J. C. Roger, S. Despiau, J. P. Putaud, and O. Dubovik (2004), A study of the mixing state of black carbon in urban zone, J. Geophys. Res., 109, D04202, doi:10.1029/2003JD003940.

Malm, W. C., M. L. Pitchford, M. Scruggs, J. F. Sisler, R. Ames, S. Copeland, K. A. Gebhart, and D. E. Day (2000), Spatial and seasonal patterns and temporal variability of haze and its constituents in the United States: Report III, Coop. Inst. for Res., Colo. State Univ., Fort Collins.

Mari, C., D. J. Jacob, and P. Bechtold (2000), Transport and scavenging of soluble gases in a deep convective cloud, J. Geophys. Res., 105(D17) $22,255-22,268$

Martin, L. R., and D. E. Damschen (1981), Aqueous oxidation of sulfur dioxide by hydrogen peroxide at low pH, Atmos. Environ., 15, 1615 1621
Mauldin, R. L., III, D. J. Tanner, J. A. Heath, B. J. Huebert, and F. L. Eisele (1999), Observations of $\mathrm{H}_{2} \mathrm{SO}_{4}$ and MSA during PEM-Tropics A, J. Geophys. Res., 104(D5), 5801-5816.

Mauldin, R. L., III, et al. (2001), Measurements of $\mathrm{OH}, \mathrm{H}_{2} \mathrm{SO}_{4}$, and MSA at the South Pole during ISCAT, Geophys. Res. Lett., 28(19), 3629-3632

Mauldin, R. L., III, C. A. Cantrell, M. A. Zondlo, E. Kosciuch, B. A Ridley, R. Weber, and F. E. Eisele (2003), Measurements of $\mathrm{OH}, \mathrm{H}_{2} \mathrm{SO}_{4}$, and MSA during Tropospheric Ozone Production About the Spring Equinox (TOPSE), J. Geophys. Res., 108(D4), 8366, doi:10.1029/2002JD002295.

McElroy, M. W., R. C. Carr, D. S. Ensor, and G. R. Markowski (1982), Size distribution of fine particles from coal combustion, Science, 215, 13-19.

McNaughton, D. J., and R. J. Vet (1996), Eulerian Model Evaluation Field Study (EMEFS): A summary of surface network measurements and data quality, Atmos. Environ., 30, 227-238.

Mebust, M. R., B. K. Eder, F. S. Binkowski, and S. J. Roselle (2003), Models-3 Community Multiscale Air Quality (CMAQ) model aerosol component: 2. Model evaluation, J. Geophys. Res., 108(D6), 4184, doi:10.1029/2001JD001410

Merrill, J. T., M. Uematsu, and R. Bleck (1989), Meteorological analysis of long-range transport of mineral aerosols over the North Pacific, J. Geophys. Res., 94(D6), 8584-8598

Meszaros, A. (1978), On the concentration and size distribution of atmospheric sulfate particles under rural conditions, Atmos. Environ., 12, $2425-2428$.

Monahan, E. C., D. E. Spiel, and K. L. Davidson (1986), A model of marine aerosol generation via whitecaps and wave disruption, in Oceanic Whitecaps, edited by E. C. Monahan and G. Mac Niocaill, Springer, New York.

Murphy, D. M., J. R. Anderson, P. K. Quinn, L. M. McInnes, F. J. Brechtel, S. M. Kreidenweis, A. M. Middlebrook, M. Posfai, D. S. Thomson, and P. R. Buseck (1998), Influence of sea-salt on aerosol radiative properties in the Southern Ocean marine boundary layer, Nature, 392, 62-64.

Nakicenovic, N., et al. (2000), Emissions Scenarios: A Special Report of Working Group III of the Intergovernmental Panel on Climate Change, 599 pp., Cambridge Univ. Press, New York.

Nightingale, P. D., G. Malin, C. S. Law, A. J. Watson, P. S. Liss, M. I. Liddicoat, J. Boutin, and R. C. Upstill-Goddard (2000), In situ evaluation of air-sea gas exchange parameterizations using novel conservative and volatile tracers, Global Biogeochem. Cycles, 14, 373-388.

Nyeki, S., U. Baltensperger, I. Colbeck, D. T. Jost, E. Weingartner, and H. W. Gäggeler (1998), The Jungfraujoch high-alpine research station $(3454 \mathrm{~m})$ as a background clean continental site for the measurement of aerosol parameters, J. Geophys. Res., 103, 6097-6107.

O'Dowd, C. D., and M. H. Smith (1993), Physicochemical properties of aerosols over the Northeast Atlantic: Evidence for wind-speed related submicron sea-salt aerosol production, J. Geophys. Res., 98, 1137-1149.

Pandis, S. N., and J. H. Seinfeld (1989), Sensitivity analysis of a chemical mechanism for aqueous-phase atmospheric chemistry, J. Geophys. Res., 94, 1105-1126.

Parungo, F., Y. Kim, C.-J. Zhu, J. Harris, R. Schnell, X.-S. Li, D.-Z. Yang, M.-Y. Zhou, Z. Chen, and K. Park (1995), Asian dust storms and their effects on radiation and climate, STC Rep. 2906, Sci. and Technol. Corp., Hampton, Va.

Penner, J. E., and M. Herzog (2002), Changes in sulfate aerosol associated with aqueous chemistry, heterogeneous reactions on aerosol and nucleation, Eos Trans. $A G U, 83(47)$, Fall Meet. Suppl., Abstract A51E-05.

Penner, J. E., H. Eddleman, and T. Novakov (1993), Towards the development of a global inventory of black carbon emissions, Atmos. Environ., Part A, 27, 1277-1295.

Penner, J. E., C. A. Atherton, and T. E. Graedel (1994), Global emissions and models of photochemically active compounds, in Global AtmospericBiospheric Chemistry, edited by R. Prinn, pp. 223-248, Springer, New York.

Penner, J. E., D. Bergmann, J. J. Walton, D. Kinnison, M. J. Prather, D. Rotman, C. Price, K. E. Pickering, and S. L. Baughcum (1998a), An evaluation of upper tropospheric $\mathrm{NO}_{\mathrm{x}}$ with two models, J. Geophys. Res., 103, 22,097-22,114.

Penner, J. E., C. C. Chuang, and K. Grant (1998b), Climate forcing by carbonaceous and sulfate aerosols, Clim. Dyn., 14, 839-851.

Penner, J. E., et al. (2001), Aerosols and radiative forcing, in Intergovernmental Panel on Climate Change, Report to IPCC From the Scientific Assessment Working Group (WGI), pp. 289-349, Cambridge Univ. Press, New York.

Pham, M., J.-F. Müller, G. P. Brasseur, C. Granier, and G. Mégie (1995), A three-dimensional study of the tropospheric sulfur cycle, J. Geophys. Res., 100(D12), 26,061-26,092. 
Pirjola, L., K. E. J. Lehtinen, H.-C. Hansson, and M. Kulmala (2004), How important is nucleation in regional/global modeling?, Geophys. Res. Lett. 31, L12109, doi:10.1029/2004GL019525.

Pósfai, M., J. R. Anderson, P. R. Buseck, and H. Sievering (1999), Soot and sulfate aerosol particles in the remote marine troposphere, J. Geophys. Res., 104(D17), 21,685-21,694.

Pósfai, M., R. Simonics, J. Li, P. V. Hobbs, and P. R. Buseck (2003), Individual aerosol particles from biomass burning in southern Africa: 1. Compositions and size distributions of carbonaceous particles, J. Geophys. Res., 108(D13), 8483, doi:10.1029/2002JD002291.

Prospero, J. M. (1999), Long-term measurements of the transport of African mineral dust to the southeastern United States: Implications for regional air quality, J. Geophys. Res., 104, 15,917-15,928.

Prospero, J. M., M. Uematsu, and D. L. Savoie (1989), Mineral aerosol transport to the Pacific Ocean, in Chemical Oceanography, vol. 10, edited by J. P. Ridley, R. Chester, and R. A. Duce, pp. 188-218, Elsevier, New York.

Pruppacher, H. R., and J. D. Klett (1997), Microphysics of Cloud and Precipitation, 954 pp., Springer, New York.

Quinn, P. K., and D. J. Coffman (1998), Local closure during the First Aerosol Characterization Experiment (ACE 1): Aerosol mass concentration and scattering and backscattering coefficients, J. Geophys. Res., 103, $16,575-16,596$

Quinn, P. K., T. S. Bates, and J. E. Johnson (1990), Interactions between the sulfur and reduced nitrogen cycles over the central Pacific Ocean, J. Geophys. Res., 95, 16,405-16,416.

Radke, L. F., D. A. Hegg, J. H. Lyons, C. A. Brock, P. V. Hobbs, R. Weiss, and R. Rasmussen (1988), Airborne measurements on smokes from biomass burning, in Aerosols and Climate, edited by P. V. Hobbs and M. P. McCormick, pp. 411-422, A Deepak, Hampton, Va.

Radke, L. F., J. A. Coakley Jr., and M. D. King (1989), Direct and remote sensing observations of the effects of ships on clouds, Science, 246, $1146-1149$

Raes, F. (1995), Entrainment of free tropospheric aerosols as a regulating mechanism for cloud condensation nuclei in the remote marine boundary layer, J. Geophys. Res., 100, 2893-2903.

Raes, F., R. V. Dingenen, E. Cuevas, P. F. J. V. Velthoven, and J. M. Prospero (1997), Observations of aerosols in the free troposphere and marine boundary layer of the subtropical northeast Atlantic: Discussion of processes determining their size distribution, J. Geophys. Res., 102(D17), 21,315-21,328

Raes, F., R. V. Dingenen, E. Vignati, J. Wilson, J.-P. Putaud, J. H. Seinfeld, and P. Adams (2000), Formation and cycling of aerosols in the global troposphere, Atmos. Environ., 34, 4215-4240.

Rasch, P. J., M. C. Barth, J. T. Kiehl, S. E. Schwartz, and C. M. Benkovitz (2000), A description of the global sulfur cycle and its controlling processes in the National Center for Atmospheric Research Community Climate Model, Version 3, J. Geophys. Res., 105(D1), 1367-1386.

Roelofs, G.-J., J. Lelieveld, and L. Ganzeveld (1998), Simulation of global sulfate distribution and the influence on effective cloud radii with a coupled photochemistry-sulfur cycle model, Tellus, Ser. B, 50, 224242.

Rosenfeld, D., Y. Rudich, and R. Lahav (2001), Desert dust suppressing precipitation: A possible desertification feedback loop, Proc. Natl. Acad. Sci. U. S. A., 98, 5975-5980.

Rotman, D. A., et al. (2004), IMPACT, the LLNL 3-D global atmospheric chemical transport model for the combined troposphere and stratosphere: Model description and analysis of ozone and other trace gases, J. Geophys. Res., 109, D04303, doi:10.1029/2002JD003155.

Rotstayn, L. D., and U. Lohmann (2002), Simulation of the tropospheric sulfur cycle in a global model with a physically based cloud scheme, J. Geophys. Res., 107(D21), 4592, doi:10.1029/2002JD002128.

Rotstayn, L. D., and J. E. Penner (2001), Indirect aerosol forcing, quasi forcing, and climate response, J. Clim., 14, 2960-2975.

Russell, P. B., P. V. Hobbs, and L. L. Stowe (1999), Aerosol properties and radiative effects in the United States East Coast haze plume: An overview of the Tropospheric Aerosol Radiative Forcing Observational Experiment (TARFOX), J. Geophys. Res., 104(D2), 2213-2222.

Sato, M., J. Hansen, D. Koch, A. Lacis, R. Ruedy, O. Dubovik, B. Holben, M. Chin, and T. Novakov (2003), Global atmospheric black carbon inferred from AERONET, Proc. Natl. Acad. Sci. U. S. A., 100, 6319-6324. Savoie, D. L., and J. M. Prospero (1989), Comparison of oceanic and contential sources of non-sea-salt sulfate over the Pacific Ocean, Nature, 339, $685-687$.

Savoie, D. L., J. M. Prospero, and E. S. Saltzman (1989), Nitrate, nonseasalt sulfate and methanesulfonate over the Pacific Ocean, in Chemical Oceanography, vol. 10, edited by J. P. Ridley, R. Chester, and R. A. Duce, pp. 219-250, Elsevier, New York.

Savoie, D. L., J. M. Prospero, R. J. Larson, F. Huang, M. Izaguirre, T. Huang, and T. H. Snowdon (1993), Nitrogen and sulfur species in Antarctic aerosols at Mawson, Palmer Station, and Marsh (King George Island), J. Atmos. Chem., 17, 95-122.

Schütz, L., and R. Jaenicke (1974), Particle number and mass distributions above $10-4 \mathrm{~cm}$ radius in sand and aerosol of the Sahara Desert, J. Appl. Meteorol., 13, 863-870.

Seinfeld, J. H., and S. N. Pandis (1998), Atmopsheric Chemistry and Physics: From Air Pollution to Climate Change, John Wiley, Hoboken, N. J. Sherman, D. E., S. M. Kreidenweis, and T. McKee (1997), The influence of synoptic and local meteorological conditions on ambient particle concentrations during the Southeastern Aerosol and Visibility Study (SEAVS), vol. 1, Coop. Inst. for Res. in the Atmos., Colo. State Univ., Fort Collins. Sievering, H., J. Boatman, E. Gorman, Y. Kim, L. Anderson, G. Ennis, M. Luria, and S. Pandis (1992), Removal of sulphur from the marine boundary layer by ozone oxidation in sea-salt aerosols, Nature, 360, 571-573.

Smith, R. M., and A. E. Martell (1976), Critical Stability Constants, vol. 4, Inorganic Complexes, Springer, New York.

Sundqvist, H., E. Berge, and J. E. Kristiansson (1989), Condensation and cloud parameterization studies with a mesoscale numerical weather prediction model, Mon. Weather Rev., 117, 1641-1657.

Tabazadeh, A., O. B. Toon, S. L. Clegg, and P. Hamill (1997), A new parameterization of $\mathrm{H}_{2} \mathrm{SO}_{4} / \mathrm{H}_{2} \mathrm{O}$ aerosol composition: Atmospheric implications, Geophys. Res. Lett., 24(15), 1931-1934.

Tegen, I., and I. Fung (1994), Modeling of mineral dust in the atmosphere: Sources, transport, and optical thickness, J. Geophys. Res., 99, 22,89722,914 .

Tegen, I., and A. A. Lacis (1996), Modeling of particle size distribution and its influence on the radiative properties of mineral dust aerosol, J. Geophys. Res., 101, 19,237-19,244.

Tegen, I., P. Hollrig, M. Chin, I. Fung, D. Jacob, and J. E. Penner (1997), Contribution of different aerosol species to the global aerosol extinction optical thickness: Estimates from model results, J. Geophys. Res., 102, 23,895-23,916.

Tegen, I., S. P. Harrison, K. Kohfeld, I. C. Prentice, M. Coe, and M. Heimann (2002), Impact of vegetation and preferential source areas on global dust aerosol: Results from a model study, J. Geophys. Res., 107(D21), 4576, doi:10.1029/2001JD000963.

Twomey, S. A. (1977), Atmospheric Aerosols, Elsevier, New York.

Twomey, S. A. (1991), Aerosols, clouds and radiation, Atmos. Environ., Part A, 25, 2435-2442.

Vehkamäki, H., M. Kulmala, I. Napari, K. E. J. Lehtinen, C. Timmreck, M. Noppel, and A. Laaksonen (2002), An improved parameterization for sulfuric acid-water nucleation rates for tropospheric and stratospheric conditions, J. Geophys. Res., 107(D22), 4622, doi:10.1029/ 2002JD002184.

von Salzen, K., H. G. Leighton, P. A. Ariya, L. A. Barrie, S. L. Gong, J.-P. Blanchet, L. Spacek, U. Lohmann, and L. I. Kleinman (2000), Sensitivity of sulphate aerosol size distributions and CCN concentrations over North America to $\mathrm{SO}_{\mathrm{x}}$ emissions and $\mathrm{H}_{2} \mathrm{O}_{2}$ concentrations, J. Geophys. Res., 105(D8), 9741-9766.

Walcek, C. J., R. A. Brost, J. S. Chang, and M. L. Wesely (1986), $\mathrm{SO}_{2}$, sulfate, and $\mathrm{HNO}_{3}$ deposition velocities computed using regional landuse and meteorological data, Atmos. Environ., 20, 949-964.

Walton, J. J., M. C. MacCracken, and S. J. Ghan (1988), A global-scale Lagrangian trace species model of transport, transformation, and removal processes, J. Geophys. Res., 93, 8339-8354.

Wang, C. (2004), A modeling study on the climate impacts of black carbon aerosols, J. Geophys. Res., 109, D03106, doi:10.1029/2003JD004084.

Wanninkhof, R. (1992), Relationship between wind speed and gas exchange over the ocean, J. Geophys. Res., 97, 7373-7382.

Weber, R. J., and P. H. McMurry (1996), Fine particle size distributions at the Mauna Loa Observatory, Hawaii, J. Geophys. Res., 101(D9), $14,767-14,775$.

Weber, R. J., et al. (2003), New particle formation in anthropogenic plumes advecting from Asia observed during TRACE-P, J. Geophys. Res., 108(D21), 8814, doi:10.1029/2002JD003112.

Weng, F., and N. C. Grody (1994), Retrieval of cloud liquid water using the special sensor microwave imager (SSM/I), J. Geophys. Res., 99, 25,53525,551 .

Werner, M., I. Tegen, S. P. Harrison, K. E. Kohfeld, I. C. Prentice, Y. Balkanski, H. Rodhe, and C. Roelandt (2002), Seasonal and interannual variability of the mineral dust cycle under present and glacial climate conditions, J. Geophys. Res., 107(D24), 4744, doi:10.1029/2002JD002365.

Wesely, M. L. (1989), Parameterization of surface resistances to gaseous dry deposition in regional-scale numerical models, Atmos. Environ., 23, $1293-1304$.

Whitby, K. T. (1978), The physical characterics of sulfur aerosols, Atmos. Environ., 12, 135-159.

Whitby, K. T., B. K. Cantrell, and D. B. Kittelson (1978), Nuclei formation rates in a coal-fired power-plant plume, Atmos. Environ., 12, 313-321. 
Wilson, J., C. Cuvelier, and F. Raes (2001), A modeling study of global mixed aerosol fields, J. Geophys. Res., 106(D24), 34,081-34,108.

Wolff, E. W., and H. Cachier (1998), Concentrations and seasonal cycle of black carbon in aerosol at a coastal Antarctic station, J. Geophys. Res., $103,11,033-11,042$.

Wyslouzil, B. E., K. L. Carleton, D. M. Sonnenfroh, and W. T. Rawlins (1994), Observation of hydration of single, modified carbon aerosols, Geophys. Res. Lett., 21, 2107-2110.

Xu, K. M., and S. K. Krueger (1991), Evaluation of cloudiness parameterizations using a cumulus ensemble model, Mon. Weather Rev., 119(2), $342-367$.

Yin, Y., Z. Levin, T. G. Reisin, and S. Tzivion (2000), The effects of giant cloud condensation nuclei on the development of precipitation in convective clouds: A numerical study, Atmos. Res., 53, 91-116.

Yu, S. C., P. S. Kasibhatla, D. L. Wright, S. E. Schwartz, R. McGraw, and A. Deng (2003), Moment-based simulation of microphysical properties of sulfate aerosols in the eastern United States: Model description, evaluation, and regional analysis, J. Geophys. Res., 108(D12), 4353, doi:10.1029/2002JD002890.

Zender, C. S., H. Bian, and D. Newman (2003), Mineral Dust Entrainment and Deposition (DEAD) model: Description and 1990s dust climatology, J. Geophys. Res., 108(D14), 4416, doi:10.1029/ 2002JD002775.

Zhang, D., J. Zang, G. Shi, Y. Iwasaka, A. Matsuki, and D. Trochkine (2003), Mixture state of individual Asian particles at a coastal site of Qingdao, China, Atmos. Environ., 37, 3895-3901.

Zhang, L., S. L. Gong, J. Padro, and L. Barrie (2001), A size-segregated particle dry deposition scheme for an atmospheric aerosol module, Atmos. Environ., 35(3), 549-560.

Zhang, Y., B. Pun, K. Vijayaraghavan, S.-Y. Wu, C. Seigneur, S. N. Pandis, M. Z. Jacobson, A. Nenes, and J. H. Seinfeld (2004), Development and application of the Model of Aerosol Dynamics, Reaction, Ionization, and Dissolution (MADRID), J. Geophys. Res., 109, D01202, doi:10.1029/ 2003JD003501.

Zhao, J., and R. P. Turco (1995), Nucleation simulations in the wake of a jet aircraft in stratospheric flight, J. Aerosol Sci., 26, 779-795.

M. Herzog, X. Liu, and J. E. Penner, Department of Atmospheric, Oceanic, and Space Sciences, University of Michigan, 2455 Hayward Street, Ann Arbor, MI 48109, USA. (xhliu@engin.umich.edu) 